University of Louisville

ThinkIR: The University of Louisville's Institutional Repository

Electronic Theses and Dissertations

$5-2018$

\title{
Principal professional development and principal self-efficacy in an urban school district.
}

Brian Thomas Garrett

University of Louisville

Follow this and additional works at: https://ir.library.louisville.edu/etd

Part of the Educational Assessment, Evaluation, and Research Commons, Educational Leadership Commons, Elementary and Middle and Secondary Education Administration Commons, Leadership Studies Commons, Organization Development Commons, Other Teacher Education and Professional Development Commons, and the Urban Education Commons

\section{Recommended Citation}

Garrett, Brian Thomas, "Principal professional development and principal self-efficacy in an urban school district." (2018). Electronic Theses and Dissertations. Paper 2918.

https://doi.org/10.18297/etd/2918

This Doctoral Dissertation is brought to you for free and open access by ThinkIR: The University of Louisville's Institutional Repository. It has been accepted for inclusion in Electronic Theses and Dissertations by an authorized administrator of ThinkIR: The University of Louisville's Institutional Repository. This title appears here courtesy of the author, who has retained all other copyrights. For more information, please contact thinkir@louisville.edu. 


\title{
PRINCIPAL PROFESSIONAL DEVELOPMENT AND PRINCIPAL SELF-EFFICACY
} IN AN URBAN SCHOOL DISTRICT

\author{
By \\ Brian Thomas Garrett \\ B.S., Campbellsville University, 1998 \\ M.A.T., Spalding University, 2001 \\ Ed.S., University of Louisville, 2011

\begin{abstract}
A Dissertation
Submitted to the Faculty of the College of Education and Human Development of the University of Louisville in Partial Fulfillment of the Requirements for the Degree of
\end{abstract} \\ Doctor of Education \\ in Educational Leadership and Organizational Development \\ Department of Leadership, Foundations, and Human Resource Education \\ University of Louisville \\ Louisville, Kentucky
}

May 2018 


\section{Copyright 2018 by Brian Thomas Garrett}

All rights reserved 

PRINCIPAL PROFESSIONAL DEVELOPMENT AND PRINCIPAL SELF-EFFICACY IN AN URBAN SCHOOL DISTRICT

\author{
By \\ Brian Thomas Garrett \\ B.S., Campbellsville University, 1998 \\ M.A.T., Spalding University, 2001 \\ Ed.S., University of Louisville, 2011 \\ A Dissertation Approved on
}

April 23, 2018

By the following Dissertation Committee:

Dr. William Kyle Ingle, Chair

Dr. Jason Immekus

Dr. Blake Haselton

Dr. Caroline Sheffield 


\section{DEDICATION}

This dissertation is dedicated to my amazing and beautiful wife, Heather, my indisputably favorite person. She is the most gifted and passionate educator on Earth, and she inspires me both personally and professionally. Without her support, I would accomplish nothing. It is dedicated to our children - Mia, Tristan, Reece, and Sophie. Their mere existence has been life-altering in the most positive ways. Their company is an ongoing contest of wits, hijinks, laughter, and joy - the way life was meant to be. It is dedicated to my parents, George and Sue, for their ever-present support and guidance.

Finally, this dissertation is dedicated to Yeshua, the Christ Jesus, who humbled Himself to be the sacrifice to take on the debt I earned and to offer me what I did not deserve and could not achieve. To consider that the creator of all the universe - the stars and heavens beyond - desires for me, the wretched and unworthy, to know Him personally, will forever perplex my simple mind. Psalm 8:3-9 


\section{ACKNOWLEDGMENTS}

Not one moment occurred on this doctoral path when I did this on my own. So many have stood by me, walked with me, guided me, encouraged me, and kicked me in the rear when needed. It is only with the support of so many that I have successfully finished this journey. My appreciation must go to Dr. William Kyle Ingle, my dissertation committee chair, who provided much needed insight and encouragement to completing this journey when I encountered roadblocks and detours. Your feedback and guidance helped me to navigate very difficult obstacles and to strive for the highest quality research I could produce. Thank you to Dr. Jason Immekus for your high expectations and standards. Your feedback was often challenging but helped me to develop my best possible work. Thank you, Dr. Blake Haselton, for your wisdom, encouragement, and desire for quality from me. With much gratitude, thank you to Dr. Caroline Sheffield. During the proposal defense, you questioned my reasons - my WHY? - for this particular research. Thank you for that question that cut to the core of who I am as an educator and a researcher and allowed me to pour out my professional heart.

Without the support of those in Jefferson County Public Schools, this would not have been possible. Thank you to Dr. Angela Parsons for your encouragement, for your advice and guidance, and your belief in me. Thank you to Dr. Joe Prather for your assistance during the data collection phase. Your generous and helpful spirit was much needed at some of the most worrisome moments in this process. To the joyous Dr. Marco 
Muñoz, thank you for positive encouragement and servant heart. To my fellow JCPS cohorts, I am so grateful to have gone through the process with you. Those who completed the process before me were an inspiration for me to finish. I will remember for a lifetime the support, camaraderie, and laughter we shared in our classes and collaborations.

Finally, my utmost appreciation and gratitude goes to my wife, Heather. She was the most vital support I had during this process. She alone is to thank for me still having a home and life during this journey. She put up with and endured me through this and often felt the pain of my laboring more than I did. Without her, there would be no dissertation, and I would likely be an empty shell of a man. Thank you for your love and support. You are amazing. 


\title{
ABSTRACT \\ PRINCIPAL PROFESSIONAL DEVELOPMENT AND PRINCIPAL SELF-EFFICACY IN AN URBAN SCHOOL DISTRICT
}

\author{
Brian Thomas Garrett
}

April 23, 2018

Educator professional development (PD) is a heavily relied upon method for school improvement, and administrator professional development (APD) is a key element to nearly all school reform efforts. District-wide APD in large school districts can carry a heavy cost in financial and human resources. Moreover, PD is frequently too inadequately planned and/or implemented to bring about lasting positive change in educator practice, school reform, and student achievement. The purpose of this study was to determine the relationship between principal PD focused on culture/climate or instruction and principal self-efficacy in an urban school district. Through hierarchical linear multiple regression (HLMR), this study explored the predictive ability of culture/climate or instruction-focused APD, principal experience, school factors, and student achievement on principal self-efficacy. Additional correlational and HLMR analyses examined the relationships and predictive utility of these variables on student achievement. Findings of nonsignificant predictors and weak but significant correlations suggest that APD for these principals may not have contributed to principal self-efficacy or student achievement. The findings of this study have implications for district leaders in planning and developing effective APD and for future research. 


\section{TABLE OF CONTENTS}

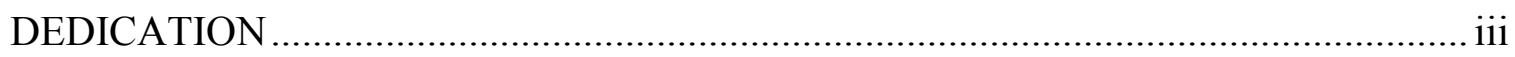

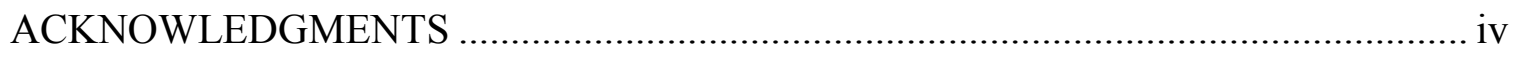

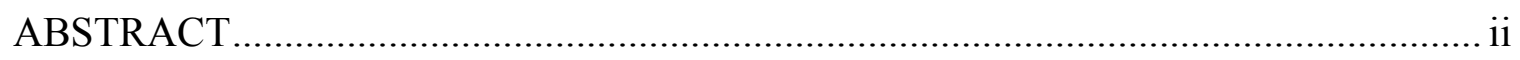

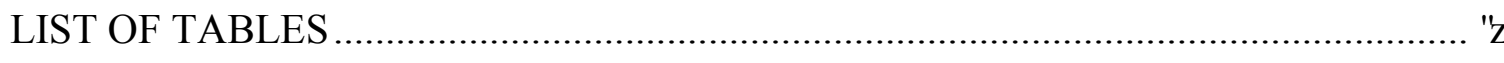

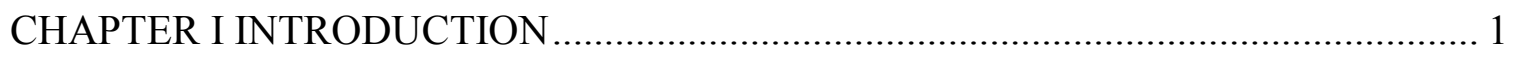

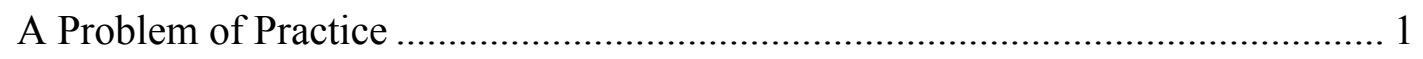

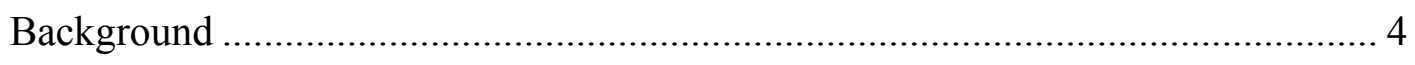

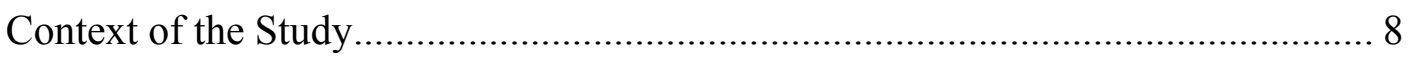

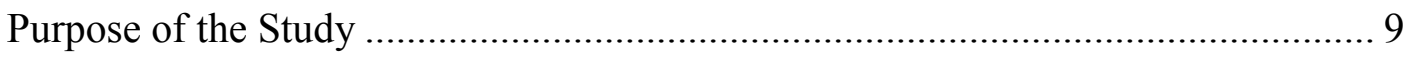

Research Question and Variables..................................................................... 10

Definition of Key Terms ................................................................................ 10

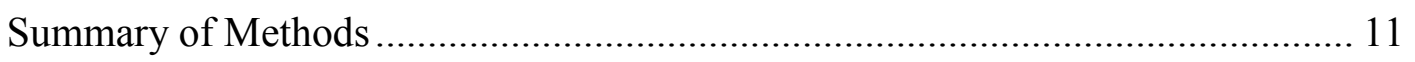

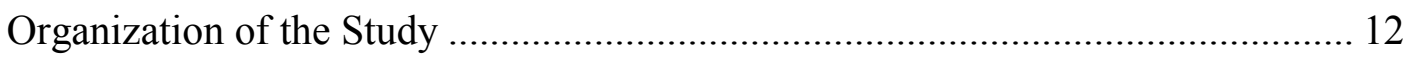

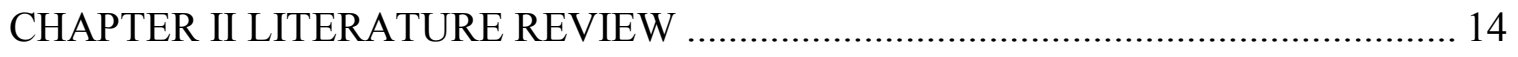

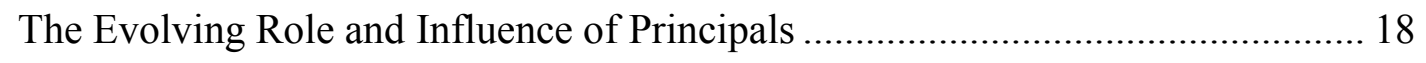

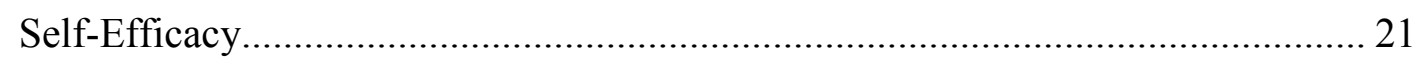

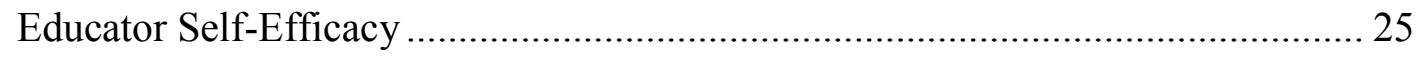

Measuring Self-Efficacy in Educators …………………………………….... 26

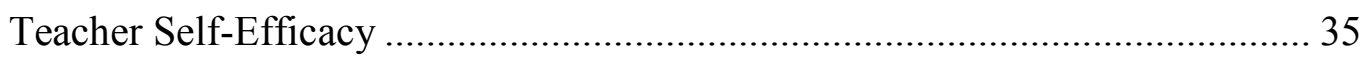




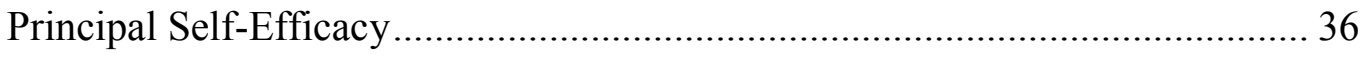

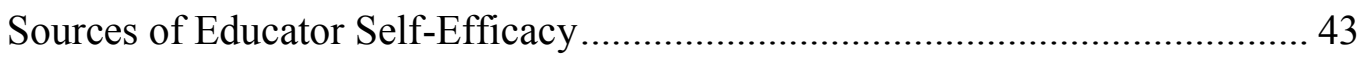

Professional Development................................................................................. 45

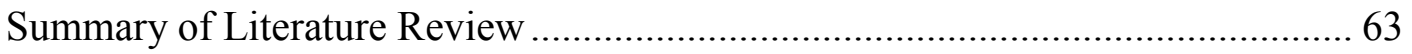

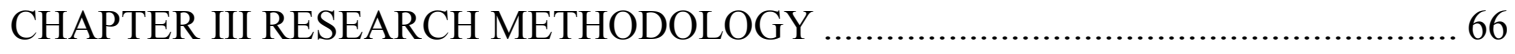

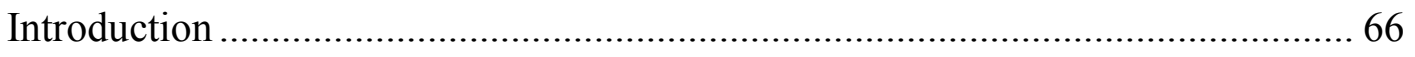

Research Question and Variables..................................................................... 67

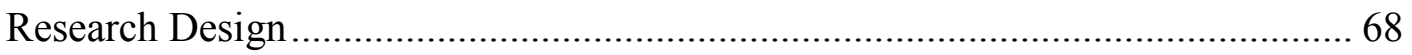

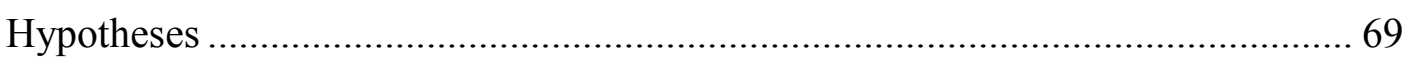

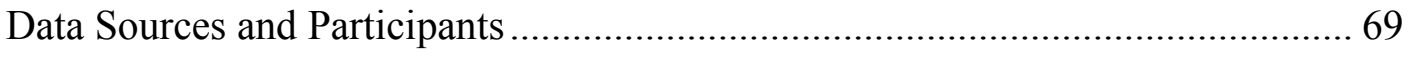

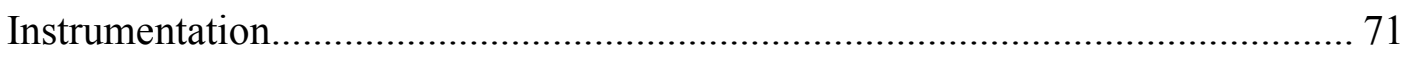

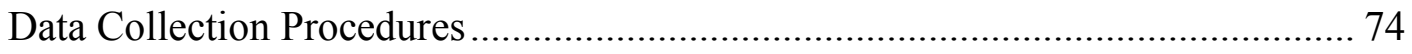

Operationalization of Variables ........................................................................ 77

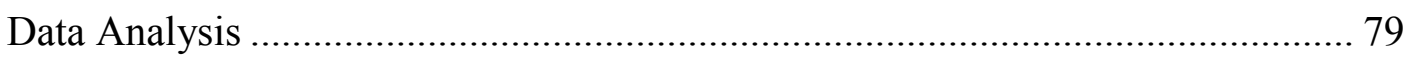

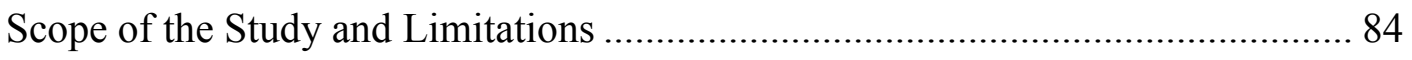

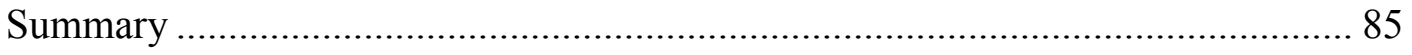

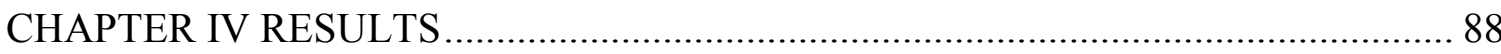

Participant Survey Responses ....................................................................... 8

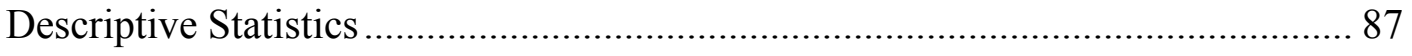

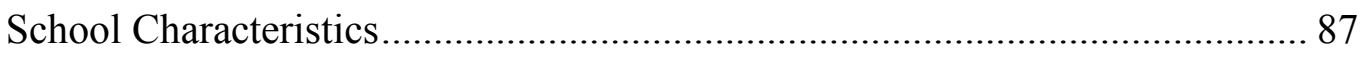

Professional Development Experiences.......................................................... 87

Principal Experience ………………………………………………………... 90 
Principal Self-Efficacy.................................................................................. 90

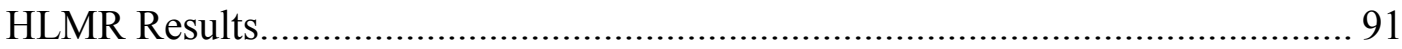

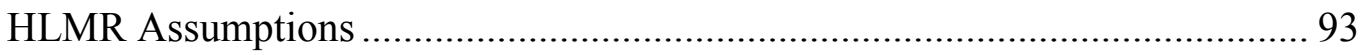

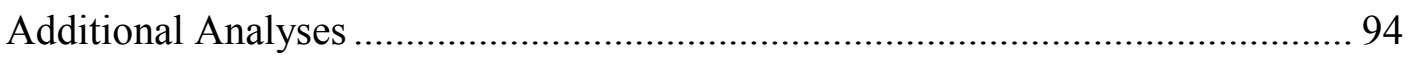

EILA Hours and Principal Self-Efficacy ……………………........................... 95

Federal or State Mandated Professional Development and Self-Efficacy.......... 96

Professional Development Focus and Reading Achievement ............................. 97

Professional Development Focus and Math Achievement ................................... 99

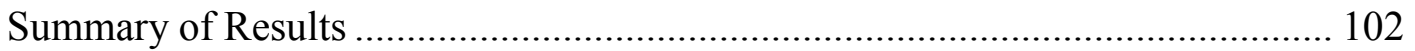

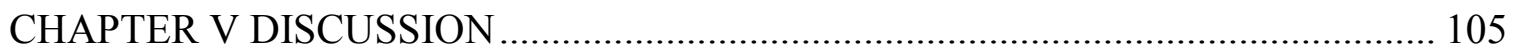

Discussion of Primary Analysis and Variables ................................................... 106

Discussion of Secondary Analyses .................................................................. 108

Implications and Suggested Future Research....................................................... 111

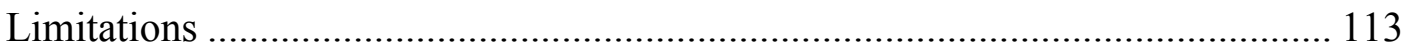

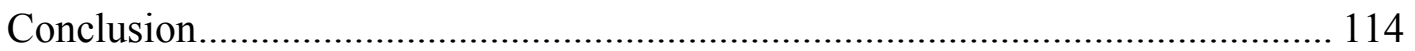

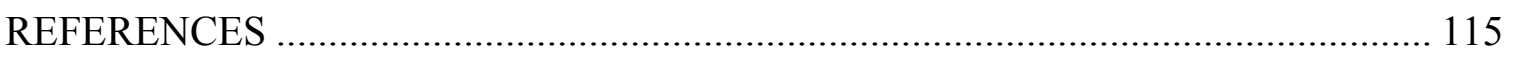

Appendix A: Permission to use instrumentation .......................................................... 132

Appendix B: Principal Sense of Efficacy Scale and Scoring Guide................................ 133

Appendix C: Email Notification to Potential Participants ............................................... 135

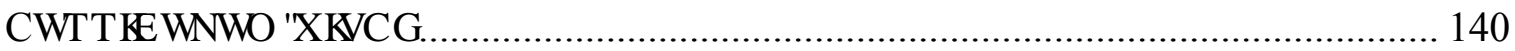




\section{LIST OF TABLES}

TABLE

PAGE

Table 1: Reliability Testing for TSESLF and Subscales .......................................... 30

Table 2: Correlations Between Principal Sense of Efficacy and Validity Variables.. 33

Table 3: 2016-2017 Reading and Math Achievement ........................................... 71

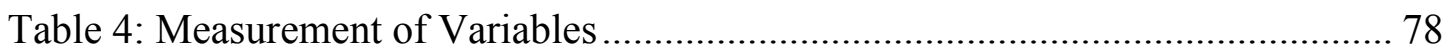

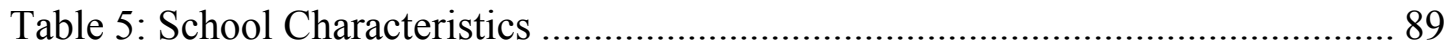

Table 6: Professional Development Hours by Focus.............................................. 90

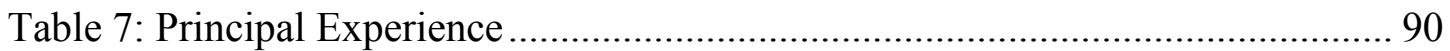

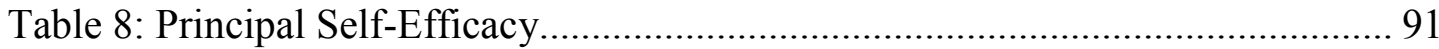

Table 9: HLMR Predicting Principal Self-Efficacy ............................................ 93

Table 10: PD Correlations with Student Reading Achievement .............................. 98

Table 11: HLMR Predicting Reading Achievement............................................ 100

Table 12: PD Correlations with Student Math Achievement ................................ 101

Table 13: HLMR Predicting Math Achievement................................................ 102 


\section{CHAPTER I}

\section{INTRODUCTION}

\section{A Problem of Practice}

In an environment of high stakes accountability, large urban school districts seek to implement meaningful and productive reforms in schools struggling to meet the demands of new standards, assessments, and accountability systems. These districts commonly look toward research-based curriculum, programs, and technology to quickly turn around low performing schools. Professional development (PD) is a common approach used to ensure educators effectively implement reform designs and practices (Desimone, 2009; Klein \& Riordan, 2009). PD is typically intended to produce educational practices that will result in improvements in student achievement. A variety of environments and formats can be used to provide PD to educators, from one time, onehour lectures or workshops to multiple day conferences and seminars to ongoing, embedded mentoring and coaching.

At times, large urban school districts conduct district-wide administrator professional development (APD) to promote effective implementation of the district's new programs, processes, and strategies. These large APD sessions may train hundreds of administrators through full-day or multiple day sessions. While new district programs, processes, and strategies may have high value and importance, these efforts for training and development may be wasted if an administrator does not have the self-efficacy 
needed to implement the needed changes in the face of school-specific challenges. Administrators with higher levels of self-efficacy are more likely to persevere and demonstrate resiliency in implementing change when faced with professional challenges (Smith et al., 2003). A higher level of self-efficacy in leaders has a positive relationship to their followers' attitudes, commitments to shared goals and tasks, and engagement (Chemers, Watson, \& May, 2000). Consequently, characteristics of administrators with higher levels of self-efficacy are related to higher levels of teacher self-efficacy (Calik, Sezgin, Kavgaci, \& Cagatay, 2012; Hartnett, 1995), which is highly correlated with student learning and achievement (Allinder, 1995; Armor et al., 1976; Calik, Sezgin, Kavgaci, \& Cagatay, 2012; Caprara, Barbaranelli, Steca, \& Malone, 2006; Domsch, 2010; Federici \& Skaalvik, 2012; Woolfolk Hoy \& Davis, 2006).

In larger school districts, district-wide and multiple day APD represents a large investment by a district in budgetary and opportunity costs (Klein \& Riordan, 2009). Opportunity costs are the options missed when resources are used for one particular purpose and not another, such as when financial or human resources used for one activity precludes their use for an alternative activity (Levin \& McEwan, 2001). One estimate was that approximately twenty billion dollars are spent annually on PD by public schools (Guskey, 2009). In addition to the costs of materials, products, consultants, and speakers to assist in implementation or training, a district may invest extensive employee-hours to prepare for implementation and training. When the salary of district staff who plan for, implement, or participate in district APD is considered, one could speculate that conducting district-wide professional development for administrators would take a serious investment of resources. According to John Collopy (personal communication, 
June 16, 2016), Director of Financial Planning and Management for Jefferson County Public Schools (JCPS) in Louisville, Kentucky, the school district spent \$26,255,965 for professional development during the 2014-2015 fiscal year. This calculation does not include the opportunity costs to school district personnel. Non-monetary costs of district wide APD include a diverting of leadership focus and time from schools to training and to the implementation of the APD content. APD requires a commitment of time from many K-12 educators and educational leaders. These school and district leaders take time away from their buildings to participate in training, which may or may not be aligned to their school's or district's needs.

When considering the amount of resources a district directs toward training administrators to implement reform, it would be prudent for district leaders to pause and consider if such APD produces the intended outcomes. District leadership should determine what immediate and long-term outcomes are desired from the APD. Leaders should consider if the methods of APD selected by a district results in the desired changes in administrative abilities and practices, and consequently, student achievement results. They should consider if any changes in administrative practices create the intended positive outcomes for schools, educators, and their students. Consequently, district leaders should consider how the self-efficacy of the administrators may affect the effectiveness of APD and how planned APD can potentially affect the self-efficacy of the participating administrators.

Focusing APD to accomplish a district's desired outcomes is critical. One could assume that not many struggling urban school districts can afford to perpetually divert significant resources to conduct APD for the implementation of completely new or 
unrelated programs every year or every few years. It is easily speculated that districts that jump from one district-wide focus to the next because of a lack of immediate improvements, ever-changing state accountability models, or, most alarming, as an attempt to keep up with the latest educational trends and fads would not likely find sustainable improvements in student achievement. Developing a long-term focus for APD that considers the starting and desired resulting levels of participator self-efficacy, may provide districts with administrators better equipped to promote positive changes. As district leaders focus development of administrators to improve instruction and student achievement, the focus, methods, and outcomes of APD must become a emphasis if dramatic improvement is to occur (Peterson, 2002).

\section{Background}

Professional development (PD) is an important means for states and districts to change educational practice and implement educational reforms (Guskey, 2009). In the research literature, no examples of school improvement without PD have been found (Guskey, 2009). Guskey (2009) claims "no improvement effort in the history of education has ever succeeded without thoughtfully planned and well-implemented professional development activities designed to enhance educators' knowledge and skills" (p. 226). If done well, PD can positively change professional practice (Garet, Porter, Desimone, Birman, \& Yoon, 2001; Yoon, Duncan, Lee, Scarloss, \& Shapley, 2007). However, PD is often conducted in ways that do not result in positive changes in educational practices (Darling-Hammond \& McLaughlin, 1995; Desimone, Porter, Garet, Yoon, \& Birman, 2002; Garet, Porter, Desimone, Birman, \& Yoon, 2001). The success 
of educational programs and school reform may be tied to the quality of the PD used to implement it in the school.

Given their limited resources, many districts focus training and development toward teachers and may not direct much attention to the development of administrators. An emphasis on teacher PD is reasonable, as teachers come into direct contact with students for a majority of every school day, directly provide academic instruction to students, and represent a greater percentage of total district personnel than administrators. Consequently, districts often provide extensive amounts of training and professional development intended to improve the practice of teaching and learning, which are correctly considered the core practices of the school. The result is an emphasis on teacher PD, which is most often focused on academic content, instructional strategies, and classroom management. In contrast, school administrators have less contact with students and do not typically provide academic instruction directly to students. As a result, districts and schools may devalue the importance of high quality PD for administrators.

However, high quality APD may provide an important and possibly underrated support for the teaching and learning that occurs at schools. Administrator leadership and practices have a direct link to the learning environment, the support and development of teacher instructional practices, and the utilization of school resources, which affect all students and have an indirect impact on student achievement (Leithwood, Patten, \& Jantzi, 2010). APD is the training and development of administrators to conduct managerial tasks or lead instructional practices. The body of research reflects the emphasis on teacher PD. However, there is still "so little good research on effective 
professional development" (Guskey, 2009, p. 226), and professional learning for educators has lacked a history of steady improvement or growing knowledge base (Guskey, 2014). Research on APD is even more limited, by comparison. While districts may look to implement researched practices for teacher PD, the more limited research on APD may not receive the same degree of implementation into district practices. There is a need for more research on effective professional development for principals (Camburn, Goldring, Sebastian, May, \& Huff, 2016). To address this need, this current study will attempt to contribute a better understanding of principal professional development.

The influences a principal has on the school are related to the administrative tasks he or she performs. For example, principal administrative behaviors are significantly related to teacher efficacy and motivation (Walker \& Slear, 2011). Administrative tasks, not effectively addressed, have a visible effect on teachers and their work (Walker \& Slear, 2011). Principals are inundated with administrative tasks that are important, but not necessarily the technical core or focus of the school, which is student learning. Consequently, pre-service and in-service principal professional development may often only be focused on training principals to perform administrative tasks.

Principals are also responsible for virtually everything related to the school. Some of the more visible responsibilities include academics, student behavior, school safety, and extracurricular activities. They are expected or required to oversee a variety of smaller initiatives or programs, which may be the result of policies adopted by the school district, laws passed by Congress or the state legislature, or demands by stakeholder groups or local community interest groups. These programs and initiatives can vary greatly from state to state, community to community, and school to school. 
Examples of these programs and initiatives can include civic-participation activities, such as staff charitable donations to local organizations or legally required school-wide activities for Veterans Day, Patriots Day, and Flag Day; student health initiatives, such as suicide and bullying awareness programs, fluoride treatment programs, vision/hearing screenings, and immunization records monitoring for students; student employability initiatives, such as community and employer partnerships, internships, and Junior Achievement; and a multitude of potentially controversial proposals and demands from stakeholders, such as the use of gender-specific restrooms and locker rooms, sex education programs, controversial or banned books, or uniforms. Many of the most controversial issues have a greater impact on middle and high schools, where older students have more age-appropriate awareness and involvement in these issues. As a result, vast demands and expectations are placed on principals, specifically middle and high school principals.

However, greater and growing emphasis has been placed on the role of the principal as an instructional and transformational leader (Robinson, Lloyd, \& Rowe, 2008). Administrators are expected to create positive school culture, manage the facilities and resources of the school, supervise all school employees, and implement a multitude of programs (as listed above), all while improving student achievement. Alone, improving student achievement, which is the core practice of schools, is challenging. In high stakes accountability, administrators are responsible for the achievement of all students. Administrators are tasked with ensuring all barriers to student learning, such as poverty, student disabilities, and limited English proficiency, are 
effectively addressed and overcome. One may question if the professional development of these principals reflects that shift.

States and districts frequently attempt to support principals' needs in addressing the diverse demands of their position, by providing them professional development opportunities for a variety of issues they must address. Often, however, the professional development opportunities are a mélange of trainings ranging in topics from differentiating instruction to budgets and school accounting procedures to classroom assessments of student learning to staff evaluations to state accountability to school safety planning to student interventions and more. While all these topics are important for a principal to manage, the APD principals are required to complete may only reflect the priorities identified by the district or state, and may not necessarily align with the individual professional needs of the principal or his or her school's specific barriers to student learning and achievement (Peterson, 2002). The whirlwind of trainings may result in a principal being designated as trained to lead a school, yet still ill-equipped to address the needs and barriers to student success within that school.

\section{Context of the Study}

In 2009, the state legislature in Kentucky passed Senate Bill 1 (SB1) into law. SB1 required the implementation of new academic standards and a new state assessment and accountability system for K-12 schools. The new system identified low performing schools and established audit and turnaround protocols for those schools (Kentucky Department of Education, 2017). As a result, Jefferson County Public Schools (JCPS) and the other Kentucky school districts have attempted to address the new standards, assessments, and school turnaround with school reforms and staff development. As 
previously stated, JCPS spent $\$ 26,255,965$ on professional development during the 20142015 fiscal year (personal communication, June 16, 2016). Despite the tens of millions of dollars spent on professional development, the Kentucky Department of Education (KDE) has classified 21 schools in JCPS as persistently low achieving/priority since 2009, with only 3 schools having shed the priority school label as of April 2017 (Kentucky Department of Education, 2017). Given that only one in seven of these schools has reached their goal, one could question if the PD being used in the district is having the desired level of impact. This study will examine the relationship of the district's APD to the self-efficacy of principals.

\section{Purpose of the Study}

The purpose of this study was to determine the relationship between principal PD and principal self-efficacy. This study further explored the predictive ability of principal experience, school factors, and student achievement on principal self-efficacy. This study also sought to add to the research on administrator professional development and administrator efficacy. This study was intended to assist the participating school district in evaluating its $\mathrm{APD}$, maximizing the efficacy of administrators, and maximizing the utility of limited resources for program and reform implementation and staff professional development. Based on the results and findings, the participating school district may utilize the results of this study when considering ways to maximize the efficacy of school principals within its APD practices. This study had implications for district practices in professional development and implementation of programs and reforms. Finally, this study acted as a beginning foundation for addressing principal self-efficacy antecedents and APD outcomes. 


\section{Research Question and Variables}

This study focused on the relationship between school administrator professional development and principal self-efficacy. To address this relationship, the following research question guided the study: To what extent do the hours of administrator professional development (APD) focused on culture/climate or instruction, school factors, and principal experience predict principal self-efficacy? The dependent variable was principal self-efficacy. The independent variables included the following: the hours of APD focused on culture/climate and instruction; principal experience; school level (elementary or secondary), student achievement, and the percentage of students in the free/reduced lunch program (FRL).

\section{Definition of Key Terms}

The following terms were used in this study:

Administrator Professional Development (APD): Activities that facilitate improvement or are intended to facilitate improvement in the professional practice of school principals and other administrative leaders and, for Kentucky principals, result in Effective Instructional Leadership ACT (EILA) credit or PD credit.

Efficacy: One's belief in his or her abilities to influence events in a manner that will produce intended outcomes (Bandura, 1994).

Effective Instructional Leadership Act (EILA): State law in Kentucky, as identified in KRS 156.101, intended to "encourage and require the maintenance and development of effective instructional leadership in the public schools of the Commonwealth" (Effective Instructional Leadership Act, 2005). 
Principal Self-efficacy: The beliefs of a principal in his or her individual ability to perform administrative tasks and influence student outcomes (Tschannen-Moran \& Gareis, 2004; Tschannen-Moran, Woolfolk Hoy, \& Hoy, 1998; Woolfolk Hoy \& Davis, 2006).

Professional Development: Activities that facilitate improvement or are intended to facilitate improvement in an educator's professional practice.

Self-efficacy: The belief in one's own ability to complete tasks or accomplish goals (Bandura, 1994).

\section{Summary of Methods}

The predictability of principal self-efficacy based on the hours of APD focused on culture/climate or instruction, school factors, and principal experience was examined through a correlational research design with quantitative data analyzed through linear regression. A correlational research design was appropriate for measuring the strength of the association between two or more variables or for determining a predictive equation for the variables (Creswell, 1994; Ho, 2014; Osborne, 2016; Petrocelli, 2003; Stevens, 2012). In this study, a relationship between the dependent variable (principal selfefficacy) and the independent variables (hours of APD focused on culture/climate or instruction, school factors, and principal experience) was analyzed and the strength and predictability of any such a relationship was measured. A correlational research design allowed for the determination of the level of influence between variables but could not provide for the testing of causality (Creswell, 1994; Ho, 2014; Osborne, 2016; Petrocelli, 2003; Stevens, 2012). 
Quantitative data came from three sources: surveys completed by principals, district-level records of individual principal PD history for 2016-2017, and publicly available school-level data from data books stored the district's website and KDE school report cards. The study sample consist of principals from JCPS, a large urban school district in Kentucky. All school principals $(N=139)$ were invited to participate in the study. Principal surveys collected demographic data and measured principal selfefficacy. District records of principal PD history for the 2016-2017 school year were used to measure completed APD hours for principals and the focus of principal PD activity. School-level data was collected from the school district's website and the statepublished school report cards. School-level data included the school grade levels, the percentage of students in the free/reduced lunch program, and student achievement in reading and math based on standardized state assessments. Data was analyzed through a hierarchical linear multiple regression (HLMR). HLMR is often used to examine the influence of multiple independent variables or predictors on a dependent variable, because it measures the extent to which variables or variable groupings contribute to the explained variance of the dependent variable (Ho, 2014; Osborne, 2016; Petrocelli, 2003; Stevens, 2012). This study sought to determine the extent of any correlation and the predictability the independent variables (APD hours focused on culture/climate or instruction; school factors, and principal experience) may have on the dependent variable (principal self-efficacy).

\section{Organization of the Study}

Chapter I of this study was an introduction that states the purpose, research questions, and a rationale for the study. It also included the definition of key terms and a 
summary of the study's methods, data sources, and structure. Chapter II reviews the literature on variables which were a part of this study, specifically principal efficacy and administrator professional development. Chapter III provides a full explanation of the study procedures, research methodology, data collection, and the process of data analysis. Chapter IV provides a narrative of the results and the analysis of the data. Finally, Chapter V summarizes the major findings of the study and the implications of the findings on educational policy and practices, as well as future research. 


\section{CHAPTER II}

\section{LITERATURE REVIEW}

The purpose of this review of literature was to explore the role of school administrators, self-efficacy in educators, and the connections professional development (PD) may have with principal self-efficacy. In this chapter, the reviewed literature establishes the context of administrator practice for this study. Additionally, this review sought to discover the connections between relevant variables that exists in research literature. Specifically, this review of the literature summarizes what is known about principal self-efficacy, effective PD, and known connections between the two. The review outlines a research-based conceptual framework for understanding the relationship between key concepts and variables and summarizes relevant gaps in the research.

First this review explores the role of the principal in schools. School principals have seen an increase in the expectations placed on them to improve schools, as states, districts, and communities have all looked to the school principal to lead the efforts for educational improvements, often measured by high-stakes accountability assessments (Grissom \& Harrington, 2010; Parylo, 2012). This attention on principals in not unwarranted. Principal effectiveness has been indirectly linked to student achievement (Hallinger \& Heck, 1998; Leithwood, Patten, \& Jantzi, 2010; Waters, Marzano, \& McNulty, 2003). 
Second, this review examines research literature on self-efficacy and the selfefficacy of educators. Self-efficacy is a set of beliefs an individual possesses about his or her ability to successfully complete specific tasks, which influences the individual's choices, effort levels, and perseverance on difficult or challenging tasks (Bandura, 1997; Pajares, 2006). Similarly, educator self-efficacy is an educator's belief in his or her ability to accomplish job-related tasks and produce desired educational outcomes for his or her students and/or school (Tschannen-Moran, Woolfolk Hoy, \& Hoy, 1998; Woolfolk Hoy \& Davis, 2006). Principal self-efficacy, like all management efficacy, has received little attention in research literature (Hannah, Avolio, Luthans, \& Harms, 2008). However, the literature that exists shows the self-efficacy of principals is a significant factor in student learning, the motivation of school staff, and the implementation of school restructuring (Federici \& Skaalvik, 2012). Additionally, high levels of selfefficacy in principals is correlated to higher levels of self-efficacy in teachers (Calik, Sezgin, Kavgaci, \& Cagatay, 2012; Hartnett, 1995; Klassen, Usher, \& Bong, 2010; Stipek, 2012). The relationship between principal and teacher self-efficacy is notable, as teacher self-efficacy is highly correlated with student learning and achievement (Allinder, 1995; Armor et al., 1976; Calik, Sezgin, Kavgaci, \& Cagatay, 2012; Caprara, Barbaranelli, Steca, \& Malone, 2006; Domsch, 2010; Federici \& Skaalvik, 2012; Woolfolk Hoy \& Davis, 2006).

Third, this review summarizes literature on professional development (PD), administrator professional development (APD), and their connections to self-efficacy. Meaningful PD can assist a principal in the task of school improvement. High quality PD is key to improving practice and student achievement (Ball \& Cohen, 1999; Darling- 
Hammond, 2010; U. S. Department of Education, 2001; Wei, Darling-Hammond, Andree, Richardson, \& Orphanos, 2009). However, APD content has been dominated by managerial tasks or addressing school accountability and less focused on leading instruction and learning (Oliver, 2005), despite the growing expectation for principals to be instructional leaders (Grissom \& Harrington, 2010; Parylo, 2012). Relatively few studies have explored the issues related to administrator professional development (Cardno \& Youngs, 2013; Grissom \& Harrington, 2010; Thorpe \& Bennett-Powell, 2014), and most studies on APD have focused attention only on participant perceptions of his or her experiences with APD, and few studies have explored APD outcomes, specifically through quantitative data (Grissom \& Harrington, 2010).

As states and school districts seek to support and develop school improvement reforms and programs through a heavy investment in PD and APD, it is reasonable to question the outcome of the methods used for PD and APD. Guskey and Yoon (2009) emphasize this point, stating:

If public schools are spending about $\$ 20$ billion annually on professional development activities...then it merits serious study. The research community must dramatically improve the precision of studies of the relationship between professional development, changes in teaching practices, and improvements in student learning. Practitioners likewise should insist on better evidence when making decisions about how to spend their limited professional development resources. (p. 499) 
This study sought to add to the body of research on APD, which may assist states, organizations, and school districts in identifying policies and practices that will improve the training and efficacy of their school principals.

As noted above and further explored in this chapter, key gaps existed in the relevant literature. While professional development (PD) for teachers has been the focus of a large body of literature over the last several decades, relatively few studies have explored the issues related to administrator professional development (Cardno \& Youngs, 2013; Grissom \& Harrington, 2010; Thorpe \& Bennett-Powell, 2014). Furthermore, while education researchers generally agreed on the characteristics that make up effective PD (Desimone, 2009; Desimone, Porter, Garet, Yoon, \& Birman, 2002; Guskey, 2009; Guskey \& Yoon, 2009; Wayne, Yoon, Zhu, Cronen, \& Garet, 2008), the specifics of which features most affect student outcomes and how to practically design the most effective PD was still weakly supported by research (Guskey, 2014; Wayne, Yoon, Zhu, Cronen, \& Garet, 2008). Finally, research on principal self-efficacy was limited, and the existing literature focused on the outcomes of principal self-efficacy and largely ignores the antecedents (Chen \& Bliese, 2002). This study helps to address these key gaps in the research literature. It adds to the deficiency of studies that explore APD and principal self-efficacy.

The purpose of this study was to determine the relationship between principal PD and principal self-efficacy. This study further explored the connection of principal experience and school factors with principal self-efficacy. This study also sought to add to the research on administrator professional development and administrator efficacy. To address this relationship, the following research question guided this study: To what 
extent does the number of hours earned for administrator professional development (APD) focused on culture/climate or instruction, school factors, and principal experience predict principal self-efficacy?

\section{The Evolving Role and Influence of Principals}

The leadership of principals in schools has evolved significantly throughout the history of education. For most of the twentieth century, principals were expected to maintain the orderly functioning of schools and students and oversee managerial tasks (Eberts \& Stone, 1998; Valentine \& Prater, 2011). The role of the principal was predominantly a resource and logistics manager and disciplinarian for student misbehavior (Brewer, 1993). Beginning in the 1980's, two differing views of the principal emerged - the instructional leader and the transformational leader (Hallinger, 2003; Hallinger \& Heck, 1998). According to Hallinger (2003), the instructional leadership models that emerged in the 1980's identified the desirable characteristics of a school leader. These characteristics reflected a desire for strong and directive leadership, and heavily influenced curriculum practices. During this time, an expectation developed for principals to be instructional leaders who coordinated, controlled, supervised, and developed curriculum and oversaw instruction in the school (Bamburg \& Andrews, 1991; Hallinger \& Murphy, 1985). This focus on the principal as the instructional leader of the school prevailed during 1980s and 1990s, but was not able to address the issues that came with the movement into high stakes accountability (Murphy, Elliott, Goldring, \& Porter, 2007; Murphy, Hallinger, \& Heck, 2013).

In the era of high stakes accountability, marked by passage of No Child Left Behind (NCLB) in 2001, principals faced increased pressure to raise student achievement 
for all students. This shift emphasized the role of leaders to effectively create positive change in schools. Principals were now expected to become transformational leaders. While the instructional leadership model placed control of curriculum and instruction in the hands of the principal (Bamburg \& Andrews, 1991; Hallinger \& Murphy, 1985), the transformational leadership model emphasized empowerment, shared leadership, and organizational learning for improving instruction and student learning (Hallinger, 2003). In this shift, the principal moved away from being the sole controller of instruction and learning to sharing leadership in the organization. The transformational leadership model created the opportunity for principals to empower teachers and develop teacher leaders throughout the organization (Day, Harris, \& Hadfield, 2001; Jackson D. , 2000). Despite this new model of shared leadership, the principal has continued to be held professionally responsible for leading the efforts for educational improvements (Grissom \& Harrington, 2010; Parylo, 2012). Therefore, in this study emphasis was placed on the development of principals in their instructional knowledge and skills and their ability to develop the learning climate and collaborative culture of their schools, staff, and students.

Principals must be effective in leading the transformation and improvement of their schools. The effectiveness of principals has an indirect connection to student achievement (Hallinger \& Heck, 1998; Leithwood, Patten, \& Jantzi, 2010; Waters, Marzano, \& McNulty, 2003). Murphy, Elliott, Goldring, and Porter (2007) explain this connection (see Figure 1) as starting with the cross-interactions of the principal's precursors - experience, knowledge, personal characteristics, and values and beliefs which influence the principal's leadership behaviors. These leadership behaviors, in turn, influence the school and classroom environments, which Murphy et al. (2007) labeled as 
influence pathways. The influence pathways directly influence student outcomes, including student achievement. Figure 1 illustrates these interactions in Murphy et al.'s (2007) Learning Centered Leadership Framework. Murphy et al. (2007) best encapsulate this indirect relationship by stating that "leaders influence the factors that, in turn, influence the outcomes" (p. 181).

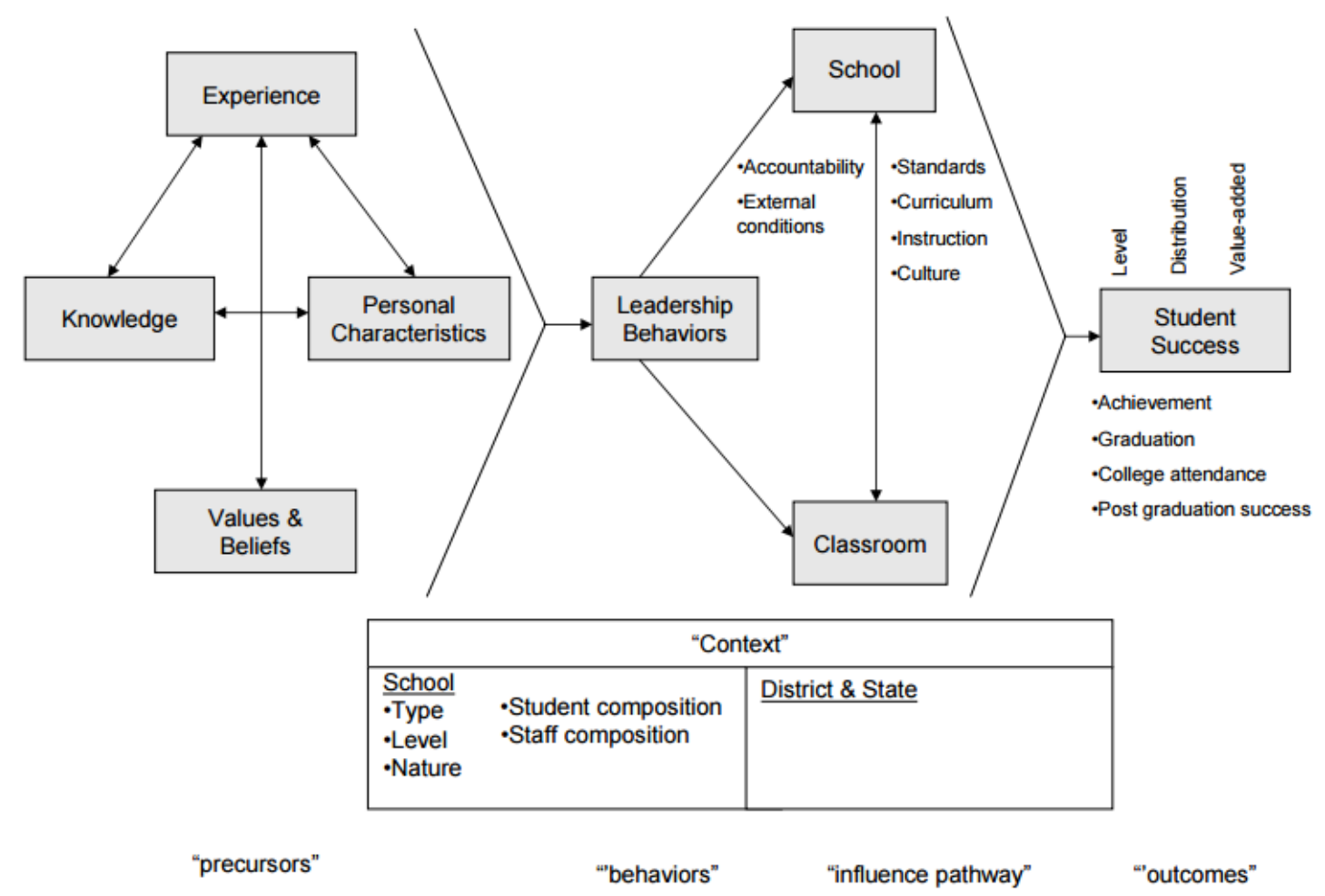

Figure 1. Learning Centered Leadership Framework. Reprinted from "Leadership for learning: A research-based model and taxonomy of behaviors" by J. Murphy, S. N Elliott, E. Goldring, and A. C. Porter, 2007, School Leadership and Management, 27, p. 180. Copyright 2007 by Taylor \& Francis.

Furthermore, as an indirect link does exist between principal effectiveness and student achievement (Hallinger \& Heck, 1998; Leithwood, Patten, \& Jantzi, 2010; Waters, Marzano, \& McNulty, 2003), the precursors that drive a principal's leadership behaviors 
should be properly examined, assessed, and developed. This review of literature will further explore the personal values and beliefs of principals, specifically their selfefficacy, and the relationship APD and personal characteristics may have with it.

\section{Self-Efficacy}

Like all human beings, a principal's professional practice is heavily influenced by his or her own perceptions of what he or she is capable of achieving, which has been called self-efficacy. Self-efficacy is a fundamental concept in Bandura's social cognitive theory (Bandura, 1977; Bandura, 1994; Bandura, 1997). Social cognitive theory emphasizes the role of human agency in behavior - that individual behavior is influenced by the individual and his or her beliefs (Bandura, 1977; Bandura, 1994; Bandura, 1997; Bandura \& Locke, 2003). In other words, social cognitive theory suggests that one's perceived abilities for a task will influence the effort one puts into the task, which may likely become a self-fulfilling prophecy that reinforces the original perception. Again, social cognitive theorists, such as Bandura $(1977 ; 1994 ; 1997)$, call these beliefs one has about himself/herself self-efficacy.

Self-efficacy is an individual's beliefs about what he or she can do and achieve in specific tasks. These beliefs influence the individual's choices, effort levels, and perseverance on difficult or challenging tasks (Bandura, 1997; Pajares, 2006). Perceived self-efficacy is the belief that individuals have regarding their own capabilities to produce effects or outcomes (Bandura, 1994). According to social cognitive theory, if one believes himself/herself as capable of accomplishing a task, he or she will be more likely to continue putting effort into the task's completion, even when confronted with difficulty. This continuation of effort increases the likelihood that the individual will 
successfully complete the task, thereby reinforcing one's positive belief in one's ability. On the contrary, one who lacks confidence in his or her ability to accomplish a task, will be more likely to minimize or stop his or her efforts in completing the task, especially when faced with difficulties. This lack or reduction of effort decreases the likelihood of successful task-completion, reinforcing the individual's negative views of their ability. Similarly, group efficacy is “a group's shared belief in its conjoint capabilities to organize and execute the courses of action required to produce give levels of attainments" (Bandura, 1997, p. 477).

An individual's level of self-efficacy can have a variety of influences on motivation and perseverance. Those with high perceived self-efficacy are more likely to produce high achievement and success with goals within their field than those with lower perceptions of self-efficacy (Bandura \& Locke, 2003). One's self-efficacy beliefs help determine patterns of thinking within the individual which lead to self-enhancing or selfdebilitating actions (Bandura \& Locke, 2003). An efficacious outlook produces an increase in the achievement of goals, reduction in stress, and decreased likelihood of depression (Bandura, 1994).

One's action in the face of obstacles is dependent on one's sense of self-efficacy, as the individual's internal motivations are guided by the belief that one can bring about desired effects (Bandura \& Locke, 2003). Individuals with a high sense of self-efficacy tend to view challenging situations as having beneficial opportunities, while those with a lower sense of self-efficacy tend to focus on avoiding risks that are associated with a challenging situation (Bandura \& Locke, 2003). People with a strong sense of efficacy set challenging goals for self, have strong commitment to goals, persevere in difficulties, 
quickly recover sense of efficacy after failures, blame failures on insufficient effort or missing knowledge and skills they can still acquire, approach threatening situations with a sense of control that can be exerted (Bandura, 1994; Pajares, 1997). Bandura (1994) stated, "Realists may adapt well to existing realities. But those with a tenacious selfefficacy are likely to change those realities" (p. 8). Similarly, lower levels of selfefficacy are associated with negative motivations. Individuals with a weak sense of efficacy avoid difficult tasks, have low aspirations, have weak commitments to goals, focus on personal deficiencies and obstacles and possible negative outcomes, give up quickly against challenges, and are slow to recover their sense of efficacy after failures (Bandura, 1994; Pajares, 1997). These individuals often have higher levels of stress and depression (Bandura, 1994). Likewise, the attitudes, levels of commitment and perseverance, resiliency, and levels of stress and depression of school administrators would be determined by their own sense of efficacy.

According to social cognitive theory, one's beliefs and abilities are shaped in the interaction of personal, behavioral, and environmental factors (Bandura, 1977). Bandura calls the interaction of these three factors triadic reciprocal causation. One's belief in one's own efficacy is a personal factor, and Bandura identifies four sources of influence on efficacy beliefs: mastery experiences, physiological and emotional states, vicarious experiences, and social persuasion (Bandura, 1994; Bandura, 1997). Of these sources, multiple studies identify mastery experiences as the most critical source of self-efficacy (Bandura, 1994; Pajares, 2006; Usher \& Pajares, 2008). As Bandura (1994) states, "the most effective way of creating a strong sense of efficacy is through mastery experiences. Successes build a robust belief in one's personal efficacy" (p. 2). Failures undermine 
one's sense of efficacy, especially failures that occur before one's sense of efficacy is strongly shaped (Bandura, 1994; Bandura, 1997). Easy successes can undermine the establishment of a strong sense of efficacy by creating expectations of quick results. Subsequent failure produces discouragement. However, obstacles overcome by persistent effort produces a resilient sense of efficacy (Bandura, 1994). Seeing peers succeed through sustained efforts increases one's belief's that they can also master similar activities. This increase in belief is dependent upon the observer perceiving the model as comparable to oneself (Bandura, 1994; Bandura, 1997). Similarly, observation of comparable peers failing despite persistent efforts can lower one's sense of efficacy (Bandura, 1994; Bandura, 1997). Social persuasion can also affect one's sense of efficacy through encouragement or discouragement and an expression of highly or lowly efficacious beliefs from individuals or groups. It should be noted that it is easier to diminish perceived efficacy than to build it through persuasion alone (Bandura, 1994).

Other factors that are related to an individual's identity, including sex, race/ethnicity, and age, may also play a role in one's level of self-efficacy. The influence of these factors are summarized and were considered for inclusion as independent variables in this study. Sex-role perceptions and beliefs and their resulting socialization have been related to higher levels of self-efficacy in males than females (Bandura, 1997; Gecas, 1989). Oates (2004) found that African-Americans generally have lower levels of self-efficacy, compared to whites, but those levels were subject to the same contextual influences as whites. In other words, self-efficacy appears to be influenced more by the self-efficacy levels of those surrounding the individual and the individual's master experiences and failures, than by race as an isolated factor. Similarly, Buchanan and 
Selmon (2008) found that there is no significant difference in self-efficacy between Whites and African-Americans. They determined, however, that the impact of gender on one's self-efficacy is conditional upon race. Additionally, several researchers have found a negative relationship between self-efficacy and age (Bausch, Michel, \& Sonntag, 2014; Chu, 2010; Maurer, 2001; Stine-Morrow, Shake, Miles, \& Noh, 2006; Touron \& Hertzog, 2004). However, some researchers have discussed factors that moderate the relationship between the two; specifically, when the context of the task is perceived as neutral and not within the domain of younger people, the influence of age is negated (Artistico, Cervone, \& Pezzuti, 2003; Schulz \& Stamov Roßnagel, 2010). These studies demonstrate a common influence of situational context, social persuasion, and mastery experiences as stronger influences on the individual's self-efficacy than the individual's specific demographic factors.

\section{Educator Self-Efficacy}

The level of self-efficacy in educators is important, given the challenges they must overcome to effectively educate students. The beliefs an educator has regarding his or her ability to succeed in teaching or administrative tasks will influence his or her perseverance when confronting challenges (Bandura, 1994; Pajares, 2006). Within the school setting, principal self-efficacy and teacher self-efficacy are connected (Gist \& Mitchell, 1992; Klassen, Usher, \& Bong, 2010; Stipek, 2012). The following sections will explore the research literature on the measures of educator self-efficacy, antecedents and outcomes of teacher self-efficacy, antecedents and outcomes of principal selfefficacy, and the sources of educator self-efficacy. 


\section{Measuring Self-Efficacy in Educators}

The self-efficacy of educators has been studied in multiple ways. Researchers have examined the relationships educator self-efficacy has with classroom practices and environment (Khourey-Bowers \& Simonis, 2004; Klassen, Usher, \& Bong, 2010; Woolfolk Hoy \& Davis, 2006), teaching career and perceptions of workplace environment (Caprara, Barbaranelli, Steca, \& Malone, 2006; Klassen \& Chiu, 2010; Klassen, Usher, \& Bong, 2010; Woolfolk Hoy \& Davis, 2006), individual personal and professional characteristics (Klassen \& Chiu, 2010; Koehler, Feldhaus, Fernandez, \& Hundley, 2013; Raudenbush, Rowan, \& Cheong, 1992; Stipek, 2012), and student achievement (Pedota, 2015; Stipek, 2012). In attempting to measure educator selfefficacy, many instruments have been developed, used, and critiqued (Tschannen-Moran \& Gareis, 2004; Tschannen-Moran \& Hoy, 2001). One of the first measures was the 2item Rand measure (Armor et al., 1976).

Early measures of educator self-efficacy. Embedded within a longer questionnaire, the Rand measure included two items that asked teachers to rate their perceptions of abilities (Armor et al., 1976). The Rand measure was based on Rotter's (1966) theory of social learning. The sum of the items were said to show the teacher's efficacy, specifically the extent to which one believed student motivation and learning were within one's control versus the control of outside factors, such as home environment. Subsequent researchers labelled the first Rand item as measuring general teaching efficacy, while the second measured personal teaching efficacy (Ashton, Olejnik, Crocker, \& McAuliffe, 1982). Using the Rand measure, teacher efficacy was significantly related to success in teaching reading to minority students (Armor et al., 
1976) and was determined to be a strong predictor of the continued use innovations after the funding for the innovations ended (Berman, McLaughlin, Bass, Pauly, \& Zellman, 1977). As researchers continued exploring the concept of teacher self-efficacy, criticisms of the two-item Rand measure's reliability motivated the development of more comprehensive measures. Following the example set by the Rand measure, three notable subsequent measures of teacher self-efficacy were developed: the responsibility for student achievement (RSA) (Guskey, 1981), the teacher locus of control (TLC) (Rose \& Medway, 1981), and the Webb scale (Ashton, Olejnik, Crocker, \& McAuliffe, 1982). Each of these measures were based on Rotter's (1966) theory of social learning, which emphasized the influence of a teacher's belief that factors they control can have a greater effect on student learning than the external factors on students that lay outside the teacher's influence (Tschannen-Moran \& Hoy, 2001). However, each of these measures were largely unused in the research on teacher efficacy (Tschannen-Moran \& Hoy, 2001). About the same period of time, a second branch of measures, based on an alternate theoretical framework, were developed. These measures were based on Bandura's (1977) social cognitive theory, which considers both efficacy expectations one's belief in his or her ability to perform the necessary actions to complete a task - and outcome expectations - one's belief that he or she can perform a task to produce an estimated outcome. Measures that incorporated social cognitive theory include the Ashton vignettes (Ashton, Buhr, \& Crocker, 1984) and the Teacher Efficacy Scale (TES) (Gibson \& Dembo, 1984). The Ashton vignettes attempted to address the assumptions that teacher efficacy is context specific by having teachers rate their perceived effectiveness in handling a teacher-relatable situation and how their effectiveness would 
compare to most teachers. As a measure of efficacy, the Ashton vignettes were also largely unused by educational researchers (Tschannen-Moran \& Hoy, 2001).

Gibson and Dembo (1984) developed the TES as a 30-item measure and assumed that its two-factor structure captured the construct of outcome expectancy. They proposed that the first factor captured self-efficacy, reflecting the Rand measure of personal teaching efficacy (PTE) while the second factor captured teaching efficacy, reflecting the Rand measure of general teaching efficacy (Gibson \& Dembo, 1984). The TES was utilized as a measure in far more studies than any prior measure (TschannenMoran \& Hoy, 2001). However, Tschannen-Moran and Hoy (2001) describe various statistical and conceptual problems with the TES, including how only 16 of the 30 items load uniquely on one factor or the other. More measures of teacher self-efficacy were needed to address the issues found in the TES (Tschannen-Moran \& Hoy, 2001).

One approach to improving on the TES was to address the context and specificity of teacher self-efficacy. "Teacher efficacy has been defined as both context and subject matter specific" (Tschannen-Moran \& Hoy, 2001, p. 790). To address specific context multiple researchers have attempted to modify the TES for measuring teacher selfefficacy in specific content areas or instructional focus. The Science Teaching Efficacy Belief Instrument (Riggs \& Enochs, 1990) measured science teaching efficacy and has been a common measure in several studies. It further addresses the context and specificity of teacher self-efficacy by differentiating between science-teaching selfefficacy and chemistry teaching self-efficacy. Emmer (1990) created a 36-item measure that adapted the TES to measure classroom management. This measure included three efficacy subscales: efficacy for classroom management and discipline, external 
influences, and personal teaching efficacy (Emmer, 1990). Coladarci and Breton (1997) and Meijer and Foster (1988) developed teacher self-efficacy measures for the specific context of special education. One other measure that was quietly utilized was an unpublished measure by Bandura that consisted of 30 items which were broken into seven subscales (Tschannen-Moran \& Hoy, 2001). Additionally, several other measures were developed, blended, and/or adapted to address a variety of contexts, conceptual concerns, and/or statistical problems (Tschannen-Moran \& Hoy, 2001).

The Ohio State Teacher Efficacy Scale. To address the various issues with the previously existing measures of teacher efficacy, Tschannen-Moran and Hoy (2001) developed the Ohio State Teacher Efficacy Scale (OSTES), also known as the Teacher Sense of Efficacy Scale (TSES). Two versions of the OSTES were developed: the 24item Teacher Sense of Efficacy Scale Long Form (TSESLF) and the 12-item Teacher Sense of Efficacy Scale Short Form. The TSESLF has a nine-point response scale, which starts at 1, representing "not at all" and ends at 9, representing "a great deal." Tschannen-Moran and Woolfolk Hoy (2001) tested TSESLF via factor analysis and found that factoring from the three subscales (efficacy in student engagement, efficacy in instructional practices, and efficacy in classroom management) revealed one strong factor that accounted for $75 \%$ of the variance. The emergence of this factor and the positive moderate correlations of the three subscales suggested the TSESLF could be used to measure efficacy, the underlying construct. With loadings ranging from 0.49 to 0.76 , all items loaded on this factor: efficacy. As outlined in Table 1, the alpha level for the total scale score was 0.94 and subscale reliability ranged from 0.87 to 0.91 , indicating that the 
scale total score and subscale scores are reliable, valid, and appropriate for assessing efficacy of teachers (Tschannen-Moran \& Hoy, 2001).

Table 1

Reliability Testing for TSESLF and Subscales

\begin{tabular}{lccc}
\hline & $M$ & $S D$ & $\alpha$ \\
\hline TSESLF & 7.1 & 0.94 & 0.94 \\
Instruction & 7.3 & 1.10 & 0.91 \\
Management & 6.7 & 1.10 & 0.90 \\
Engagement & 7.3 & 1.10 & 0.87 \\
\hline
\end{tabular}

Adapted from Tschannen-Moran \& Hoy, 2001

TSESLF and the subscales of efficacy in student engagement, efficacy in instructional practices, and efficacy in classroom management have been validated against multiple preexisting measures of teacher self-efficacy, including the Rand measures of teacher efficacy, general teacher efficacy (GTE), and Gibson and Dembo's personal teacher efficacy (PTE) (Tschannen-Moran \& Hoy, 2001). Total scores on the TSESLF were positively related to both the first Rand item $(r=0.18, p<0.01)$ and the second Rand item $(r=0.53, p<0.01)$, Gibson and Dembo's PTE factor $(r=0.64, p<$ $0.01)$, and the GTE factor $(r=0.16, p<0.01)$ (Tschannen-Moran \& Hoy, 2001). These significant correlations and the resulting analysis from Tschannen-Moran and Hoy (2001) suggested that the TSESFL is a valid and reliable instrument to measure teacher selfefficacy. However, in a confirmatory factor analysis, Roberts and Henson (2001) suggested eliminating the third factor, efficacy in classroom management, in favor of a stronger two-factor model. Even with the criticism of the third factor, TSESFL has been a commonly used instrument for measuring teacher self-efficacy in educational research and additional adaptations were developed for use in other languages, countries, and 
contexts (Tschannen-Moran \& Gareis, 2004), including adaptations for measuring principal self-efficacy.

Early measures of principal self-efficacy. Like measures for teacher selfefficacy, attempts to develop reliable and valid measures for principal self-efficacy have been difficult. One of the earliest measures of principal efficacy was included in Hillman's (1986) self-efficacy measures for student, teacher, and principal efficacy beliefs. This measure was based in attribution theory (Weiner, 1979) and did not align well with the prevailing self-efficacy constructs based in social cognitive theory. It was similar in format to the Guskey (1981) and Rose and Medway (1981) teacher selfefficacy measures and, like those instruments, did not find popularity in educational studies (Tschannen-Moran \& Gareis, 2004). Another early attempt to measure principal self-efficacy was Imants and De Bradbander's (1996) measure of perceived self-efficacy and perceived school efficacy in pupil-oriented and school-oriented tasks. However, this measure lacked a demonstration of its validity and of the validity of its conceptualization (Tschannen-Moran \& Gareis, 2004).

In another early measure of principal self-efficacy, Dimmock and Hattie (1996) asked principals to respond to vignettes that a principal would likely encounter. The vignettes covered a variety of managerial and instructional leadership scenarios. This measure was included as part of Tschannen-Moran and Gareis' (2004) exploration of the reliability and validity of principal self-efficacy measures. The analysis revealed low communalities (ranging from 0.21 to 0.44 ). The Cronbach's alpha reliability was 0.77 , but item-total correlations were low (ranging from 0.34 to 0.61 ). Based on this analysis, 
they determined that this measure "was of insufficient stability and reliability to prove useful for future study" (Tschannen-Moran \& Gareis, 2004, p. 577).

The Principal Sense of Efficacy Scale. The Principal Sense of Efficacy Scale (PSES) (Tschannen-Moran \& Gareis, 2004) was adapted from the TSESLF in an attempt to solve validity issues with earlier measures. PSES is an 18 item survey, in which each item begins each question with the statement, "In your current role as principal, to what extent can you..." and offers a nine-point response scale which starts at 1, "not at all" and ends at 9, "a great deal." The PSES is subdivided into three subscales, each with six items. The first subscale measures principals' sense of efficacy on handling management components of the position, such as the management of paperwork, prioritizing tasks, and managing various and competing demands. Second, the PSES measures their sense of efficacy for instructional areas of the principalship, including creating a positive learning environment, ensuring student learning, and developing a shared vision. Finally, the scale measures their sense of efficacy on moral leadership, such as promoting ethical behavior of staff, promoting school spirit, and promoting positive image of school (Tschannen-Moran \& Gareis, 2004).

The PSES has been validated against measures of work alienation and principals' trust in teachers and clients (Tschannen-Moran \& Gareis, 2004). Validity was tested by correlating the scale to these other known constructs. As Tschannen-Moran and Gareis (2004) anticipated, the sense of self-efficacy of sampled principals was "significantly negatively related to work alienation $(r=-0.45, p<0.01)$ and positively correlated to both trust in teachers $(r=0.42, p<0.01)$ and trust in students and parents $(r=0.17, p<$ 
0.01)" (p. 580). Table 2 summarizes the correlations between constructs, as found in Tschannen-Moran and Gareis' (2004) sample study.

Table 2

Correlations Between Principal Sense of Efficacy and Validity Variables

\begin{tabular}{lcccccc}
\hline & 2 & 3 & 4 & 5 & 6 & 7 \\
\hline Principal sense of efficacy & $0.79^{* *}$ & $0.86^{* *}$ & $0.85^{* *}$ & $0.45^{* *}$ & $0.42^{* *}$ & $0.47^{* *}$ \\
PSE for instruction & & $0.46^{* *}$ & $0.58^{* *}$ & $0.41^{* *}$ & $0.44^{* *}$ & $0.39^{* *}$ \\
PSE for management & & & $0.58^{* *}$ & $0.37^{* *}$ & $0.27^{* *}$ & $0.33^{* *}$ \\
PSE for moral leadership & & & & $0.37^{* *}$ & $0.37^{* *}$ & $0.49^{* *}$ \\
Work alienation & & & & & $0.37^{* *}$ & $0.44^{* *}$ \\
Principal trust in teachers & & & & & & $0.48^{* *}$ \\
Principal trust in students and & & & & & & \\
parents & & & & & & \\
\hline
\end{tabular}

Note. $N=544,{ }^{*} p<0.05$, and ${ }^{* *} p<0.01$

Source: Tschannen-Moran \& Gareis, 2004

Tschannen-Moran and Gareis' (2004) sample study of 544 principals was used to validate the PSES and explore correlations between principal sense of efficacy and demographic variables. In testing the validity of PSES, Tschannen-Moran and Gareis (2004) found that race had a slight relationship with self-efficacy, "with white principals having slightly higher sense of efficacy than black principals $(r=0.09, p<0.05)$ " (TschannenMoran \& Gareis, 2004, p. 580). More efficacious principals were somewhat more likely to agree that they would pursue a principal position if they could go back and do it again $(r=.017, p<0.01)($ Tschannen-Moran \& Gareis, 2004). Conversely, neither the socioeconomic status of the students at the school and gender had a significant relationship to the principals' sense of efficacy. Tschannen-Moran and Gareis (2004) also found that experience as a principal and tenure at their school each had no significant relationship to the principals' sense of efficacy. Based on their findings, Tschannen-Moran and Gareis 
(2004) suggest the PSES as a suitable measure for principal self-efficacy as both an antecedent and outcome.

The Principal Self-Efficacy Scale. Smith and Guarino (2005) (see (Smith et al., 2003; Smith, Guarino, Strom, \& Adams, 2006) developed the Principal Self-Efficacy Scale as a contribution to the lack of research literature on principal self-efficacy and instructional effectiveness. It consists of fourteen items that assess two factors - nine items for instructional leadership and five items for management skills. Responses are scored on a four point Likert-based scale. Items require respondents to rate their belief in their ability in tasks common to school principals. Responses are phrased as Very Weak Beliefs in My Abilities (VW), Weak Beliefs in My Abilities (W), Strong Beliefs in My Abilities (S), and Very Strong Beliefs in My Abilities (VS). The measure was used in a study included 284 participating principals from twelve states (Smith W. , Guarino, Strom, \& Adams, 2006) and Smith and Guarino (2005) analyzed the results through confirmatory factor analysis. Subsections were determined to be statistically significant ( $p<0.01$ ), with factor loadings ranging between 0.59 and 0.60 for instructional leadership and between 0.44 and 0.77 for management skills. The correlation between the two factors was 0.69 , indicating discriminate validity. The Cronbach's alpha reliability was 0.86 for instructional leadership and 0.74 for management. As individual items demonstrated construct validity and instructional leadership and management constructs are both considered important for principal effectiveness, Smith and Guarino (2005) describe their survey as a promising measure for the self-beliefs of principals, although they suggest further replications of their initial results, as their research was exploratory in nature. 


\section{Teacher Self-Efficacy}

Definition and outcomes of teacher self-efficacy. Teacher self-efficacy is the teacher's belief regarding his or her ability to perform teacher tasks and is positively associated with student learning and outcomes, even with students who are more difficult or may be unmotivated (Tschannen-Moran, Woolfolk Hoy, \& Hoy, 1998; Woolfolk Hoy \& Davis, 2006). Much like one's general sense of efficacy, educator self-efficacy is an important factor in determining the successful completion of tasks. For teachers, a high sense of self-efficacy is related to a variety of positive factors in the classroom (Woolfolk Hoy \& Davis, 2006) and improved classroom culture (Khourey-Bowers \& Simonis, 2004). A higher sense of efficacy also benefits teachers with longer careers (Woolfolk Hoy \& Davis, 2006), reduced stress, improved teacher-student rapport, and higher levels of effectiveness (Klassen, Usher, \& Bong, 2010). Most importantly, teacher self-efficacy is highly correlated with student learning and achievement (Allinder, 1995; Armor et al., 1976; Calik, Sezgin, Kavgaci, \& Cagatay, 2012; Caprara, Barbaranelli, Steca, \& Malone, 2006; Domsch, 2010; Federici \& Skaalvik, 2012; Woolfolk Hoy \& Davis, 2006). Conversely, Pedota (2015) suggests that student achievement also influences the selfefficacy of teachers (Pedota, 2015; Stipek, 2012).

Antecedents of teacher self-efficacy. Among teachers, other additional variables may influence teacher self-efficacy. Student tracking and the resulting perceived differences in student engagement can result a teacher's level of self-efficacy shifting between individual classes and varying situations (Raudenbush, Rowan, \& Cheong, 1992). Female teachers may also tend to have lower levels of self-efficacy than male teachers (Raudenbush, Rowan, \& Cheong, 1992). Klassen and Chiu (2010) tested gender 
and teaching experience as they correlate with the three dimensions of teacher selfefficacy: instructional strategies, classroom management, and student engagement. Gender and self-efficacy in classroom management are correlated; specifically, females may have lower levels of self-efficacy in classroom management. When other factors are controlled, there is no difference in self-efficacy for teachers with a master's degrees and those without (Raudenbush, Rowan, \& Cheong, 1992). For pre-service teachers, graduate degrees have a negative relationship with one's self-efficacy in a variety of teaching tasks (Koehler, Feldhaus, Fernandez, \& Hundley, 2013). When isolated, there is no significant difference in the self-efficacy of secondary teachers, based on the disciplinary specialization (Raudenbush, Rowan, \& Cheong, 1992). Years of teaching experience may also correlate with self-efficacy levels in all three domains, and the level of poverty in a school may also influence the self-efficacy of the teachers (Stipek, 2012).

\section{Principal Self-Efficacy}

Outcomes of principal self-efficacy. The self-efficacy of administrators is an important construct with multiple potential benefits for schools, faculties, and students, yet it has received inadequate study (Leithwood \& Jantzi, 2008; Tschannen-Moran \& Gareis, 2004). Administrators play a role in the self-efficacy of teachers. Administrators who are more supportive may be a factor of influence in schools whose teachers report high levels of collective efficacy beliefs (Klassen, Usher, \& Bong, 2010; Stipek, 2012). A higher sense of efficacy in leaders results in higher levels of effort and persistence (Bandura, 1997; Gist \& Mitchell, 1992) and has a positive relationship to their followers' attitudes, commitments to shared goals and tasks, and engagement (Chemers, Watson, \& May, 2000). Additionally, administrators with higher levels of self-efficacy have higher 
levels of resiliency and perseverance when faced with professional challenges and tend to spend more time on instructional leadership activities, such as providing instructional feedback, procuring and/or leading PD for teacher, and engaging with teachers in discussions of student learning, and (Smith et al., 2003). Greater involvement in instructional leadership and resiliency, a key indicator of self-efficacy in administrators, are related to higher levels of teacher self-efficacy (Calik, Sezgin, Kavgaci, \& Cagatay, 2012; Hartnett, 1995).

Federici and Skaalvik's (2012) quantitative study of 1,818 principals in Norway explored relationships between principal self-efficacy, job satisfaction, and motivations to quit. Participants responded to the 22-item researcher-developed Norwegian Principal Self-Efficacy Scale (NPSES). The NPSES measures self-efficacy in eight dimensions: instructional leadership, economic management, administrative management, teacher support, school environment, relation to municipal authority, parental relations, and relation to local community. The data was analyzed by a confirmatory factor analysis and structural equation modeling. Their study revealed that principals' self-efficacy is a significant factor in the general management of school, the outcome of student learning, and the overall motivation of school staff (Federici \& Skaalvik, 2012). A high sense of self-efficacy in principals has also been found to be valued in schools undergoing restructuring (Federici \& Skaalvik, 2012). These findings may be limited by the specific geographical context of the study (Norway). Despite its importance, little attention has been given to the study of leadership efficacy in management literature (Hannah, Avolio, Luthans, \& Harms, 2008). 
This study attempted to define the relationship between APD and principal selfefficacy. A better understanding of this relationship may lead to insights into enhancing APD practices to improve the development of principal self-efficacy and, indirectly, provide an additional benefit of improved teacher self-efficacy. As previously addressed, principal efficacy has been shown to have indirect relationships with student learning and achievement. While there is a lack of adequate research on principal efficacy beliefs (Leithwood \& Jantzi, 2008; Tschannen-Moran \& Gareis, 2004), even less is known about the antecedents of leader self-efficacy (Chen \& Bliese, 2002). The following sections will explore the empirical evidence on potential principal self-efficacy antecedents of principal experience, gender, and race/ethnicity, as well as school factors: school level, level of student socioeconomic status (SES), and student achievement.

Principal experience. As discussed previously, in their validation of the PSES, Tschannen-Moran and Gareis (2004) suggest there is no significant relationship between principal experience and principal self-efficacy. However, that finding has been disputed in other studies. One study that is inconsistent with Tschannen-Moran and Gareis' (2004) findings is DeMoulin's (1992) early study of the perceived self-efficacy analyzed the results of 375 principals who completed the Career Awareness Index (CAI) - a 100 question instrument with a three-part analysis: performance attributes and stress attributes; character assessment; motivation, confidence, and perceived efficacy. Efficacy levels were measured in the third part and the scores ranged from 0 to +30 (positive self-efficacy) with +30 representing the highest level of efficacy and 0 to -40 (negative self-efficacy) with -40 representing the lowest level of efficacy. DeMoulin found that secondary principals with lower efficacy tended to be older, with more 
experience. This finding was limited to the high school principals, as the study did not find a relationship with efficacy and experience or age with elementary and middle school principals.

Leithwood and Jantzi (2008) surveyed 96 principals and 2,762 teachers in their study of the leader contributions to student learning. Using stratified random sampling, the study selected schools within districts within states, the study survey included 6 items for measuring leader self-efficacy and 4 items to measure leader collective efficacy influenced by PSES (Tschannen-Moran \& Gareis, 2004). This study used five types of analyses: Pearson product correlations to estimate the strength between variables; standard multiple regressions to determine the effects of specific variables apart from other independent variables; a hierarchical multiple regression to test the effects of specific variables or sets of variables on dependent variables after setting controls for other variables; a $t$ test to compute the significance of leader gender; and analyses of variance (one-way ANOVA) to determine the significance of leaders' race/ethnicity. Leader experience demonstrated no relationship to leader efficacy in this study (Leithwood \& Jantzi, 2008).

In a more recent study of 123 Israeli principals surveyed with PSES, Fisher (2014) found that the sense of efficacy of principals changes throughout a principal's tenure. Fisher (2014) found that principals reported their highest sense of efficacy in their first year as a principal, followed by a drop in the second through fifth years. Their sense of efficacy rose between the fifth and tenth year, leveling off and maintaining after the tenth year. The Fisher (2014) study is limited by its small sample size and its limited context among Israeli principals, but provides new evidence of possible changes in 
principal self-efficacy in relation to experience. In summary, research is limited and conflicting research on the relationship between principal experience and principal selfefficacy (DeMoulin, 1992; Fisher, 2014; Tschannen-Moran \& Gareis, 2004). The more recent Fisher (2014) study strongly suggests that principal experience has a patterned relationship to principal self-efficacy. While research literature has conflicting findings on the role of experience as an antecedent of principal self-efficacy, the Fisher findings are compelling enough to warrant continued exploration of experience's relationship to principal self-efficacy. To add to the literature and in an attempt to provide more clarity on this relationship, this study will include principal experience as an independent variable.

Principal gender. Researchers have also reported mixed findings in analyzing the relationship between gender and self-efficacy. Buchanan and Selmon (2008) found that gender alone did not have a significant connection to self-efficacy. However, they did determine that gender had a mitigating effect on the relationship between race and self-efficacy. In teachers, Klassen and Chiu (2010) suggest that females may have lower levels of self-efficacy in classroom management. For principals, the connection between gender and self-efficacy has been just as unclear. In the Tschannen-Moran and Gareis' (2004) study, they determined that gender was not a significant factor. In contrast, the Smith et al. (2006) study, female principals had higher levels of self-efficacy than male principals (beta $=.286, p<.001$ ). In an attempt to add to these findings, Szymendera (2013) analyzed 207 survey responses from elementary, middle, and high school principals in Pennsylvania. He used the PSES (Tschannen-Moran \& Gareis, 2004) to measure self-efficacy and analyzed the results through a canonical correlation analysis. 
The results of this study reflected Tschannen-Moran and Gareis' (2004) and Leithwood and Jantzi's (2008) findings that there was no significant relationship between gender and self-efficacy in principals. However, Szymendera (2013) stated that a more sophisticated analysis, such as a hierarchical linear model may have better picked up existing significant correlations that could have been missed in the canonical correlation analysis. Due to the unclear findings and no compelling evidence that gender has a direct and significant relation to principal self-efficacy, this study will not use gender as a variable.

Principal race/ethnicity. As previously discussed, Oates (2004) found that African-Americans generally have lower levels of self-efficacy, compared to whites, but those levels were subject to the same contextual influences as whites. In other words, self-efficacy appears to be influenced more by the self-efficacy levels of those surrounding the individual and the individual's master experiences and failures, than by race as an isolated factor. Similarly, Buchanan and Selmon (2008) found that there is no significant difference in self-efficacy between Whites and African-Americans. They determined, however, that the impact of gender on one's self-efficacy is conditional upon race. Sex-role perceptions and beliefs and their resulting socialization have been related to higher levels of self-efficacy in males than females (Bandura, 1997; Gecas, 1989). In principals, Tschannen-Moran and Gareis (2004) determined that white principals had only a slightly higher level of self-efficacy than African-American principals, while Leithwood and Jantzi (2008) found no relationship between race/ethnicity and leader self-efficacy. Based on the literature that has found the race/ethnicity of a principal has little or no relation to his or her self-efficacy, it was eliminated as a variable for this study. 
School level. In Demoulin's (1992) previously discussed study, it was found lower efficacy levels in principals of middle and high schools compared to elementary school principals. The study found no significant difference in the efficacy levels between middle and high school principals. In Lyons and Murphy's (1994) study of principal self-efficacy and power, 121 school principals in an urban Midwest school district completed surveys that measured self-efficacy, based on Bandura's (1977) theories. The survey had eight subscales and a sum efficacy score (Hillman, 1986). An additional phase of surveying $10 \%$ of the teachers at 25 of the participating principals' schools followed. The additional phase was to measure teacher perceptions of the how the principal used power. Based on the self-efficacy measures of the first phase, the study determined that school level was not related to the principal's self-efficacy. In contrast, in the previously discussed Leithwood and Jantzi (2008) study, they found that school level acts as a moderating variable on the relationship between principal efficacy and classroom/school conditions along with student achievement. Due to the limited number of studies, this study will use school level as an independent variable to further explore its relationship to principal self-efficacy.

Student socioeconomic status (SES). Osterman and Sullivan's (1996) qualitative study on the perceptions of efforts for school change involved 12 new principals in New York City Public Schools. Principals responded based on their perceptions of various factors that supported or restricted their efforts for school improvement. Optimistic responses were considered a demonstration of high efficacy, while pessimistic answers were considered a demonstration of low efficacy. In the study, the SES of students was found to be unrelated to the principal's level of efficacy. Smith 
et al.'s (2006) study surveyed 284 principals in twelve states using the Principal SelfEfficacy Scale, as previously discussed. Four separate stepwise regression analyses were used to analyze the data. This study found that principals in schools with higher percentages of students who received free or reduced lunch had higher levels of selfefficacy than principals in schools with lower percentages of free or reduced lunch students $\left(R^{2}=.195, p=.001\right)$. Again, the mixed findings from these studies would indicate the need for additional investigation. Therefore, this study included FRL, a proxy for SES, as an independent variable.

Student achievement. As previously discussed, student learning and achievement is considered an indirect outcome of principal self-efficacy (Hallinger \& Heck, 1998; Leithwood, Patten, \& Jantzi, 2010; Murphy, Elliott, Goldring, \& Porter, 2007; Waters, Marzano, \& McNulty, 2003). In relation to student achievement acting as an antecedent for principal self-efficacy, some researchers suggest that it influences the self-efficacy of teachers (Pedota, 2015; Stipek, 2012). However, searches for research literature that explores the effect of student achievement on principal self-efficacy only result in studies that address the role of principal self-efficacy in student achievement. As stated earlier, few studies have explored the antecedents of principal self-efficacy (Chen \& Bliese, 2002). This study will attempt to examine the relationship between administrator professional development and principal self-efficacy and will examine the relationship student achievement may have with principal self-efficacy.

\section{Sources of Educator Self-Efficacy}

Similar to the sources of individual self-efficacy, teacher self-efficacy is developed through mastery experiences, social persuasion, vicarious experiences, and 
emotional and physiological states (Bandura, 1994; Pajares, 2006; Usher \& Pajares, 2008). Likewise, the collective efficacy of teachers is influenced by prior group successes, the observation of the success of groups, and encouragement received from others (Goddard \& Goddard, 2001). Morris and Usher (2011) undertook a qualitative case study of twelve award-winning university professors, drawing from interviews in which the professors self-identified sources of efficacy for themselves. Morris and Usher found that the most prevalent sources of efficacy among the professors were mastery experiences, social persuasion, or a combination of both. These findings lend support to mastery experiences as the most effective way to build self-efficacy (Bandura, 1994; Pajares, 2006; Usher \& Pajares, 2008). These finding suggest that the utilization of APD that facilitates principals engaging in experiences that become mastery experiences may positively affect administrator self-efficacy. Based on these findings, APD that provides administrators with opportunities to practice and successfully master challenging tasks in their schools over time, while receiving positive social persuasion, or coaching, from mentors who have demonstrated similar successes may potentially increase their individual sense of efficacy.

This study assumed that all PD experiences are intended to grow participant knowledge and skills, thereby enabling the participant to experience more mastery experiences either during the PD experience or in his or her professional practice after. This study sought to discover any connection the amount of APD hours earned and/or the APD focus may have on principal self-efficacy. The potential implications would be that enhancements in APD methods and practices and intentional APD focus areas could lead 
to improvements in the development in principal self-efficacy and, by indirect means, improved teacher practices, school environment, and student achievement.

A considerable gap in literature exists in regards to principal self-efficacy. Research on educator self-efficacy has been dominated by studies on teacher selfefficacy. Despite the amount of time principal self-efficacy literature has existed, there have been very few adequate studies conducted on principal efficacy beliefs (Leithwood \& Jantzi, 2008; Tschannen-Moran \& Gareis, 2004). Within the list of studies on principal self-efficacy, the vast majority have focused on its outcomes on teachers, schools, students. Little research focus has been placed on the antecedents of school leader self-efficacy (Chen \& Bliese, 2002). Additionally, because self-efficacy is very context oriented (Bandura, 1977; Bandura, 1994; Bandura, 1997), much of the literature that does address principal self-efficacy is also context-specific, as studies address specific dimensions of self-efficacy for principals or for principals in a specified task or environment. This study will address this gap by investigating the connections between APD, principal and school characteristics, and principal self-efficacy. The remainder of Chapter II will explore the research literature on professional development and its known connections to educator self-efficacy.

\section{Professional Development}

As administrators and teachers with higher levels of self-efficacy provide numerous benefits to their schools and students (e.g., student learning and achievement) (Woolfolk Hoy \& Davis, 2006), it would be reasonable for states and school districts to be aware of and seek to develop their staff's self-efficacy. Intentional methods and structures of professional development (PD) have been linked to statistically significant 
changes in educator self-efficacy (Khourey-Bowers \& Simonis, 2004). Khourey-Bowers and Simonis (2004) suggest designers and facilitators of PD consider the development of educator efficacy within the PD design (Khourey-Bowers \& Simonis, 2004). However, not all PD accomplishes what is intended. The following sections will review what is known about effective PD, administrator professional development (APD) and principal PD in Kentucky, criticisms of common PD, and the relationship between PD and educator self-efficacy.

\section{Effective Professional Development}

Researchers generally agree on the characteristics that make up effective PD (Desimone, 2009; Desimone, Porter, Garet, Yoon, \& Birman, 2002; Guskey, 2009; Guskey \& Yoon, 2009; Wayne, Yoon, Zhu, Cronen, \& Garet, 2008). However, the specifics of which features most affect student outcomes and how to practically design the most effective PD is still weakly supported by empirical research (Guskey, 2014; Wayne, Yoon, Zhu, Cronen, \& Garet, 2008). What we do know is that the development of PD should be high quality in its theory of action, planning, design, and implementation (Yoon, Duncan, Lee, Scarloss, \& Shapley, 2007). It should be intensive, sustained, content-focused, coherent, well-defined, and strongly implemented based on valid theory of teacher learning and change, while promoting and extending effective curricula and instructional models (Yoon, Duncan, Lee, Scarloss, \& Shapley, 2007). Ongoing coaching/mentoring focused on the development of specific practices or skills and participatory action research that implements research-based practices as solutions to an identified measurable issue within a school are two examples of PD models that can incorporate many or all of the above attributes. 
According to Camburn and Won Han (2015), professional learning requires an appropriate infrastructure to support learning. Camburn and Won Han (2015) studied included 887 teachers in a large urban district to measure the predictability of PD focus and other variables on teacher reflective practices and changes in English/Language Arts (ELA) instruction. After collecting data using a survey for self-reporting, the data was analyzed through hierarchical linear models. Teacher characteristics, teacher behaviors, and school factors were included as independent variables for controls. These researchers found that teachers who engaged in more PD focused on instruction were more likely to report they had changed their ELA instruction. Teachers who engaged in more PD focused on school-wide issues were less likely to report changes in instructional practice. Additionally, neither the frequency of collaboration with peers nor the number of peers sought for collaboration were significant predictors to changes in instructional practice. Teacher engagement in more reflective practice was associated with more changes in instructional practice. These findings reveal that PD infrastructure that focuses on instruction and reflective practice has an association with changes in instructional practice. This infrastructure would include appropriate tools for instructional learning and reflection in PD and designated time for educators to reflect on their practice.

Additionally, an educator's prior experience is a component of this infrastructure for reflection. Learning occurs as an experience connected to the learner's schema. As noted by Noddings (2012), Dewey placed emphasis on meaning and affect: "When Dewey talks about experience in the context of education, we expect to find an emphasis on personal meaning and social interaction... To be educative, an experience has to be 
built on or connected to prior experience" (p. 31). In other words, a learner in the learning environment - in the context of this study, an educator participating in PD - is encountering concepts that are new or challenge his or her current understandings. In order for the concept to be recognized and result in individual growth or development, the learner must be able to connect the concept to prior experiences and/or knowledge. If the concept is not seen as connected to prior knowledge and/or experience, the learner misses the concept completely or may disregard it as incomplete, unrealistic, or irrelevant. In order for the concept to lead to individual growth and development, the learner must see the concept as a next step in or shed new light on what is already known and understood. This could be described as relevance for the learner. Dewey's emphasis on context was echoed by Nespor (1987): "Knowledge and skills are content specific. Unless the connections between contexts are explicitly made in social interaction and make sense in practice, the skills people learn in [specific contexts] will not be applied outside those contexts" (p. 50). For this relevance to occur in PD, the content must directly connect to the teacher's daily context and focused on daily practice and reflection (Camburn \& Won Han, 2015). Lack of opportunity to try out new practices in context of day-to-day activity and reflect on practice or teaching hampers the ability of teachers to change their teaching (Camburn \& Won Han, 2015).

Similarly, relevant education means learners must see education as the means by which they can improve their communities, rather than the means by which to escape those communities (Duncan-Andrade \& Morell, 2008). In terms of educators as learners, relevant professional development means teachers must see PD as the means by which they can improve their daily work environment, rather than a separate reality from their 
daily work environment (Camburn \& Won Han, 2015). Garet, Porter, Desimone, Birman, and Yoon (2001) found study groups conducted during the school day offered intentional follow-up of standards based instruction, which differed from traditional inservice PD. When this type of PD takes place during teachers' normal work-day, it allows for longevity, follow-up, duration, and active engagement focused on the student learning process (Martin et al., 2010). High quality PD includes continuous development over time, follow-up support, active engagement in relevant activities, access to new technologies, collaboration and community building among participants, and a shared understanding of student achievement (Garet, Porter, Desimone, Birman, \& Yoon, 2001; Guskey, 2009; Guskey \& Yoon, 2009; Martin et al., 2010). In schools using highly effective PD to improve teachers' pedagogy, new teachers work with expert practitioners, and veteran teachers collaborate to renew their own practices (Darling-Hammond \& McLaughlin, 1995). As cited by Cantrell and Hughes (2008), PD programs that take place over several months and involve collaboration and coaching were more likely to see an increase in efficacy.

To have an effective PD experience, teachers must share what they know and connect new knowledge to their teaching context (Darling-Hammond \& McLaughlin, 1995). Effective PD should focus on the teaching and learning of specific academic content and build strong working relationships among teachers focused on student achievement (Jaquith, Mindich, Wei, \& Darling-Hammond, 2011). Here is where the use of outside experts can be critically important to help educators connect what they already know to new ideas and research (Guskey \& Yoon, 2009). School PD policies and practices should be an exercise in implementing new skills, instead of emphasizing the 
accumulation of credits and hours (Jaquith, Mindich, Wei, \& Darling-Hammond, 2011). More recent models of effect teacher development and support include (a) time for teachers to reflect on content and pedagogy, the specific needs of their students, and collaborate with colleagues (Darling-Hammond \& McLaughlin, 1995; Garet, Porter, Desimone, Birman, \& Yoon, 2001; Graham \& Fennell, 2001; Kuchey, Morrison, \& Greer, 2009; Martin et al., 2010); (b) active reflection and analysis of practice, outcomes, and next steps (Camburn \& Won Han, 2015); (c) a directly focused on classroom teaching; and (d) ongoing coaching and feedback (Camburn \& Won Han, 2015). These activities align with a growing model for PD that utilizes the collaborative work of professional learning communities (PLCs) as ongoing support for teacher growth and development (Mindich \& Lieberman, 2012). Collaborative PD activities may also provide a method for creating mastery experiences, social persuasion, and vicarious experience that may increase participating educator self-efficacy.

The research literature on teacher PD is vast, especially when compared to the amount of literature on administrator professional development. It is worth noting that based on the contexts, samples, and methods for conducting research, the knowledge about teacher learning contained in the research literature may not always be generalizable. However, one could reasonably extrapolate these insights when considering what would constitute effective APD. The next section address the research literature on APD.

\section{Administrator Professional Development}

Administrators engage in a variety of APD modes or types. The participation in APD can be the result of individual growth planning by a principal or the result of PD 
requirements set by the district or state. Grissom and Harrington (2010) found that principal participation in different modes of APD showed no clear or definitive patterns. However, they found urban principals are more likely participate in mentoring or coaching (55\% participation) than suburban or rural principals. Principals in schools with higher rates of student poverty are more likely to participate in mentoring or coaching than principals at more affluent schools. Education levels of the principals did not appear to influence APD participation, but less experienced principals do have higher participation rates in most types of APD (Grissom \& Harrington, 2010).

As with teacher PD, the mode or type of APD makes a difference in participant outcomes. While nearly every principal (over 94\%) participates in short term or one-shot PD models, such as workshops, conferences, or training over the course of a year, far fewer participate in ongoing PD models like mentoring, coaching, or a principal network (Grissom \& Harrington, 2010). Principals who participate in ongoing PD models, such as mentoring and coaching, are rated as being more effective by the teachers at their school (Grissom \& Harrington, 2010). In contrast, principals who devote PD time to university coursework or networking were rated less effective (Grissom \& Harrington, 2010). Ongoing PD is effective, but it still must be the right type of ongoing PD model. The outcomes of APD and student performance are less clear. Clark, Martorell, and Rockoff (2009) found mixed evidence on the correlation between principal professional development and school performance. However, they noted in their study that the study sample was not conducive for determining APD effects. Grissom and Harrington (2010) found that university courses taken as APD had a significant negative 
correlation with school performance. The Grissom study does not address the relationship between other APD modes and student performance.

The focus, time, and location must be considerations in the design of APD. The focus of PD influences its outcomes for participants (Garet, Porter, Desimone, Birman, \& Yoon, 2001). The type of leadership needed in a school varies and is dependent on the context and needs of the specific school (Hallinger, 2003). Despite the need for APD that develops school-specific leadership practices, administrators report their APD as being dominated by managerial items such as legal issues, human resource procedures, and assessment procedures (Oliver, 2005). This study explored the role of APD focused on non-management and non-state accountability items, specifically APD focused on academic content, instruction, school culture, and learning climate.

APD outcomes should be focused on the school context and needs. Therefore, the time, location, and mode of APD are critical to administrators and important in determining APD effectiveness (Houle, 2006; Oliver, 2005). Administrators prefer to learn while engaged in their work, as in job-embedded PD, creating a challenge for those who provide APD to create meaningful, ongoing APD delivered through new methods (Houle, 2006). Houle (2006) and Oliver (2005) advise that participants in APD should be provided time and a safe environment to reflect and engage in dialogue on concepts, their practice, and strategies for improvement, in order to connect learned concepts and researched-based practices to their school context and current practices.

\section{Principal Professional Development in Kentucky}

In Kentucky, The Effective Instructional Leadership Act (EILA), identified in KRS 156.101, is the governing legislation for professional development for school and 
district administrators and other instructional leaders. It is intended to "encourage and require the maintenance and development of effective instructional leadership in the public schools of the Commonwealth" (Effective Instructional Leadership Act, 2005). In support of this purpose, EILA requires superintendents, principals, assistant principals, and other instructional leaders of schools to complete hours of instructional leadership development programs each year to maintain certification. EILA hours or credits are the equivalent of administrator professional development (APD) hours for Kentucky district and school administrators.

The Technical Assistance Manual for Instructional Leaders and Training Program Providers (Kentucky Department of Education, 2014) identifies the required credit hours for Kentucky administrators, as required by KRS 156.101. It also identifies instructional leaders who are required to earn EILA credits in Kentucky. More importantly, the Technical Assistance Manual also sets forth guidelines for leadership development programs to be provided by district personnel and independent providers. The guidelines for program development are making instructional decisions that support teaching and learning; establishing organizational direction; developing and supporting high performance expectations; creating a learning culture; and developing leadership capacity. The manual also establishes parameters and best practices for development of instructional leadership programs. Key parameters include an outcomes based focus on increasing student achievement, the need of participants for a variety of plan models, individual participant needs should be addressed while programs are aligned to state and district priorities, and that systemic change takes a significant amount of time (Kentucky Department of Education, 2014). 


\section{Criticisms of Common Professional Development}

Professional development is a key component to school improvement and education reform (Guskey, 2009; Guskey \& Yoon, 2009). In fact, “no improvement effort has ever succeeded in the absence of thoughtfully planned and well-implemented professional development” (Guskey \& Yoon, 2009, p. 497). However, not all PD is thoughtfully planned and well implemented. When PD is not properly planned, it often leads to teacher complaints (Mizell, 2010). Teachers often complain that PD was poorly planned (Mizell, 2010), boring (Borko, Elliott, \& Uchiyama, 2002; Thibeault, 2016), and/or irrelevant (Jackson, 2011). One could speculate that irrelevant PD, no matter how well planned, may be viewed as boring by an educator who sees no purpose in the PD or no connections to his or her practice. The most critical problem with PD is that, while PD is intended to assist teachers in improving instructional practice and student learning outcomes, it too often improves neither. This is often because poorly planned PD lacks purpose and a direction to achieve that purpose (Guskey, 2014). Additionally, PD can be disconnected from a school's policies and philosophy (Bennett \& Marr, 2003).

Common teacher in-service models, such as lecture-based instruction, conferences, online presented content and learner quizzes, and one shot introduction and explanation of content and/or pedagogical practices are often not effective in creating sustained improvement and reform (Darling-Hammond \& McLaughlin, 1995). Although the methods and models of PD can greatly impact the effectiveness in achieving intended outcomes, the typical model of PD has not focused on effectively facilitating the intended learning (Darling-Hammond \& McLaughlin, 1995). One common model of PD is a traditional workshop-based model, in which an outside expert presents a program or 
system intended to fix content issues, address pedagogical problems, and motivate teachers. The expert facilitator delivers the content to be learned and may even do so in an entertaining manner or by facilitating a variety of activities that engage learners. However, this traditional model lacks consistency and long-term support, which are important to ensuring implementation of the PD skills and knowledge in the classroom (Graham \& Fennell, 2001). While an outside expert is often an important necessity to bring in new ideas, research-based practices, or expertise on a topic, the value of the expert is diminished in a traditional one-shot and done setting (Guskey \& Yoon, 2009). In fact, traditional components of PD only lead to less than $10 \%$ transfer of new skills or knowledge into the classroom (Hirsh, 2006). Traditional and typical methods of PD do not generate the results that school leaders and PD facilitators intend.

Most educators attend PDs that last only a few hours and often do not involve the participant practicing the new knowledge and skills within the context of his or her authentic work. PD efforts that involve a limited amount of training (between 5 and 14 hours) show no statistically significant effect on student learning (Wei, DarlingHammond, Andree, Richardson, \& Orphanos, 2009). However, this is exactly the type of PD nearly all educators experience. Wei et al. (2009) state that over $90 \%$ of teachers have participated in professional learning that consisted of short-term conferences or workshops. Teachers in the United States report little professional collaboration in designing curriculum and sharing practices. The collaboration that does occur tends to be weak and not focused on strengthening teaching and learning. Consequently, American teachers say that much of the professional development available to them is not useful (Wei, Darling-Hammond, Andree, Richardson, \& Orphanos, 2009). 


\section{Professional Development and the Development of Self-Efficacy}

If the research community is largely in agreement on what constitutes effective PD (Desimone, 2009; Desimone, Porter, Garet, Yoon, \& Birman, 2002; Guskey, 2009; Guskey \& Yoon, 2009; Wayne, Yoon, Zhu, Cronen, \& Garet, 2008), then districts should be able to focus that effectiveness on developing educator self-efficacy. Multiple studies have demonstrated the potential for using PD to increase educator self-efficacy (Airola, Bengtson, Davis, \& Peer, 2014; Cantrell \& Hughes, 2008; Henson, 2001; KhoureyBowers \& Simonis, 2004). The following section describes studies that have explored the connections between PD and self-efficacy.

The potential for PD to intentionally improve self-efficacy has been demonstrated in teacher PD. Henson (2001) initially determined through a mixed methods study that extended PD had a positive effect on teacher efficacy. Henson measured the general teaching efficacy and personal teaching efficacy of teachers taking part in a participatory research model of PD through pretreatment and post-treatment surveys. Efficacy was measured in pre- and post-project with the Teacher Efficacy Scale (1984) and qualitative data was gathered through interviews and field notes. Quantitative data was analyzed through repeated measures analyses and regression analyses. Qualitative analysis were analyzed through a constant comparative analysis for thematic trends. Henson found significant gains in teacher efficacy, with the greatest effect on efficacy was found among teachers who demonstrated lower initial levels of efficacy. This finding suggests that the extended, ongoing PD that engaged teachers in designing research-based solutions to school issues may have positively affected their self-efficacy. Teacher collaboration was a predictor of resulting self-efficacy. However, teacher implementation of his or her 
project was not a predictor of resulting self-efficacy. This suggests that collaboration for study, planning, and reasonable implementation of solutions involved in the PD may have been more important for efficacy development than the level of implementation the teacher actually accomplished. Henson' (2001) study is limited by the small sample size of 15 participating teachers and the unique context - an alternative school setting where teachers primarily taught self-contained classrooms that typically contained multiple grades with small class sizes.

Khourey-Bowers and Simonis' (2004) study measured the change in self-efficacy of science teachers $(N=135)$ who participated in a specially designed PD. The PD included 10 full days of instruction over the span of 10 months. The researchers wanted to establish if a PD program intentionally designed to incorporate a constructivist approach aligned to the sources of self-efficacy identified in Bandura's (1977; 1994; 1997) work could raise the self-efficacy levels of the participating teachers. They additionally wanted to determine which aspects of PD enhanced efficacy and outcome expectancy. The study collected quantitative data from participants who completed the Science Teaching Efficacy Belief Instrument (STEBI) Form A as a pre-PD measure and a post-PD measure. They also collected qualitative data from post-PD evaluations and interviews of selected participants. Paired $t$ test analysis showed statistically significant changes in self-efficacy and outcome expectancy after the PD. Evaluations and interviews revealed that participants reported increase belief in their science teaching efficacy and outcome expectancy as a result of activities tied to vicarious experiences and social persuasion. These findings demonstrate the possibility that deliberately planned PD may increase the self-efficacy of educators. Khourey-Bowers and Simonis (2004) 
recommend that PD should plan opportunities for mastery experiences, include tasks directly incorporated into the participant's professional practice, allow for collaboration and discussion, and create opportunities for vicarious experiences and social persuasion. While this study shows the potential of planning PD to increase self-efficacy, other researchers have suggested that changing the efficacy of experienced teachers may often be difficult and may require more complex and intentional support, in terms of PD (Cantrell \& Hughes, 2008).

Cantrell and Hughes (2008) studied the impact of extended literacy PD on the personal, general, and collective efficacy of sixth and ninth grade content teachers for teaching literacy. They also examined how teachers viewed the development of their efficacy after completing the extended PD. The study used sequential mixed methods and analyzed survey data from the full sample before conducting interviews from selected participants. During the summer, participating teachers worked in regional teams to explore research and new techniques for teaching literacy and design lesson plans. During the school year external coaches visited teachers monthly to discuss the ongoing progress of the work, assist teachers in planning, and model lessons. Teachers also participated in three follow up meetings during the year. A 65-item survey to measure teacher efficacy and teacher collective efficacy, based on multiple other instruments was administered to participants at the beginning and end of the PD process. Of the 38 participants, 28 completed the pre- and post-PD surveys. Additionally, observations of teachers in the fall and spring collected quantitative data using an observation protocol based on the Global Content Literacy Classroom Implementation construct (GCLCI) which focused on three facets of content literacy teaching. Finally, 22 
teachers were interviewed at the last meeting to collect qualitative data. Quantitative data was analyzed through descriptive statistics, paired sample $t$ tests, and bivariate correlations. Qualitative data was coded in two levels: first as positive, negative, or neutral expressions of teacher efficacy then as the attribute for efficacy or change in efficacy. This coding resulted in a code that tied the teacher's evaluation (positive, negative, or neutral) to a PD attribute (coaching, collaboration, etc.), and the researchers were able to tally codes to discover emerging themes.

Cantrell and Hughes (2008) found statistically significant increases in personal efficacy for teacher literature $(t(21)=-4.236 ; p<.001)$, general teaching efficacy $(t(21)=$ $-3.000 ; p<.001)$, and collective efficacy $(t(21)=-2.051 ; p<.05)$. In the correlations, they also found that individual self-efficacy was significant for practice implementation during the fall observations, but by spring, collective efficacy was significant for implementation. Teachers with higher self-efficacy levels at the start of the program were more likely to implement the techniques from the PD. Qualitative analysis revealed that coaching was essential for efficacy development and technique implementation. Opportunities to practice and master techniques (mastery experiences) and collaboration with teachers from other schools to learn from their successes and challenges (vicarious experiences) were also identified as important components for self-efficacy for literacy teaching. One identified barrier to self-efficacy for literacy teaching that emerged was the lack of time teachers felt they had for skill development, implementing techniques, and collaborating with colleagues. This study was limited by a lack of a control group for comparison to determine changes were a result of the PD. The small sample size may not be representative of the entire population. Of the participants who started the PD, 
only $58 \%$ completed all phases of the PD and data collection, leading to a possible differential impact and selection of teachers who were interviewed was biased to those who were actively involved enough to attend the after-school end-of-year meeting . Also, the limited observations was not ideal for determining the extent of implementation. Cantrell and Hughes' (2008) findings corroborate Khourey-Bowers and Simonis' (2004) findings that PD designed to create experiences that align with Bandura's $(1977 ; 1994 ; 1997)$ sources of efficacy may help to increase the efficacy of educators.

Airola, Bengtson, Davis, and Peer (2014) studied 27 principals who participated in the Arkansas Leadership Academy's School Support Program (SSP) to determine what effect SSP had on their self-efficacy. The SSP was a PD for principals of low performing schools and was designed to build principal capacity for leading their schools. The principals were in three separate cohorts in three different phases of SSP. Cohort 1 participants were in the third year of SSP, Cohort 2 principals were in their second year, and Cohort 3 leaders were in their first year. To measure self-efficacy, participants completed the PSES in October of the training year and again in following May. The researchers used SSP cohorts as the between-group variable (independent variable) to conduct the Kruskal-Wallis test, a type of one-way ANOVA used for small sample sizes, for each subscale of the PSES. The analysis found that the means of each cohort's subscales increased based on the number of years of experience in SSP. The difference between Cohort 1 and Cohort 3 principals Instructional Leadership Efficacy levels were statistically significant. 
Airola et al. (2014) then sought to determine what SSP experiences, specifically, may have caused the self-efficacy increase. A focus group discussion was conducted via conference call, from which three themes emerged. First, SSP capacity builders, embedded in the schools, became a part of the school community and culture, and developed mutual trust and a strong knowledge of the specific school context. Second, SSP's focus on developing the leadership capacity of administrators and teachers helped to develop shared leadership in the school and afforded the principal more time and focus on areas of concern often left unaddressed. Third, SSP support helped principals and faculty maintain a focus on instruction and learning. This study supports earlier research that suggests that coaching, support, and development in the context of the work environment has a positive effect on outcomes, specifically on self-efficacy. This study further extends that idea to show that specific PD practices for developing self-efficacy is applicable to principals. This study was highly contextualized to the 27 participating principals and their experiences in SSP. This study also did not take into account other variables that may have been influencing the development of self-efficacy, such as increased principal experience.

These studies demonstrate the potential for using deliberately designed PD to increase educator self-efficacy in a variety of contexts for a various tasks. Each study showed a positive connection between PD that attempts to build capacity, knowledge, and/or skills and educator self-efficacy. Two key patterns are evident in these studies that showed increases in self-efficacy. First, these studies showed a common pattern in the methods used for PD. Each PD in these studies used ongoing PD over the span of an entire school year. The PDs were not one-time workshops or conferences. Collaboration 
was prevalent in each, and many of the PDs incorporated coaches and/or ongoing feedback. Additionally, the PDs utilized activities that reflected the work or practice of the participants, and, in most cases, partially took place within the participant's work environment during the course of his or her practice. The second pattern that emerges is the use of experiences that align with Bandura's $(1977 ; 1994 ; 1997)$ sources of selfefficacy. All the PDs facilitated time and opportunities for participants to develop mastery experiences and/or vicarious experiences to develop their knowledge and skills. Many of them also utilized social persuasion as a means to develop participant beliefs and confidence. From this, it can be concluded that intentionally creating experiences that will be sources for self-efficacy, through methods that research suggests are effective in $\mathrm{PD}$, could potentially maximize the development of educator self-efficacy.

To maximize the positive influence of PD on educator self-efficacy, PD designers should consider the sources of efficacy beliefs when designing PD. Bandura (1997) identified four sources of influence on efficacy beliefs: mastery experiences, physiological and emotional states, vicarious experiences, and social persuasion. Subsequently, many other researchers identified how these sources connect to PD methods and activities. First, mastery experiences would include PD activities that utilize and integrate authentic work tasks and practices, preferably within the context of the work environment and allows the educator to successfully overcome a difficult task with little assistance (Bandura, 1997; Khourey-Bowers \& Simonis, 2004). Physiological and emotional states can be incorporated into PD through activities that generate collegial excitement or moderate professional stress or anxiety, specifically with opportunities to allow the participant to overcome these negative responses (Bandura, 1994; Khourey- 
Bowers \& Simonis, 2004). Vicarious experiences can be used in PD via activities that allow for observation and critique of successful practitioners or allows the learner to be an active participant alongside the successful practitioner's work (Bandura, 1997;

Khourey-Bowers \& Simonis, 2004). Finally, social persuasion can be used in PD activities that utilize individual and group communication about specific practices and tasks or educational beliefs and philosophies, with feedback between participants or from the facilitators or coaching (Bandura, 1997; Cantrell \& Hughes, 2008; Khourey-Bowers \& Simonis, 2004; Tschannen-Moran, Woolfolk Hoy, \& Hoy, 1998).

\section{Summary of Literature Review}

After a review of educational research, several key themes emerge. An educator's sense of self efficacy is a basis for and indicator of educator practices, and that increased administrator self-efficacy correlates with improved practices and outcomes. Specifically, the literature suggests a positive relationship between the self-efficacy of

administrators to the efficacy of the school staff, general school management, and student outcomes. However, the study of school leadership efficacy has received little attention in research literature (Smith et al., 2003). Evidence suggests that the most prevalent sources of efficacy among educators are mastery experiences, social persuasion, or a combination of both.

The literature suggests that well-designed PD can have an influence on educator self-efficacy and improves educator practices. However, some common PD practices and models provided to educators are strongly criticized as ineffective. There is a consensus among educational researches as to what characteristics constitute effective $\mathrm{PD}$, and a common body of best practices has developed and endured. However, there is little 
literature that provides strong evidence for determining which specific characteristics of delivery of PD in a variety of settings and by facilitators not involved in the design most affect educator practice and student outcomes (Wayne, Yoon, Zhu, Cronen, \& Garet, 2008).

While most studies on PD have been focused on teacher PD, fewer have explored APD. As noted previously, administrator leadership is key to the attitudes and actions of teachers and, indirectly, the outcomes for students. Discouragingly, preparation for modern principals has been criticized for not adequately equipping principals for the challenges they face in leading schools (Camburn, Goldring, Sebastian, May, \& Huff, 2016). Some researchers suggest that well-designed, research-based APD can help to fill the critical need of developing and supporting principals in confronting the challenges of school leadership (Davis, Darling-Hammond, LaPointe, \& Meyerson, 2005). However, critical gaps in principal self-efficacy research exist.

In this review of the literature, multiple gaps were discovered. First, principal self-efficacy, like all management efficacy, has received little attention in research literature (Hannah, Avolio, Luthans, \& Harms, 2008). Within the limited research on principal efficacy beliefs, the majority of studies have focused on its outcomes on teachers, schools, students (Leithwood \& Jantzi, 2008; Tschannen-Moran \& Gareis, 2004). Even less is known about the antecedents of leader and principal self-efficacy (Chen \& Bliese, 2002). In the examination of PD literature, the specifics of which PD features most affect student outcomes and how to practically design the most effective PD is still weakly supported by empirical research (Wayne, Yoon, Zhu, Cronen, \& Garet, 2008). Moreover, few studies have explored the issues related to administrator 
professional development (Cardno \& Youngs, 2013; Grissom \& Harrington, 2010; Thorpe \& Bennett-Powell, 2014), and even fewer studies have explored APD through quantitative data and analysis (Grissom \& Harrington, 2010). Finally, because selfefficacy is very context oriented (Bandura, 1977; Bandura, 1994; Bandura, 1997), much of the literature on APD and principal self-efficacy is also context-specific, as studies address specific dimensions of self-efficacy for principals or for principals in a specified task or environment.

Further research is needed to explore the implementation of APD characteristics and their outcomes. Minimal understanding of APD outcomes should cause decision maker to take pause when considering how to invest in APD. Grissom and Harrington (2010) specifically noted these concerns.

The current research is in too nascent a stage to make recommendations about APD policy... [There is a] need for a much closer look at districts' principal professional development programs. We suggest that districts undertake more rigorous evaluation of their in-service professional opportunities for principals before making costly investments of resources and personnel hours that may not realize positive returns. (p. 609)

Based on this review of the literature, more research is needed on design (including focus), implementation, and outcomes of APD and, specifically, quantitative research designs are needed to fill a substantial void in the body APD research literature. Through quantitative data and analysis, this study examined principal PD in a large urban school district and the predictability of the hours of APD focused on culture/climate or instruction on principal self-efficacy. 


\section{CHAPTER III \\ RESEARCH METHODOLOGY}

\section{Introduction}

The purpose of this study was to examine the relationship between principal professional development (PD) and principal self-efficacy. Effectively implementing educational reforms and improving educator practice is difficult (Payne, 2008; Tyack \& Cuban, 1995; Tyack \& Tobin, 1994). Well-designed and well-implemented professional development is a key component to successful school improvement and education reform (Guskey, 2009; Guskey \& Yoon, 2009). School administrators are held responsible for making improvements within their school, but professional development that is well intended may, in reality, be an ineffective support in enhancing professional practice and reaching the desired results (Darling-Hammond \& McLaughlin, 1995; Desimone, Porter, Garet, Yoon, \& Birman, 2002; Garet, Porter, Desimone, Birman, \& Yoon, 2001; Graham \& Fennell, 2001). Administrator professional development (APD) is often tied to management tasks, such as budgeting, scheduling, or employee evaluations (Bennett \& Marr, 2003). While these topics may be important, a principal may often feel they are disconnected from the needs of the school and staff (Bennett \& Marr, 2003), which may include overcoming learning barriers associated with poverty, developing effective instruction in new or ineffective teachers, or addressing a negative culture among students or staff. This disconnect may further amplify APD ineffectiveness. This study 
further explored the influence of school factors and principal experience on principal selfefficacy, and it sought to add to the research on administrator professional development and administrator efficacy, by determining possible predictors to principal self-efficacy that may be furthered explored for causality. This study was intended to assist the participating school district in evaluating its APD, maximizing the efficacy of administrators, and maximizing the utility of limited resources for program and reform implementation and staff professional development. Determining any tested variables were predictors of self-efficacy would have highlighted factors the school district may have considered in designing and implementing future APD.

\section{Research Question and Variables}

To address this relationship, the following research question guided this study: To what extent does the number of hours earned for administrator professional development (APD) focused on culture/climate or instruction, principal experience, and school factors predict principal self-efficacy? The dependent variable was principal selfefficacy. The independent variables included the following: the earned hours of APD focused on culture/climate or instructional; school level (elementary or secondary); student achievement (combined percentages of students scoring Proficient or Distinguished in Reading and Math state assessments); level of student socioeconomic status (SES) (percentage of students who participate in the free or reduced lunch program); and principal experience. 


\section{Research Design}

The predictability of principal self-efficacy based on the hours earned for APD focused on culture/climate or instruction, school factors, and principal experience were examined through a correlational research design with quantitative data analyzed through linear regression. A correlational research design was appropriate for measuring the strength of influence between two or more variables or for determining a predictive equation for the variables (Creswell, 1994; Ho, 2014; Osborne, 2016; Petrocelli, 2003; Stevens, 2012). A correlational research design allowed for the determination of the level of influence between variables but did not provide for testing causality (Creswell, 1994; Ho, 2014; Osborne, 2016; Petrocelli, 2003; Stevens, 2012). In this study, a relationship between the dependent variable (principal self-efficacy) and the independent variables (hours of APD focused on culture/climate or instruction, school factors, and principal experience) was examined and the strength and direction of any such a relationship was measured.

A proposal to conduct this research was submitted to the University of Louisville. Once approved, an Institutional Review Board (IRB) application was submitted to the University of Louisville. Upon IRB approval, a research request for staff-level data was submitted to the participating school district, Jefferson County Public Schools (JCPS). After JCPS approval, the principal survey was delivered to all JCPS principals. All survey data and district-provided PD records were analyzed in aggregate and no individually identifiable data was analyzed or reported. 


\section{Hypotheses}

The following hypotheses regarding the research question were used to guide this study.

Hypothesis: APD and principal self-efficacy

- Null $\left(\mathrm{H}_{0}\right)$ - hours of APD focused on culture/climate or instruction, school factors, and principal experience are not predictors of principal self-efficacy.

- Alternative $\left(\mathrm{H}_{1}\right)$ - hours of APD focused on culture/climate or instruction, school factors, and principal experience are predictors of principal self-efficacy.

\section{Data Sources and Participants}

This study was conducted in cooperation with Jefferson County Public Schools (JCPS), a large urban school district located in Kentucky. JCPS serves over 100,600 students with 155 unique schools and educational settings, over 6,400 teachers, and over 14,400 full time employees. JCPS has 18 high schools, 22 middle schools, 91 elementary schools, and 3 schools classified as combined schools, because they included more than one level (two $6^{\text {th }}-12^{\text {th }}$ grade schools and one Kindergarten- $12^{\text {th }}$ grade school). Additionally, the district serves students in 5 mixed-level alternative schools and a variety of educational program sites (Jefferson County Public Schools, 2016).

As reported in the most recently available reports, the district 2015-2016 school year, the district experienced $95.09 \%$ teacher attendance during $2015-2016$ and $87.2 \%$ teacher retention during 2016-2017 (Jefferson County Public Schools, 2017). Teacher retention represents teachers who ended the 2015-2016 school year at a school and began the 2016-2017 school year at the same school. Additionally, according to the office of 
Human Resources, Administrator Recruitment and Development, JCPS has approximately 630 school-based administrators (personal communication, June 16, 2016) who are required by the state to annually obtain a minimum of 21 hours of professional development, known as Educator Instructional Leadership Act (EILA) hours (Kentucky Department of Education, 2014).

Based on the district's most recently available data from the 2016-2017 school year, as reported on the Kentucky Department of Education's (2017) district report card, $64.6 \%$ of JCPS students qualify for free and reduced lunch, a common measure of poverty. Students are $45.1 \%$ white (not Hispanic), 36.1\% African American, 10.5\% Hispanic, 3.9\% Asian, . $1 \%$ American Indian or Alaska Native, .1\% native Hawaiian or other Pacific Islander, and $4.2 \%$ are categorized as two or more races. The percentage of students who receive exceptional child education (ECE) services is $12.2 \%$ and $7 \%$ are English Language Learners, meaning they have limited English proficiency (Jefferson County Public Schools, 2017). According to the school district academic data from 2016-2017, 46.3\% of elementary students scored Proficient or Distinguished in reading on state standardized assessments. In the same year, $44.9 \%$ of elementary students scored Proficient or Distinguished in math. In middle school, $46.7 \%$ of students scored Proficient or Distinguished in reading and 38.8\% scored Proficient or Distinguished in math. In high school reading, 49.4\% scored Proficient or Distinguished, while 35.3\% scored Proficient or Distinguished in math. The percentages of students scoring Proficient or Distinguished on state assessments in reading and math are listed in 
Table 3. Based on these scores, over half of all students at all levels are not considered proficient in reading and math. A significant need for improved student performance is evidenced in these scores.

Table 3

2016-2017 Reading and Math Achievement

\begin{tabular}{lcc}
\hline & \multicolumn{2}{c}{ Percentage of students scoring Proficient } \\
\hline & Reading & Math \\
Elementary & 46.3 & 44.9 \\
Middle & 46.7 & 38.8 \\
High & 49.4 & 35.3 \\
\hline
\end{tabular}

This study surveyed 139 principals at JCPS elementary, middle, high, and combined level schools. All principals were invited to participate. Additionally, PD data from 2016-2017 for the participating principals from the district's PD database, known as PD Central, was obtained from JCPS. Specifically, the list of attended/participated PD, number of PD hours completed for each PD event, and title/categorical data connected to each PD event in PD Central was requested.

\section{Instrumentation}

To measure the self-efficacy levels of principals, which served as the dependent variable, and principal experience, which served as an independent variable, this study utilized a two-part survey. The first part of the survey included demographic questions to measure principal characteristics for describing the population sample and to measure principal experience. Data on principal experience was used as an independent variable or predictor in the primary statistical analysis. Demographic data was used to compile 
descriptive statistics on the participants. Demographic data included principal gender, age, and years of experience as a certified educator.

The second part of the survey measured principal self-efficacy. For this measure, two instruments were considered: the Principal Sense of Efficacy Scale (PSES) by Tschannen-Moran and Gareis (2004) and the Principal Self-Efficacy Scale by Smith and Guarino. For the purposes of this study, the Smith and Guarino (2005) measure was considered problematic. The prompts and responses, as they were written, may have led respondents to respond that their belief in their ability is strong, while still fully believing their efforts cannot overcome challenges to lead to the desired outcomes. Response choices range from Very Weak Beliefs in My Abilities to Very Strong Beliefs in My Abilities. This language may have lead respondents to presume that a weak belief is a reflection of lack of confidence or weak ability, which could potentially have resulted in an overestimation of their belief in their ability. This created the potential for an overinflation of positive belief in one's own ability and skewed the scores for one's selfefficacy. In contrast, in Tschannen-Moran \& Gareis' (2004) PSES, principals were asked to rate the extent to which they can accomplish specific tasks in their school. The prompt and response language appeared more neutral, leaving room for a respondent to view an inability to accomplish a task as potential a result of external challenges and not, necessarily, his or her own personal weaknesses. While this may, to an extent, overlap with Rotter's (1966) theory of social learning and loci of control, it more clearly aligns to Bandura's $(1977 ; 1994 ; 1997)$ social cognitive theory and, specifically, outcome expectancy, which he identified as a key construct in self-efficacy. 
To answer the research question, the PSES was selected for measuring self-efficacy. It is an 18-item survey, in which each item began with the statement, "In your current role as principal, to what extent can you..." and offered a nine-point response scale which started at 1, "not at all" and ended at 9, "a great deal." The PSES was created by Tschannen-Moran and Gareis (2004) and was publicly available on Dr. TschannenMoran's website ${ }^{1}$. Additionally, permission to use the PSES was obtained via email from Dr. Tschannen-Moran, a co-creator the instrument. Correspondence granting permission has been provided in the Appendix (See

Appendix A). The complete questionnaire, with demographic questions and the original scoring guide, have been included in

Appendix B.

Additional questions were added to the survey. Principals were prompted to rate the extent to which his/her PD experiences were relevant to his/her needs and the extent to which PD was relevant to the needs of his/her school. Responses were listed in a 4point Likert scale, with the choices of always, sometimes, rarely, or never. The

\footnotetext{
${ }^{1}$ http://wmpeople.wm.edu/site/page/mxtsch/researchtools
} 
additional questions did not directly address the research question and were not included in the data analysis. However, the data allowed additional insight into principal perspectives of APD experiences for utilization in future follow up studies or analysis.

Tschannen-Moran and Gareis' (2004) PSES is subdivided into three subscales, each with six items. The first subscale measures principals' sense of efficacy on handling management components of the position, such as the management of paperwork, prioritizing tasks, and managing various and competing demands. Factor loadings for efficacy for management ranged from 0.53 to 0.82 . Second, PSES measures their sense of efficacy for instructional areas of the principalship, including creating a positive learning environment, ensuring student learning, and developing a shared vision. Factor loadings for efficacy for instructional leadership ranged from 0.45 to 0.81 . Finally, the scale measures their sense of efficacy on moral leadership, such as promoting ethical behavior of staff, promoting school spirit, and promoting positive image of school. Factor loadings for moral leadership ranged from 0.42 to 0.81 . The PSES has been validated against measures of work alienation and principals' trust in teachers and clients (Tschannen-Moran \& Gareis, 2004). Validity was tested by correlating the scale to these other known constructs. As Tschannen-Moran and Gareis (2004) anticipated, the sense of self-efficacy of sampled principals was "significantly negatively related to work alienation $(r=-0.45, p<0.01)$ and positively correlated to both trust in teachers $(r=$ $0.42, p<0.01)$ and trust in students and parents $(r=0.17, p<0.01)$ " (p. 580). In other words, as the self-efficacy levels of principals went up, their trust in students and parents went up and the feeling of work alienation went down.

\section{Data Collection Procedures}


Prior to the collection of data, all collection procedures were subjected to approval by the dissertation committee, approval by the University of Louisville's Institutional Review Board (IRB), and approval by the participating school district, Jefferson County Public Schools (JCPS). Once approved, invitations to complete the principal survey were emailed to all principals, which initiated the data collection process. On July 17, 2017, principals were contacted via email to invite their participation in completing the principal survey. The email included a brief introduction to explain the purpose of the survey and provide assurances of individual and school confidentiality. The email also provided a brief description of how this study may potentially benefit school principals and schools. The email provided a link to the online survey, which was created and conducted through Qualtrics. The survey window was open for approximately three work weeks and closed on August 4, 2017. To increase the potential response rate, follow up invitations were sent via email to principals one week prior to the close of the survey on July 31, 2017 and one day before the close of the survey on August 3, 2017 (Sue \& Ritter, 2007). The follow up invitations reminded potential participants of the original invitation, restated the potential benefits for principals, assurances of confidentiality, and provided the link to the online survey. It also thanked participants who had already completed the survey and notified them that they may disregard the rest of the message. All email correspondence is provided in

Appendix C. The beginning of the survey requested consent to participate and consent to have the participant's individual PD records released for use in the study. If consent was 
not given, the survey ended for the respondent. If consent was provided, the respondent was directed to the rest of the survey. The survey consisted of demographic questions, including principal experience and school location number, the 18-item PSES, and the additional questions to measure respondent perception of PD relevance. At the end of the survey window, survey responses will be downloaded from Qualtrics into an Excel spreadsheet and reviewed for completeness and other concerns.

Due to a low usable response rate after the initial survey window, a request was made on October 30, 2017 to the JCPS Office of Data Management for additional contacts with potential participants. JCPS approved one additional contact for invitation to participate to only be sent to principals who had not yet responded and were not in a state-identified low performing school. No follow up contacts were approved. One additional and final email was sent individually to each of the approved principals on November 21, 2017. The additional email followed a similar structure as the previous messages but with a less formal and more personal tone. The body of the email is included in Error! Reference source not found.. Principals were given no deadline to c omplete the survey.

PD data for individuals who gave consent was requested from the JCPS Office of Data Management. The request was for all PD/EILA credit history of consenting school principals for the period of July 1, 2016 to June 2, 2017, listed by school (cost center) code, including data for the following fields:

- Session title;

- Session category

- Instructional content/Non-instructional content; 
- Start/end dates/times;

- Delivery type (Districtwide or School-based);

- Earned credits for each completed event; and

- Any additional descriptive information fields in PD Central.

Additional publicly-available data was collected for measuring school factors.

School levels (elementary or secondary) and the percentage of students who participate in the free and reduced lunch program (FRL) for each school are available through JCPS data books (Jefferson County Public Schools, 2017). Student achievement data was obtained through the Kentucky Department of Education School Report Cards (Kentucky Department of Education, 2017). All data for school factors were coded, as explained in the following section and combined with all data into one Microsoft Excel spreadsheet for uploading into SPSS. School factors were matched to principal survey data and district PD data by the school (cost center) code.

\section{Operationalization of Variables}

This section identifies the variables used in this study and explains how each variable was operationalized and measured. Variables and measurements for variables are listed in

Table 4.

Principal self-efficacy. Principal self-efficacy was coded as a raw score from the Principal Sense of Efficacy Scale (PSES) (Tschannen-Moran \& Gareis, 2004) portion of the principal survey. The PSES is an 18 item survey, in which each item begins each question with the statement, "In your current role as principal, to what extent can you..." and offers a nine-point response scale which starts at 1, "not at all" and ends at 9, "a great deal." The total score for each respondent calculated as a mean of all 18 items. Scores 
will be calculated for each respondent in each of the three subscales: efficacy for management, efficacy for instructional leadership, and efficacy for moral leadership. Subscale scores were calculated as the mean of all six items listed within each subscale.

Principal Experience. Principal experience was coded as the self-reported raw number of years provided by the respondent.

School level. For the purposes of this study, the school level was determined by the grades served by the school during the 2016-2017 school year. Schools that served Kindergarten through $5^{\text {th }}$ grade were considered an elementary school and were coded as 0 . Schools that served $6^{\text {th }}$ through $8^{\text {th }}$ grades and schools that served $9^{\text {th }}$ through $12^{\text {th }}$ grades were considered secondary schools and were be coded as 1. Three schools included in the sample served students in Kindergarten through $12^{\text {th }}$ grades. To establish a better balance of the number of schools represented in each level, each of these multilevel schools was coded as a secondary school (1). Only data from these schools' middle school grades $\left(6^{\text {th }}-8^{\text {th }}\right)$ were included in their school-level data.

Student socioeconomic status (SES). The SES of the student population of a school was determined by the percentage of students who participate in the free and reduced lunch program (FRL).

Table 4

Measurement of Variables

\begin{tabular}{lll}
\hline Independent variables & Measurement & $\begin{array}{l}\text { Level of } \\
\text { measurement }\end{array}$ \\
\hline Principal experience & Years & Interval \\
School level & $0=$ Elementary \\
& $1=$ Secondary (middle or high) & Nominal \\
Student socioeconomic status & FRL percentage & Interval
\end{tabular}




\begin{tabular}{lll} 
Student achievement & $\begin{array}{l}\text { Combined percentage of students } \\
\text { scoring Proficient or Distinguished } \\
\text { in Reading or Math }\end{array}$ & Interval \\
Pours of culture/climate or & Interval \\
instruction-focused PD & & \\
\hline Dependent variable & & Interval \\
\hline Principal self-efficacy & PSES score and subscale scores & \\
\hline
\end{tabular}

Student achievement. The student achievement for each school will be determined by the percentage of students in a school who scored Proficient or Distinguished (P/D) on state assessments in Reading (R) or Math (M). The combined P/D for Reading or Math is reported for each school by the Kentucky Department of Education (KDE) (2017).

PD focus on culture/climate or instruction. The focus of PD will be determined by the number of hours a participant earned for PD events with a focus on culture and climate or instruction. PD events were separated by title and category into four focus areas: management, accountability, culture/climate, and instruction. Events that emphasized organizational leadership, managerial tasks, staff evaluation, implementing or managing work flow processes or procedures, or was identified as a meeting were considered to be management-focused. Events that emphasized state accountability processes, measures, or data were considered to be accountability-focused. Events that emphasized student behavior (or related data), staff collaboration, or teamwork were considered to be culture/climate-focused. Events that emphasized subject content, teacher instruction, and student learning were considered to be instructionfocused.

\section{Data Analysis}


To answer the research question, this study analyzed data through a hierarchical linear multiple regression (HLMR). HLMR is often used to examine the influence of multiple independent variables or predictors on a dependent variable, because it measures the extent to which variable groupings contribute to the explained variance of the dependent variable (Ho, 2014; Osborne, 2016; Petrocelli, 2003; Stevens, 2012). This study sought to determine the extent of any correlation and the predictability power the independent variables (APD focus on instruction or school culture/climate; school factors, and principal experience) may have on the dependent variable (principal selfefficacy). HLMR analysis is sensitive to sample size due to the repeated cross analysis of multiple independent variables on the same population (Ho, 2014; Osborne, 2016; Petrocelli, 2003; Stevens, 2012). A sample size ratio of 15 observations for each independent variable is generally recommended and 10 for each is suggested as a minimum (Ho, 2014; Osborne, 2016; Petrocelli, 2003; Stevens, 2012). This research study considered a variety of independent variables for analysis. However, based on the review of literature, some variables (principal gender and principal race/ethnicity) were eliminated do to a lack of a clear correlation to principal self-efficacy. Ultimately, 5 independent variables were included in this study. As this study solicited responses from 139 principals, a usable response rate of $53.95 \%$ ( 75 usable responses) was needed to reach the 15 responses to each independent variable recommendation. The usable sample size fell below the recommendation but above the suggested minimum at 56 usable responses or 11.2 observations per independent variable (Ho, 2014; Osborne, 2016; Petrocelli, 2003; Stevens, 2012). 
Three variable blocks of independent variables were entered into the HLMR model. When entering variable blocks into the HLMR model, the sequencing of variable blocks must be derived from a theoretical or logical basis (Ho, 2014; Osborne, 2016; Petrocelli, 2003; Stevens, 2012). For this study, principal self-efficacy was the dependent variable and variable blocks of independent variables were aligned to the personal, environmental, and behavioral factors that interact in triadic reciprocal causation (Bandura, 1977). School level, student SES, and school achievement are environmental factors in which a principal engages in during his or her professional practice. These environmental factors constitute Block 1 variables. School level is an existing factor prior to a principal's work in the school, placing it beyond any control the principal may have. Similarly, principals have no control over the SES status of students and little, if any, control over the SES makeup of the student body. Placing these variables in Block 1 allows for controls over them and the ability to more clearly test the focal variable in this study. Professional development participation is a behavior in which a principal engages either actively for his or her improvement or passively to fulfill obligatory requirements. APD hours focused on culture/climate or instruction was the Block 2 variable. This second block was the primary focus of this study. Finally, principal experience is a developed aspect of one's professional identity and is considered a personal factor. However, prior research was conflicting in establishing a relationship between principal experience and principal self-efficacy. Therefore, principal experience was the Block 3 variable. For this study, HLMR was preferred for data analysis to determine the extent to which the variables and variable blocks were related to principal self-efficacy. IBM's SPSS software was used to compute the HLMR and analyze data outputs. 


\section{HLMR Outputs and Interpretation}

When conducting the HLMR in SPSS, three outputs were generated: the model summary, the analysis of variance (ANOVA) table, and the table of coefficients. The first output, the model summary, provided the $R, R^{2}$, adjusted $R^{2}$, the standard error of the estimate, and the $F$ change. The $R, R^{2}$, and adjusted $R^{2}$ calculations for independent variables and each variable block provided the amount of variance in the dependent variable that could be explained by variation of the independent variables (Cronk, 2012; Ho, 2014; Osborne, 2016; Petrocelli, 2003; Stevens, 2012). The $R, R^{2}$, and adjusted $R^{2}$ scores were reported as a decimal that could be converted into a percentage that represented the amount of variance explained as a percentage, meaning variables that are highly predictive were scored closely to 1, which represents 100\% (Cronk, 2012; Ho, 2014; Osborne, 2016; Petrocelli, 2003; Stevens, 2012). The model summary included the change in $R^{2}$ which helped to explain the change in variance on principal efficacy, the dependent variable, as independent variables were added to the model (Ho, 2014; Osborne, 2016; Petrocelli, 2003; Stevens, 2012). The standard error of the estimate measured the accuracy of prediction in each model, and the $F$ change measured the power of the independent variables (Ho, 2014; Osborne, 2016; Petrocelli, 2003; Stevens, 2012).

The ANOVA table showed the level of significance for each variable block. Statistical significance was measured at the 0.05 level ( $p$ value) (Ho, 2014; Osborne, 2016; Petrocelli, 2003; Stevens, 2012). A significant model ( $p$ value less than 0.05) would verify that the $F$ measure, which would explain the influence of the independent variables on the dependent variables, was statistically significant and the null hypothesis 
would be rejected (Ho, 2014; Osborne, 2016; Petrocelli, 2003; Stevens, 2012). The last output of the HLMR was the coefficient table, which provided measures for the predictive equation. In significant models, the standardized coefficient beta would provide the beta value - the amount by which the dependent variable would change for each unit increase of independent variable.

\section{HLMR Assumptions}

When performing an HLMR as a statistical analysis, one must ensure certain assumptions are not violated (Cronk, 2012; Ho, 2014; Osborne, 2016; Petrocelli, 2003; Stevens, 2012). The assumptions for HLMR were linearity; homoscedasticity; and the absence of multicollinearity, outliers, and autocorrelation.

Linearity. It was assumed that the independent and dependent variables had a linear relationship and linear distributions. Charting scores on scatter plots and using fitted lines was used to show linearity. Nonlinearity and nonconstant variance would require changes to the model (Ho, 2014; Osborne, 2016; Petrocelli, 2003; Stevens, 2012).

Multicollinearity. Multicollinearity is the intercorrelation of the independent variables or predictors. If a strong intercorrelation existed between these variables, the influence of the independent variable on the dependent variable would be reduced and would limit the size of the $R^{2}$ (Ho, 2014; Osborne, 2016; Petrocelli, 2003; Stevens, 2012). It was assumed that there was little, if any, multicollinearity between independent variables. However, a Variation Inflation Factor (VIF) measure was included in the table of coefficients in the HLMR outputs and was used to identify violations of multicollinearity (Ho, 2014; Osborne, 2016; Petrocelli, 2003; Stevens, 2012). If a 
violation existed, independent variables with a high level of intercorrelation would have been removed from the model.

Homoscedasticity. It is assumed that scores will have a normal distribution. Plotting residuals on a normal probability plot with a fitted line was used to examine scores for normal distribution (Ho, 2014; Osborne, 2016; Petrocelli, 2003; Stevens, 2012).

Outliers. It was assumed that scores for all variables were free from outliers. Outlier scores that fall well outside the normal distribution and standard deviation would have a skewed influence on $R^{2}$ calculations (Ho, 2014; Osborne, 2016; Petrocelli, 2003; Stevens, 2012). Cook's distance and the residuals table were used to identify outlier data. Based on Stevens' (2012) recommendation, scores greater than 1 for Cook's distance or greater than 2 standard deviations were considered outliers.

Autocorrelation. It was assumed that predicted scores were independent of each other, meaning autocorrelation was not present. Autocorrelation was analyzed by a Durbin-Watson test, and autocorrelation was determined by scores between 1.2 and 2.6 (Ho, 2014; Stevens, 2012).

\section{Scope of the Study and Limitations}

In this research, principals' self-efficacy was measured in principals of schools in JCPS. Self-efficacy measurements were analyzed to determine if and to what extent any relationship existed to the number of hours of APD focused on culture/climate or instruction completed by principals. Additionally, principal and school factors were controlled as additional independent variables. Results of the study were made available to the participating school district, JCPS. Had the study determined that APD hours 
focused on culture/climate or instruction had a strong ability to predict principal selfefficacy, it would be recommended that JCPS consider the findings in evaluating APD practices. Results were also used to identify additional studies and recommend future research.

This study had several limitations that minimized the generalizability of the findings. First, the correlational research design of this study explored the relationship between variables, but could not assess the directions of influence between the variables or causality. This study drew upon a limited sample size from one urban school district. The context of the school district made findings less relatable to many other districts. Additionally, this study had a limited focus on APD factors. Only principal PD hours focused on culture/climate or instruction served as the APD variable. Finally, this study did not consider the development of participants outside the PD credit system of the district.

\section{Summary}

In this chapter, details of the research design and data collection were identified and discussed. Rationales for sample selection and the selection of a correlational research design were explained. Variables were listed and described, and how they were be operationalized was described. Instrumentation used for measuring key variables was also rationalized and vetted. The techniques utilized for the collection of data were outlined. Finally, the procedures for analyzing data through a Hierarchical Linear Multiple Regression were discussed. In the remaining chapters, results of the data analysis are presented and the meanings and implications of the findings, as well as recommendations for future research, are discussed. 


\section{CHAPTER IV}

\section{RESULTS}

This study examined the relationship between principal professional development (PD) and principal self-efficacy. Specifically, this study attempted to answer the following research question: To what extent does the number of hours earned for administrator professional development (APD) focused on culture/climate or instruction, principal experience, and school factors predict principal self-efficacy? This chapter details the findings of the study, as related to the research question. Descriptive and inferential statistics were employed to understand the characteristics of the variables and their relationships. Independent variables were grouped into three variable blocks: school characteristics (Block 1), professional development hours and focus (Block 2), and principal experience (Block 3). A hierarchical linear multiple regression (HLMR) was used to analyze the predictive ability of the independent variables on principal selfefficacy.

\section{Participant Survey Responses}

In this study, all principals in the participating school district received invitations to participate. Of the 139 targeted principals, 60 principals responded, which resulted in a $43.2 \%$ initial response rate. However, three principals declined to have their PD records released for the study and were not included in the study. One respondent did not 
provide his or her school cost center data and was removed. This resulted in 56

participants agreeing to be included in the study. Another four principals (7.1\%) did not complete the self-efficacy scale on the survey. The missing self-efficacy scores were imputed with the means of the self-efficacy score and sub scores. Additionally, the 56 principals include two principals of alternative schools. As the achievement scores for these schools recently became available, this study included their data in the analysis. The 56 participants used in this study represents a final response rate of $40.3 \%$.

\section{Descriptive Statistics}

Descriptive statistics were used to understand the makeup and characteristics of participating principals, the characteristics of their schools, and the characteristics of their professional development experiences. Measures of central tendency and variability were used to explore the principal, PD, and school characteristics. The following paragraphs provide outlines of the descriptive statistics for each variable block.

\section{School Characteristics}

School characteristics was the first variable block. The 56 principals in the survey represent 35 of 91 elementary schools (38.5\% response rate), 7 of 22 middle schools (31.8\% response rate), 11 of 18 high schools ( $61.1 \%$ response rate), 1 of 3 combined school (33.3\% response rate), and 2 of 5 alternative schools with multiple grade levels ( $40.0 \%$ response rate). The one combined school and the two alternative schools serve all three grade levels (elementary, middle, and high). Each of these combined level schools had separate data sets at each level for state achievement scores and student demographic data. For the purposes of this study, the combined school and alternative schools were grouped into secondary schools and only their middle school data was 
included in the school characteristics variable block. The secondary school level group consisted of middle and high schools. The resulting school groups left elementary schools as the largest school level group $(N=35)$ at $62.5 \%$ of participants, with secondary schools $(N=21)$ as the smaller school level group at $41.1 \%$ of participants.

Table 5

School Characteristics

\begin{tabular}{lcccc}
\hline & $M$ & $S D$ & Min & Max \\
\hline Free and Reduced Lunch & 67.98 & 19.53 & 21.4 & 95.3 \\
Proficient/Distinguished Reading & 44.05 & 19.52 & 5.2 & 95.2 \\
Proficient/Distinguished Math & 41.73 & 18.45 & 4.0 & 82.0 \\
Combined Proficient/Distinguished Reading and Math & 42.03 & 19.55 & 4.7 & 88.6 \\
\hline
\end{tabular}

$M=$ Mean

$S D=$ Standard Deviation

Other school characteristics included in the variable block were the percentage of students on free and/or reduced lunch (FRL) and the combined percentage of students who scored proficient or distinguished (P\&D) on reading and math state assessments. Descriptive statistics for these characteristics are also reported in Table 5. Participating schools ranged from $21.4 \%$ to $95.3 \%$ of student on FRL $(M=67.98 \%, S D=19.53)$. The percentage of students scoring $\mathrm{P} \& \mathrm{D}$ on state reading and/or mathematics assessments ranged from $4.7 \%$ to $88.6 \%(M=42.03 \%, S D=19.55)$.

\section{Professional Development Experiences}

The second variable block was the PD experiences of the participating principals. Specifically, the number of hours a principal spent in trainings focuses on culture and climate or instruction. As reported in 
Table 6, total PD hours for participants ranged from 38 to 191 hours $(M=87.22$, $S D=29.12)$. Principals spent a majority of their PD $(56.8 \%)$ in trainings that were focused on management. Conversely, principals spent only 33.3\% of their PD hours in trainings focused on the culture/climate of their schools and/or instruction $(M=28.95$, $S D=18.85)$

Table 6

Professional Development Hours by Focus

\begin{tabular}{lcccc}
\hline & $M$ & $S D$ & Min & Max \\
\hline Total PD Hours & 87.22 & 29.12 & 38 & 191 \\
Management PD Hours & 49.61 & 14.50 & 25 & 86.5 \\
Accountability PD Hours & 8.66 & 9.89 & 0 & 75 \\
Culture/Climate PD Hours & 18.79 & 14.32 & 2 & 82 \\
Instruction PD Hours & 10.16 & 12.34 & 0 & 57 \\
Combined Instruction and Culture/Climate PD Hours & 28.95 & 18.85 & 4 & 94 \\
\hline$M=$ Mean & & & &
\end{tabular}

Table 7

Principal Experience

\begin{tabular}{lcccc}
\hline & $M$ & $S D$ & Min & Max \\
\hline Total Years in Education & 21.32 & 6.19 & 9 & 35 \\
Years as a Classroom Teacher & 8.29 & 4.25 & 1 & 24 \\
Years as a Non-Classroom Teacher in a Supporting Role & 2.09 & 2.51 & 0 & 10 \\
Years as a School Counselor & 0.91 & 2.49 & 0 & 13 \\
Years as an Assistant Principal & 3.25 & 3.74 & 0 & 15 \\
Years as a Principal & 6.79 & 6.03 & 1 & 22 \\
Years as Principal of Current School & 4.75 & 4.35 & 1 & 16 \\
\hline$M=$ Mean & & & &
\end{tabular}




\section{Principal Experience}

The number of years a principal has served in the role of principal was the third variable block. Table 7 provides descriptive statistics for principal experiences. Total experience as a principal ranged from 1 to 22 years $(M=6.79, S D=6.03)$ and years as principal of his or her current school ranged from 1 to 16 years $(M=4.75, S D=4.35)$. Additionally, experience as classroom teacher ranged from 1 to 24 years $(M=8.29, S D=$ 4.25), and overall experience as a certified educator ranged from 9 to 35 years $(M=$ 21.32, $S D=6.19)$.

\section{Principal Self-Efficacy}

The dependent variable for this study was principal self-efficacy. Using Tschannen-Moran and Gareis’ (2004) Principal Sense of Efficacy Scale (PSES), participants provided responses regarding their professional beliefs. The PSES, allowed for scoring respondents in overall self-efficacy in their role as principal and three subscales: self-efficacy for management, self-efficacy for instructional leadership, and self-efficacy for moral leadership. Overall and subscale scores are reported in Table 8.

Table 8

Principal Self-Efficacy

\begin{tabular}{lcccc}
\hline & $M$ & $S D$ & Min & Max \\
\hline Overall Self-Efficacy & 7.58 & .71 & 6.22 & 8.94 \\
Self-Efficacy for Management & 7.24 & .99 & 5.17 & 9.00 \\
Self-Efficacy for Instructional Leadership & 7.81 & .81 & 5.50 & 9.00 \\
Self-Efficacy for Moral Leadership & 7.68 & .90 & 5.00 & 9.00 \\
\hline$M=$ Mean & & & &
\end{tabular}


Each subscale was averaged into a score ranging from 1-9, and the overall score was a composite of all score, then averaged, and ranging from 1-9. Respondents scored highest in the self-efficacy for instructional leadership $(M=7.81, S D=.81)$, followed by selfefficacy for moral leadership $(M=7.68, S D=.90)$, and then self-efficacy for management $(M=7.24, S D=.99)$. Overall self-efficacy ranged from 6.22 to $8.94(M=$ $7.58, S D=.71)$.

\section{HLMR Results}

To answer the research question HLMR was employed to measure the degree to which school characteristics (Block 1), professional development (Block 2), and principal experience (Block 3) predict principal self-efficacy. School characteristics included the variables of school grade level (elementary or secondary), the socioeconomic status of the school as represented by the percentage of students who participate in the free and reduced lunch program, and the level of school achievement as represented by the combined percentages of students who scored proficient or distinguished on state reading and math assessments. The variable block for PD included the number of hours spent in PD focused on culture/climate or instruction. Principal experience is the total number of years a participant has served as a principal. The dependent variable was principal selfefficacy. For the HLMR analysis, each independent variable block was entered into the model sequentially to measure its level of influence on principal self-efficacy. Results for the HLMR analysis are reported in Table 9.

In this analysis, school characteristics (Block 1) was not found to be statistically significant $(F(3,52)=.696, p>.05)$ with an $R^{2}$ of .039 and an adjusted $R^{2}$ of -0.17 . The school characteristics in Block 1 were not significant predictors of principal self-efficacy. 
When the PD focus (Block 2), which is the variable of greatest interest in this study, was added to the analysis, the change in $R^{2}$ was .047 or a $4.7 \%$ increased change in the accounted variance. The adjusted $R^{2}$ is -.017, compared to an $R^{2}$ of .086 , which may reflect the modest sample size $(N=56)$ for the number of independent variables (5). The recommended number of observations for each independent variable is 15 (Ho, 2014;

Osborne, 2016; Petrocelli, 2003; Stevens, 2012), and the suggested minimum number of observations for each independent variable is 10 (Stevens, 2012). This study had an average of 11.2 observations for each independent variable.

Table 9

HLMR Predicting Principal Self-Efficacy

\begin{tabular}{|c|c|c|c|c|c|}
\hline \multirow[b]{2}{*}{ Variable } & \multirow[b]{2}{*}{$R^{2}$} & \multirow[b]{2}{*}{$A R^{2}$} & \multirow[b]{2}{*}{$\Delta R^{2}$} & \multicolumn{2}{|c|}{ Estimates } \\
\hline & & & & $B$ & $S E$ \\
\hline Step 1 & .039 & -.017 & & & \\
\hline School Level & & & & .207 & .228 \\
\hline Free and Reduced Lunch & & & & .007 & .010 \\
\hline Reading and Math P\&D & & & & .011 & .009 \\
\hline Step 2 & .086 & .014 & .047 & & \\
\hline School Level & & & & .280 & .230 \\
\hline Free and Reduced Lunch & & & & .006 & .010 \\
\hline Reading and Math P\&D & & & & .008 & .010 \\
\hline APD Hours in Instruction \& Culture & & & & -.009 & .006 \\
\hline Step 3 & .089 & -.002 & .003 & & \\
\hline School Level & & & & .311 & .243 \\
\hline Free and Reduced Lunch & & & & .006 & .010 \\
\hline Reading and Math P\&D & & & & .008 & .010 \\
\hline APD Hours in Instruction \& Culture & & & & -.008 & .006 \\
\hline Principal Experience & & & & .008 & .018 \\
\hline
\end{tabular}


Ultimately, PD focus on instruction and culture/climate was not found to be statistically significant $(F(4,51)=1.194, p>.05)$ and, therefore, not a significant predictor of overall principal self-efficacy. Finally, when principal experience (Block 3) was entered, there was a change in $R^{2}$ of .003 or $.03 \%$. Principal experience was not found to be a statistically significant $(F(5,50)=.490, p>.05)$ predictor of principal self-efficacy.

\section{HLMR Assumptions}

Tests for possible violations of specific assumptions were conducted prior to executing the regression analysis. The assumptions for which testing and examination were conducted are linearity, homoscedasticity, multicollinearity, outliers, and autocorrelation.

Linearity. All variables are assumed to have a linear relationships and linear distributions. Normal probability plotting with a fitted line was used to examine potential violations of linearity. The diagonal plot aligned with the fitted line, and, therefore, no concerns of violation were identified (Ho, 2014; Osborne, 2016; Petrocelli, 2003;

Stevens, 2012).

Homoscedasticity. On the residuals plot, equal variance between variables was observed as being normally distributed at the 0 line of the residuals plot. This indicated no concerns of violation of homoscedasticity.

Multicollinearity. Intercorrelation between independent variables can interfere with the predictability of independent variables on the dependent variable (Ho, 2014; Osborne, 2016; Petrocelli, 2003; Stevens, 2012). The Variance Inflations Factor (VIF) was reviewed for each independent variable. A VIF value of 10 or greater indicates possible violations of the multicollinearity assumption (Ho, 2014; Osborne, 2016; 
Petrocelli, 2003; Stevens, 2012). Based on the analysis of the data, no violations of this assumption were found, as all VIF values ranged from 1.213 to 3.897 .

Outliers. Outlier data for variables can have a skewing influence of the $R^{2}$ (Ho, 2014; Osborne, 2016; Petrocelli, 2003; Stevens, 2012). The influence of outliers was measured with Cook's distance. Cook's distance values ranged from .000 to .222 . In this study, outlier data did not overly influence the $R^{2}$, as the value of each residual had a Cook's distance below the recommended maximum of 2 standard deviations (Stevens, 2012).

Autocorrelation. Predicted values should be independent to avoid errors through autocorrelation. Violations of autocorrelation were tested through a Durbin-Watson test. Scores between 1.2 and 2.6 satisfy this assumption (Ho, 2014; Stevens, 2012). The Durbin-Watson score fell within this range at 1.67 .

\section{Additional Analyses}

The HLMR analysis found that no tested variable was a significant predictor of principal self-efficacy. However, the sample size for the number of tested variables was just over the suggested minimum number of observations. To more richly explore the relationships between the variables, the researcher decided to run additional statistical analyses to answer the following additional questions related to the data. Is self-efficacy different for principals based on their hours spent in EILA-qualified professional learning? Is self-efficacy for these principals different based on their participation in federal or state mandated PD? What is the relationship between PD focus and student achievement? 
This study used causal comparative analyses to explore the relationship between the accumulation of EILA hours and principal self-efficacy, the relationship between the accumulation of federal or state mandated PD hours and principal self-efficacy, and the relationship between the percentage of a principal's PD hours spent in federal or state mandated PD and his or her self-efficacy. Additionally, Pearson correlations and a stepwise regression were used to examine the relationships between the different focus areas of PD and school reading and math achievement.

\section{EILA Hours and Principal Self-Efficacy}

In further exploring the relationship between PD and principal self-efficacy, this study determined to answer this question: Is self-efficacy different for principals based on their hours spent in EILA-qualified professional learning? To examine differences in principal self-efficacy based on participation in EILA, participants were divided into two groups: principals who accumulated less than 50 hours of EILA-qualified professional development (coded as $0, N=29$ ) and principals who accumulated more than 50 hours of EILA-qualified professional development (coded as 1, $N=27$ ). Accumulated EILA hours ranged from 28 to 116 hours $(M=52.188)$. An independent-samples $t$ test was conducted to compare differences between the means of each group. No significant difference was found $(t(54)=-1.153, p>.05)$ between the mean of principals with less than 50 EILSA hours $(M=7.473, S D=.75)$ and the mean of principals with over 50 EILA hours $(M=7.691, S D=.65)$. Among the principals, there was no significant difference in self-efficacy based on the hours spent in EILA-qualified PD. 


\section{Federal or State Mandated Professional Development and Self-Efficacy}

In further exploring the relationship between PD and principal self-efficacy, this study determined to answer this question: Is self-efficacy for these principals different based on their participation in federal or state mandated PD? This study added an analysis of self-efficacy of principals based on the accumulation of mandated PD hours and an analysis of self-efficacy of principals based on the percentage of PD hours in mandated PD. For comparing self-efficacy based on the accumulation of mandated PD hours, participating principals were divided into two groups: principals who accumulated less than 6 hours of federal or state mandated PD (coded as $0, N=31$ ) and principals who accumulated 6 or more hours of federal or state mandated PD (coded as $1, N=25)$. Accumulated mandated PD hours ranged from 0 to 25 hours $(M=6.152)$. An independent samples $t$ test was conducted to compare the differences between the mean self-efficacy score of each group. No significant difference was found $(t(54)=.660, p>$ $.05)$. The mean of principals who accumulated less than 6 hours of mandated PD $(M=$ $7.634, S D=.67$ ) was not significantly different from the mean of principals who accumulated 6 or more hours of mandated PD $(M=7.508, S D=.76)$.

For comparing self-efficacy based on the percentage of PD hours spent in mandated PD, participants were divided into two groups. The first group were principals who spent less than $6 \%$ of their PD hours in mandated PD (coded as $0, N=25$ ), and the second group were principals who spent $6 \%$ or more of their PD hours in mandated PD (coded as $1, N=31$ ). Participation in mandated PD ranged from $0 \%$ to $29.4 \%$ of total PD hours $(M=7.752)$. An independent samples $t$ test was used to compare the differences between the mean of each group. There was no significant difference between them 
$(t(54)=-.050, p>.05)$. The self-efficacy score mean of principals who spent less than $6 \%$ of their PD hours in mandated PD $(M=7.573, S D=.68)$ was not significantly different from the mean of principals who spent $6 \%$ or more of their PD hours in mandated $\mathrm{PD}(M=7.582, S D=.74)$. Based on both $t$ tests, there were no differences found in self-efficacy, based on participation in mandated PD.

\section{Professional Development Focus and Reading Achievement}

To better understand the relationship between PD focus and achievement, this study included an additional question: What is the relationship between PD focus and student achievement? To explore the relationships between PD focus and student reading achievement $(M=44.045, S D=19.52)$ Pearson correlations and a stepwise regression were conducted. First, student achievement in reading was examined for correlations with PD hours focused on management, PD hours focused on accountability, PD hours focused on culture/climate, PD hours focused on instruction, combined PD hours focused on culture/climate or instruction, and total PD hours. Table 10 summarizes the results for each PD variable's Pearson correlations with student reading achievement scores.

Table 10

PD Correlations with Student Reading Achievement

\begin{tabular}{lc}
\hline & $r$ \\
\hline Management-focused PD hours & -.007 \\
Accountability-focused PD hours & .107 \\
Culture/Climate-focused PD hours & -.156 \\
Instruction-focused PD hours & $-.286^{*}$ \\
Combined Culture/Climate or Instruction-focused PD Hours & $-.305^{*}$ \\
Total PD hours & -.165 \\
\hline$* p<.05$ &
\end{tabular}


Very weak correlations that were not significant were found for managementfocused PD hours $(r(53)=-.007, p>.05)$, accountability-focused PD hours $(r(53)=.107$, $p>.05)$, culture/climate-focused PD hours $(r(53)=-.156, p>.05)$, and total PD hours $(r(53)=-.165, p>.05)$. These variables were not related to student reading achievement. Weak but significant negative correlations were found for instruction-focused PD hours $(r(53)=-.286, p<.05)$ and combined culture/climate or instruction-focused PD hours $(r(53)=-.305, p<.05)$. Principals with more hours in instruction PD or with more combined hours of culture/climate or instruction PD tended to have lower student reading achievement.

Second, a hierarchical linear multiple regression was used to analyze the predictability of PD focus on student reading achievement. HLMR results are listed in Table 11. Block 1 variables included school level and FRL. The hours a principal participated in culture/climate or instruction-focused PD was the variable entered in Block 2, and Block 3 consisted of years of experience as a principal. Block 1 was found to be a statistically significant predictor of student reading achievement scores $(F(2,52)=$ $90.391, p<.01$ ), with an $R^{2}$ of .777. Schools' student achievement scores in reading is equal to $111.579-7.810$ (school level) - .94(FRL). School level and FRL accounted for $77.7 \%$ of the variance in student reading achievement. The predicted percentage of students in a school scoring Proficient or distinguished on the reading achievement test decreased by 7.810 percentage points for secondary schools and decreased by .94 percentage points for each percent increase in FRL.

When PD hours focused on culture/climate or instruction (Block 2) were added to the analysis, the change in $R^{2}$ was .008 or a $.8 \%$ increased change in the accounted 
variance. The regression model including Blocks 1 and 2 was found to be statistically significant $(F(3,51)=61.899, p<.01)$. However, the $F$ change from adding Block 2 was not statistically significant $(p<.05)$. Therefore, the hours of culture/climate or instruction-focused PD was not a significant predictor of student reading achievement. Finally, when principal experience (Block 3) was entered, there was a change in $R^{2}$ of .000 , and the $F$ change was not statistically significant $(p<.05)$. Principal experience was not found to be a statistically significant predictor of principal self-efficacy.

\section{Table 11}

HLMR Predicting Reading Achievement

\begin{tabular}{|c|c|c|c|c|c|}
\hline \multirow[b]{2}{*}{ Variable } & \multirow[b]{2}{*}{$R^{2}$} & \multirow[b]{2}{*}{$A R^{2}$} & \multirow[b]{2}{*}{$\Delta R^{2}$} & \multicolumn{2}{|c|}{ Estimates } \\
\hline & & & & $B$ & $S E$ \\
\hline Step 1 & .777 & .768 & $.777 * *$ & & \\
\hline School Level & & & & $-7.810^{*}$ & 2.703 \\
\hline Free and Reduced Lunch & & & & $-.940^{* *}$ & .070 \\
\hline Step 2 & .785 & .772 & .008 & & \\
\hline School Level & & & & $-6.537 *$ & 2.838 \\
\hline Free and Reduced Lunch & & & & $-.912^{* *}$ & .072 \\
\hline APD Hours in Instruction or Culture/Climate & & & & -.098 & .072 \\
\hline Step 3 & .785 & .767 & .000 & & \\
\hline School Level & & & & $-6.582^{*}$ & 3.041 \\
\hline Free and Reduced Lunch & & & & $-.913 * *$ & .074 \\
\hline APD Hours in Instruction \& Culture/Climate & & & & -.099 & .076 \\
\hline Principal Experience & & & & -.011 & .245 \\
\hline
\end{tabular}

$* p<.05$

$* * p<.01$

\section{Professional Development Focus and Math Achievement}

Pearson correlations were also calculated to explore the relationships between PD focus and student math achievement $(M=41.727, S D=18.45)$. Student achievement in 
math was examined for correlations with PD hours focused on management, PD hours focused on accountability, PD hours focused on culture/climate, PD hours focused on instruction, combined PD hours focused on culture/climate or instruction, and total PD hours. Table 12 summarizes the results for each PD variable's Pearson correlations with student math achievement scores.

Table 12

PD Correlations with Student Math Achievement

\begin{tabular}{lc}
\hline & $r$ \\
\hline Management-focused PD hours & -.060 \\
Accountability-focused PD hours & .147 \\
Culture/Climate-focused PD hours & -.199 \\
Instruction-focused PD hours & $-.296^{*}$ \\
Combined Culture/Climate or Instruction-focused PD Hours & $-.345^{*}$ \\
Total PD hours & -.203 \\
\hline${ }^{*} p<.05$ &
\end{tabular}

Very weak correlations that were not significant were found for managementfocused PD hours $(r(54)=-.060, p>.05)$, accountability-focused PD hours $(r(54)=.147$, $p>.05)$, culture/climate-focused PD hours $(r(54)=-.199, p>.05)$, and total PD hours $(r(54)=-.203, p>.05)$. These variables were not related to student math achievement. Weak but significant negative correlations were found for instruction-focused PD hours $(r(54)=-.296, p<.05)$ and combined culture/climate or instruction-focused PD hours $(r(54)=-.345, p<.05)$. Principals with more hours in instruction PD or with more combined hours of culture/climate or instruction PD tended to have lower student math achievement.

Second, a hierarchical linear multiple regression was used to analyze the predictability of PD focus on student math achievement. HLMR results are listed in 
Table 13. Block 1 variables included school level and FRL. The hours a principal participated in culture/climate or instruction-focused PD was the variable entered in Block 2, and Block 3 consisted of years of experience as a principal. Block 1 was found to be a statistically significant predictor of student reading achievement scores $(F(2,52)=$ 43.367, $p<.01$ ), with an $R^{2}$ of .625 . Schools' student achievement scores in math is equal to $100.689-14.47$ (school level) - .778(FRL). School level and FRL accounted for $62.5 \%$ of the variance in student math achievement. The predicted percentage of students in a school scoring Proficient or distinguished on the reading achievement test decreased by 14.47 percentage points for secondary schools and decreased by .778 percentage points for each percent increase in FRL.

Table 13

HLMR Predicting Math Achievement

\begin{tabular}{|c|c|c|c|c|c|}
\hline \multirow[b]{2}{*}{ Variable } & \multirow[b]{2}{*}{$R^{2}$} & \multirow[b]{2}{*}{$A R^{2}$} & \multirow[b]{2}{*}{$\Delta R^{2}$} & \multicolumn{2}{|c|}{ Estimates } \\
\hline & & & & $B$ & $S E$ \\
\hline Step 1 & .625 & .611 & $.625 * *$ & & \\
\hline School Level & & & & $-14.470 * *$ & 3.310 \\
\hline Free and Reduced Lunch & & & & $-.778 * *$ & .086 \\
\hline Step 2 & .635 & .613 & .010 & & \\
\hline School Level & & & & $-13.142 * *$ & 3.491 \\
\hline Free and Reduced Lunch & & & & $-.749 * *$ & .089 \\
\hline APD Hours in Instruction or Culture/Climate & & & & -.103 & .088 \\
\hline Step 3 & .636 & 607 & .002 & & \\
\hline School Level & & & & $-13.720 * *$ & 3.734 \\
\hline Free and Reduced Lunch & & & & $-.755^{* *}$ & .090 \\
\hline APD Hours in Instruction \& Culture/Climate & & & & -.116 & .094 \\
\hline Principal Experience & & & & -.139 & .301 \\
\hline
\end{tabular}


When PD hours focused on culture/climate or instruction (Block 2) were added to the analysis, the change in $R^{2}$ was .010 or a $1.0 \%$ increased change in the accounted variance. The regression model with Block 2 variables entered was found to be statistically significant $(F(3,51)=29.554, p<.01)$. However, the $F$ change was not statistically significant $(p>.05)$. Therefore, the hours of culture/climate or instructionfocused PD was not a significant predictor of student math achievement. Finally, when principal experience (Block 3) was entered, there was a change in $R^{2}$ of .002 or .2\%, and the $F$ change was not statistically significant $(p>.05)$. Principal experience was not found to be a statistically significant predictor of principal self-efficacy.

\section{Summary of Results}

Through the data calculations and analysis in a hierarchical linear multiple regression (HLMR), this study attempted to measure the predictive ability of school factors, PD focus, and principal experience on principal self-efficacy. School factors (Block 1) consisted of school level, FRL, and student achievement. Principal PD focus (Block 2) was the hours of PD a principal spent in trainings with a focus on culture/climate or instruction. Principal experience was the number of years a participant has spent in the role of principal. This study did not find any of the variable blocks to have a significant influence on principal self-efficacy. Additionally, no coefficients demonstrated significance in the analysis.

The following hypotheses were used to guide this study in answering the research question.

Hypothesis: Administrator professional development (APD) and principal self-efficacy 
- Null $\left(\mathrm{H}_{0}\right)$ - APD focus, school factors, and principal experience are not predictors of principal self-efficacy.

- Alternative $\left(\mathrm{H}_{1}\right)$ - APD focus, school factors, and principal experience are predictors of principal self-efficacy.

The results of this study did not demonstrate any of the variable blocks to be significant predictors of principal self-efficacy. Therefore, the null hypothesis is upheld.

Additional analyses were conducted to answer the following secondary questions. Is self-efficacy different for principals based on their hours spent in EILA-qualified professional learning? Is self-efficacy for these principals different based on their participation in federal or state mandated PD? What is the relationship between PD focus and student achievement?

To determine any differences in principal self-efficacy based on the hours spent in EILA-qualified professional learning, a $t$ test was calculated to measure the difference between the mean of principals with fewer than 50 EILA hours and the mean of principals with 50 or more hours. There was no significant difference in self-efficacy based on the hour spent in EILA-qualified PD. Additional $t$ tests were conducted to determine differences in principal self-efficacy based on participation in federal or state mandated PD. The first $t$ test measured the difference in self-efficacy between principals with fewer than 6 hours of mandated PD and principals with 6 or more hours. The second $t$ test measured the difference in self-efficacy between principals who spent less than $6 \%$ of their PD hours in mandated PD and those who spent $6 \%$ or more. There was no significant difference, based on the hours or percentage of hours spent in mandated PD. 
This study also explored the relationships between PD focus and student achievement. Pearson correlations were calculated between the different foci of PD and reading achievement and again between the different PD foci and math achievement. Reading achievement had significant but weak negative correlations with instructionfocused PD hours and combined hours culture/climate or instruction-focused PD. Similarly, math achievement had significant but weak negative correlations with instruction-focused PD and combined culture/climate or instruction-focused PD. Principals with more hours in instruction PD or with more combined hours of culture/climate or instruction PD tended to have lower student reading and math achievement.

HLMR analyses were also calculated to determine if the focus areas of PD were predictors of student reading and math achievement. In predicting school student achievement in reading and math, the control variables of school level and FRL were found to be significant predictors of achievement. However, a principal's combined hours in PD focused on culture/climate or instruction was not determined to be significant predictor for achievement in either area. Chapter 5 discusses the implications of these results on practice and policy, connections to existing literature, and recommendations for future research. 


\section{CHAPTER V \\ DISCUSSION}

The purpose of this study was to examine the relationship between principal professional development (PD) focused on culture/climate or instruction, school factors (school level, student socioeconomic status, and student achievement), principal experience, and principal self-efficacy. Principal self-efficacy influences teacher selfefficacy (Calik, Sezgin, Kavgaci, \& Cagatay, 2012; Hartnett, 1995), climate for staff (Federici \& Skaalvik, 2012), and student outcomes (Federici \& Skaalvik, 2012). Murphy et al. (2007) articulate how values and beliefs of principals result in behaviors that influence school and classroom environments and student outcomes through influence pathways. This study intended to address key gaps in existing relevant literature.

Specifically, this research adds a new quantitative analysis to what is known about the features of effective principal PD and potential antecedents of principal self-efficacy. To this end, this study sought to answer the following research question: To what extent does the number of hours earned for administrator professional development (APD) focused on culture/climate or instruction, principal experience, and school factors predict principal self-efficacy?

Principals from Jefferson County Public Schools, a large urban school district, were invited to participate in the study. Participation included completing a survey to gather demographic data, to identify principal experience, and to measure principals' sense of efficacy and granting permission for individual PD records to be reviewed and 
analyzed. The survey was delivered to potential participants via email, and the initial survey window remained open for approximately three weeks, with a secondary invitation to principals sent via email sent three months later. In the survey, self-efficacy was measured with the Principal Sense of Efficacy Scale (PSES) (Tschannen-Moran \& Gareis, 2004). Principals also reported the number of years of experience in various certified educator roles, most notably the number of years as a principal and the number of years as principal in his or her current school. Finally, the survey prompted participants to rate their perceptions of the relevancy of their PD experiences from 20162017. Of the 139 invited principals, 56 (40.3\%) usable responses were received.

PD records from 2016-2017 were collected for each consenting participant. Participant PD events were categorized as focused on management, accountability, culture/climate, or instruction. Each participant's total PD hours and total PD hours for each focus category was calculated. Total hours of APD focused on culture/climate or instruction served as the focal independent variable for this study. Additionally, publicly available school data was collected to determine school level, student SES, and student achievement.

\section{Discussion of Primary Analysis and Variables}

A hierarchical linear multiple regression (HLMR) was used to analyze all the data to determine what predictive relationship, if any, existed between the independent variables and the dependent variable. Variable blocks were determined and progressively added to the model, in accordance to Bandura's (1977) concept of triadic reciprocal causation. Environmental factors (school level, student SES, and student achievement) were entered in as Block 1 variables. Behavior factors (number of hours in APD focused 
on culture/climate or instruction) were entered in as Block 2 variables. Personal factors (years of experience as a principal) were entered in as Block 3 variables. In analyzing the data, the HLMR results demonstrated none of the variable blocks were statistically significant predictors of principal self-efficacy. This upheld the null hypothesis. No coefficients had a significant relationship to principal efficacy.

None of the independent variables were shown to be predictors. Based on the research literature, three of the independent variables (school level, socioeconomic status, and principal experience) had mixed findings in their relationship with principal selfefficacy. Based on school level, principal self-efficacy had been shown to be higher in elementary principals than secondary school principals (DeMoulin, 1992), unrelated to school level (Lyons \& Murhpy, 1994), and moderated by school level in its school and classroom contributions (Leithwood \& Jantzi, 2008). The results of this study aligns with Lyon and Murphy (1994) with no demonstrated connection to principal self-efficacy.

The limited previous findings for socioeconomic status (SES) as an antecedent of principal self-efficacy have been mixed, as well. Osterman and Sullivan (1996) found SES and principal self-efficacy to be unrelated, while Smith et al. (2006) found that principals in schools with higher percentages of students participating in free and reduced lunch programs (FRL) tended to have higher self-efficacy scores. The HLMR analysis in this study found no connections between FRL and principal self-efficacy.

Previous literature has also found mixed results in the connections between principal self-efficacy and principal experience. High school principals with more experience have been found to have higher levels of self-efficacy (DeMoulin, 1992), while principal experience has also been found to be unrelated to principal self-efficacy 
(Leithwood \& Jantzi, 2008; Tschannen-Moran \& Gareis, 2004). Additionally, Fisher (2014) found a pattern of change in principal self-efficacy that follows principal experience over time. This study calculated no significant connections between principal experience and self-efficacy.

Two independent variables (academic achievement and APD focus on culture/climate or instruction) had no prior literature regarding their relationships to principal self-efficacy. While there were suggestions that achievement may influence principal self-efficacy (Pedota, 2015; Stipek, 2012), there were no studies that focused on achievement as an antecedent of principal self-efficacy. This study found no significant connections between either of these variables and principal self-efficacy.

Based on the results of the primary analyses, there is no basis to assume that the overall planning, methods, and implementation of the instruction or climate/culturefocused APD in which these principals participated was purposeful and/or effective in the growth and development of the self-efficacy of principals. Guskey (2014) has highlighted that PD has a historical lack of planning with clear purpose. District leadership must determine if increased principal self-efficacy is a desired outcome from APD. If so, intentional and purposeful planning must occur to ensure principal engagement in mastery and vicarious experiences and encounters with positive social persuasion to initiate and produce the desired increases in self-efficacy.

\section{Discussion of Secondary Analyses}

Additional analyses were conducted to further examine the relationships among the variables. These analyses included $t$ tests, Pearson correlations, and hierarchical linear multiple regression (HLMR). The participants were grouped and their self-efficacy 
scores were compared based on their amount of participation in PD that qualified for Effective Instructional Leadership Act (EILA) credit and their amount of participation in federal or state mandated PD. Neither the level of participation in EILA PD or in mandated PD were found to be significantly associated with self-efficacy levels.

Hierarchical linear multiple regressions were calculated to determine the predictability of environmental factors (school level and FRL), hours of APD focused on culture/climate or instruction, and principal experience on reading achievement and math achievement. While school level (elementary or secondary) and FRL were both significant predictors that accounted for most of the variance of achievement scores, the principal's PD hours focused on culture/climate or instruction and principal experience were not significant predictors of achievement in either area. These results may further indicate that the purposefulness and effectiveness of culture/climate or instructionfocused APD may be lacking. However, many other variables not accounted for in this analysis could be at play and need to be further examined and studied. Prior year achievement data, changes in achievement scores, and other PD focus areas need to be analyzed to better determine relationships and causality.

Pearson correlations were calculated to determine correlations between the various focus areas of PD and reading and math achievement. Of all the focus areas, only PD hours focused on instruction and the combined PD hours focused in culture/climate or instruction were determined to have a significant correlation with reading and/or math achievement. PD hours focused on management, accountability, or culture/climate (alone) were not significantly correlated with reading achievement nor math achievement. Additionally, a principal's total PD hours were not correlated to either area 
of achievement. PD hours of instruction and the combined PD hours in culture/climate or instruction each had a weak but significant negative correlation with reading achievement and a weak but significant negative correlation with math achievement. As the number of hours in instruction-focused PD or the number of combined hours in culture/climate or instruction PD increased, the achievement in both reading and math tended to decrease.

The negative correlational relationships among the significant variables would, at first, appear to be contradictory to most logical assumptions. One would likely and logically speculate that principals who spend more time in instruction-focused PD or culture/climate-focused PD would be more likely to implement positive practices learned in these PDs and see higher achievement scores. However, these correlations do not provide any directional indication of the relationships between the variables. Therefore, one may assume that principal PD choices would drive the instructional outcomes of the school. However, in the context of this study, the reverse may be true. Prior achievement outcomes may have driven the principal PD choices. This study did not collect the achievement data of the schools from the prior year (2015-2016). However, it would be reasonable to speculate that schools with low achievement scores in 2017 had low achievement scores in 2016 also. It would be unlikely that many low-achieving schools would make a sudden leap to score on the same level as the higher achieving schools in one year. A thoughtful principal at a low achieving school may likely attend more PD on instruction or school culture and climate. Implications of these findings and additional research that may address new questions that originate from these identified negative relationships are addressed in the next section. 


\section{Implications and Suggested Future Research}

If the purpose of PD is to improve professional practice through professional learning to create improved school learning environments and student outcomes, then it is imperative that school districts assess the goals and outcomes of the PD and APD. Parlaying APD activities into improved student outcomes does not follow a direct path. The best lessons and learning from high-quality APD can be easily mitigated by the challenges that face schools, teachers, and students before taking root. Further research will be needed to determine how to best create and implement high-quality APD that leads to improved outcomes for students. Principal self-efficacy may still be an important variable in translating professional learning from APD into student outcomes.

Through the HLMR, the analysis of this study's data has successfully determined a sequence of three variable blocks that, in this context, do not provide significant predictions of principal self-efficacy. These findings provide an additional piece of the puzzle to a greater understanding of principal self-efficacy and principal PD. The complexities of self-efficacy development may not be as clearly related to the specific independent variables as this study hypothesized. Notably, if district leaders who are responsible for designing APD seek to improve principal self-efficacy, they may consider school factors and participant experience as a context for developing relevant APD experiences (Camburn \& Won Han, 2015; Nespor, 1987). However, as antecedents, these factors would seemingly have no significant relationship to the level of self-efficacy in the individual. Likewise, ensuring a principal merely accumulates hours in PD focused on culture/climate or instruction does not have a significant relationship to a principal's level of self-efficacy. Ensuring PD is of high quality and intentionally 
includes activities that are sources of self-efficacy may be needed to make a PD experience better connect to an individual principal's self-efficacy. This type of PD planning for outcomes must be intentional and begin with the end results in mind (Guskey, 2014).

As a result of findings from the Pearson correlations, more studies on the relationships between the focus areas of PD and student achievement must be done. As this study found negative relationships for instruction and culture/climate PD hours and achievement, new questions have developed. If principals with lower achievement scores are attending more hours of instruction and culture/climate PD, what is the effect of these extra PD hours on student achievement? Further data collection of prior year achievement scores and analyses of growth or decline in achievement, based on principal PD, should be conducted.

Through the process of this study, it has become apparent that more focus on culture/climate APD and instruction APD is needed. The sample district, Jefferson County Public Schools, and the rest of Kentucky regularly conduct a workplace and learning environment survey called the Teaching, Empowering, Leading and Learning (TELL) Survey. This survey, conducted every other year, provides powerful insights into the perceptions that school staff have of their school and district. Analyzing data from the TELL Survey in conjunction with the type and quality of APD in which principals participate could reveal new insights. New research should explore if and how TELL Survey data drives APD offerings and participation and whether specific, high-quality APD focused on culture and climate can assist principals in improving their school environments. 
In a connected point of interest, the examination of the APD records for principals did corroborate the reporting of administrators in Oliver's (2005) study that managerial tasks and assessment items dominated their APD experiences. In 2016-2017, 66.7\% of all the participants' APD hours were spent in trainings focused on management (56.8\%) and state accountability (9.9\%). This could suggest that management-focused APD is more readily available or more often required of principals than APD focused on instruction and/or culture/climate. District leaders should ensure that appropriate amounts of relevant APD on instruction and culture/climate are available to principals and that the specific needs of schools and principals are addressed by APD.

\section{Limitations}

This study had several limitations. First, the usable sample size was modest. The limited starting population of the participating school district prevented this study from being generalizable. The modest usable response rate was above the suggested minimum (11.2), but below the recommended number of observations (15) per independent variable (Ho, 2014; Osborne, 2016; Petrocelli, 2003; Stevens, 2012). Future similar studies should address this limitation with a larger sample from more school districts. Ideally, a large sampling from multiple urban school districts would provide more generalizable results. However, similar studies conducted in multiple districts may face a variety of barriers in obtaining the specific PD records for individuals. Different types of retrievable PD data may be kept by each district and the methods and technology of data storage may result in labor intensive processes to code and combine the data.

This study also explored only one limited aspect of APD - the number of hours of APD focused on instruction or culture/climate. More studies on the categories, methods, 
and strategies of APD are needed to better understand the various dimensions of APD and any connections to principal self-efficacy. Based on this study's findings, it is recommended that a variety of APD variables be measured against principal self-efficacy and the three individual subscales in the PSES. Including PSES subscales as dependent variables in future studies would allow for a more sophisticated examination of the relationship APD variables may have with self-efficacy. Additionally, there is a strong need for studies on APD and self-efficacy that can potentially measure causality.

Specifically, experimental and quasi-experimental research would allow for the testing of various aspects of APD methods, strategies, and foci to be tested for significant effects on administrator self-efficacy and/or self-efficacy sub-scales.

\section{Conclusion}

Self-efficacy is a powerful agent that determines the persistence and endurance of educators. Determining the antecedents of self-efficacy and developing APD experiences for principals that can grow their sense of efficacy could potentially have a considerable influence on the effectiveness of principals in producing positive student outcomes. This study identified variables that did not have a significant correlation to principal selfefficacy. However, more research is needed to address the limitations of this study and to further explore the potential of altering APD variables to produce an increased sense of efficacy in principals. 


\section{REFERENCES}

Airola, D., Bengtson, E., Davis, D., \& Peer, D. (2014). Principals' sense of efficacy: The influence of the Arkansas Leadership Academy. Journal of Educational Administration, 52(6), 754-774.

Allinder, R. M. (1995). An examination of the relationship between teacher efficacy and curriculum-based measurement and student achievement. Remedial and Special Education, 16(4), 247-54.

Armor, D., Conry-Oseguera, P., Cox, M., King, N., McDonnell, L., Pascal, A., . . . Zellman, G. (1976). Analysis of the school preferred reading program in selected Los Angeles minority schools. Santa Monica, CA: Rand Corp.

Artistico, D., Cervone, D., \& Pezzuti, L. (2003). Perceived self-efficacy and everyday problem solving among young and older adults. Psychology and Aging, 18(1), 6879.

Ashton, P. T., Buhr, D., \& Crocker, L. (1984). Teachers' sense of efficacy: A self- or norm-referenced construct? Florida Journal of Educational Research, 26(1), 2941.

Ashton, P. T., Olejnik, S., Crocker, L., \& McAuliffe, M. (1982). Measurement problems in the study of teachers' sense of efficacy. Paper presented at the annual meeting of the American Educational Research Association. New York. 
Ball, D., \& Cohen, K. (1999). Developing practice, developing practitioners: Toward a practice-based theory of professional edcuation. In G. Sykes, \& L. DarlingHammond, Teaching as the Learning Profession: Handbook of Policy and Practice (pp. 3-32). San Francisco: Jossey-Bass.

Bamburg, J. D., \& Andrews, R. L. (1991). School goals, principals, and achievement. School Effectiveness and School Improvement, 2(3), 175-191.

Bandura, A. (1977). Self-efficacy-Toward a unifying theory of behavioral change. Psychological Review, 84(2), 191-215.

Bandura, A. (1994). Self-efficacy. In V. S. Ramachaudran, Encyclopedia of Human Behavior (Vol. 4, pp. 71-81). New York.

Bandura, A. (1997). The exercise of control. New York: Freeman.

Bandura, A., \& Locke, E. A. (2003). Negative self-efficacy and goal effects revisited. Journal of Applied Psychology, 88(1), 87-99.

Bausch, S., Michel, A., \& Sonntag, K. (2014). How gender influences the effect of age on self-efficacy and training success. International Journal of Training and Development, 18(3), 171-187.

Bennett, N., \& Marr, A. (2003). Judging the impact of leadership-development activities on school practice. Educational Forum, 67(4), 344-353.

Berman, P., McLaughlin, M., Bass, G., Pauly, E., \& Zellman, G. (1977). Federal programs supporting educational change. Vol. VII: Factors affecting implementation and continuation. The Rand Corporation, Santa Monica, CA. 
Borko, H., Elliott, R., \& Uchiyama, K. (2002). Professional development: A key to Kentucky's educational reform effort. Teaching and Teacher Education, 18(8), 969-987.

Brewer, D. J. (1993). Principals and student outcomes: Evidence from US high schools. Economics of Education Review, 12(4), 281-292.

Buchanan, T., \& Selmon, N. (2008). Race and gender differences in self-efficacy: Assessing the role of gender role attitudes and family backgroud. Sex Roles, $58(11), 822-836$.

Calik, T., Sezgin, F., Kavgaci, H., \& Cagatay, K. A. (2012). Examination of the relationship between instructional leadership of school principals and self-efficacy of teachers and collective teacher efficacy. Educational Sciences: Theory and Practice, 12(4), 2498-2504.

Camburn, E. M., \& Won Han, S. (2015). Infrastructure for teacher reflection and instructional change: An exploratory study. Journal of Educational Change, 16(4), 511-533.

Camburn, E. M., Goldring, E., Sebastian, J., May, H., \& Huff, J. (2016). An examination of the benefits, limitations, and challenges of conducting randomized experiments with principals. Educational Administration Quarterly, 52(2), 187-220.

Cantrell, S. C., \& Hughes, H. K. (2008). Teacher efficacy and content literacy implementation: An exploration of the effects of extended professional development with coaching. Journal of Literacy Research, 40(1), 95-127.

Caprara, G. V., Barbaranelli, C., Steca, P., \& Malone, P. S. (2006). Teachers' selfefficacy beliefs as determinants of job satisfaction and students' academic 
achievement: A study at the school level. Journal of School Psychology, 44(6), 473-490.

Cardno, C., \& Youngs, H. (2013). Leadership devlopmentfor experienced New Zealand principals: Perceptions of effectiveness. Educational Management and Leadership, 41(3), 256-271.

Chemers, M. M., Watson, C. B., \& May, S. T. (2000). Dispositional affect and leadership effectiveness: A comparison of self-esteem, optimism, and efficacy. Personality and Social Psychology Bulletin, 26(3), 267-277.

Chen, G., \& Bliese, P. D. (2002). The role of different levels of leadership in predicting self- and collective efficacy. Journal of Applied Psychology, 87, 549-556.

Chu, R. J. (2010). How family support and internet self-efficacy influences the effects of e-learning among higher aged adults-analyses of gender and age differences. Computers \& Education, 55(1), 255-264.

Clark, D., Martorell, P., \& Rockoff, J. (2009). School principals and school performance. National Center for Analysis of Longitudinal Data in Education Research.

Coladarci, T., \& Breton, W. (1997). Teacher efficacy, supervision, and the special education resource-room teacher. Journal of Educational Research, 90, 230-239.

Creswell, J. W. (1994). Research Design: Qualitative and Quantitative Approaches. Thousand Oaks: SAGE.

Cronk, B. C. (2012). How to use SPSS: A step-by-step guide to analysis and interpretation (7th ed.). Glendale, CA: Pyrczak Publishing. 
Darling-Hammond, L. (2010). The Flat World and Education: How America's

Commitment to Equity will Determine our Future. New York: Teachers College Press.

Darling-Hammond, L., \& McLaughlin, M. W. (1995). Policies that support professional development in an era of reform. Phi Delta Kappan, 76(8), 597-604.

Davis, S., Darling-Hammond, L., LaPointe, M. A., \& Meyerson, D. (2005). School leadership study: Preparing successful principals. Stanford, CA: Stanford University, Stanford Educational Leadership Institute.

Day, C., Harris, A., \& Hadfield, M. (2001). Challenging the orthodoxy of effective school leadership. International Journal of Leadership in Education, 4(1), 39-56.

DeMoulin, D. F. (1992). Demographic characteristics associated with perceived self efficacy levels of elementary, middle, and secondary principals. Paper presented at the annual meeting of the Mid-South Educational Research Association. Knoxville, TN.

Desimone, L. M. (2009). Improving impact studies of teachers' professional development: Toward better conceptualizations and measures. Educational Researcher, 38(3), 181-199.

Desimone, L. M., Porter, A. C., Garet, M. S., Yoon, K. S., \& Birman, B. F. (2002). Effects of professional development on teachers' instruction: Results from a threeyear longitudinal study. Educational Evaluation and Policy Analysis, 24(2), 81112. 
Dimmock, C., \& Hattie, J. (1996). School principals' self-efficacy and its measurement in the context of restructuring. School Effectiveness and School Improvement, 7(1), $62-75$.

Domsch, G. D. (2010). A study investigating relationships between elementary principals' and teachers' self-efficacy and student achievement. Saint Louis University.

Duncan-Andrade, J. M., \& Morell, E. M. (2008). The art of critical pedagogy. New York, New York: Peter Lang.

Eberts, R., \& Stone, J. (1998). Student achievement in public schools: Do principals make a difference? Economics of Education Review, 7(3), 291-299.

Effective Instructional Leadership Act, KRS 156.101 (2005).

Emmer, E. (1990). A scale for measuring teacher efficacy in classroom management and discipline. Paper presented at the annual meeting of the American Educational Research Association. Boston, MA.

Federici, R., \& Skaalvik, E. (2012). Principal self-efficacy: relations with burnout, job satisfaction and motivation to quit. Social Pyschology of Education, 15(3), 295320.

Fisher, Y. (2014). The timeline of self-efficacy: Changes during the professional life cycle of school principals. Journal of Educational Administration, 52(1), 58-83.

Garet, M. S., Porter, A. C., Desimone, L., Birman, B. F., \& Yoon, K. S. (2001). What makes professional developmnet effecteive? Results from a national sample of teachers. American Educational Research Jounal, 38(4), 915-45. 
Gecas, V. (1989). The social psychology of self-efficacy. Annual Review of Sociology, $15,291-316$.

Gibson, S., \& Dembo, M. (1984). Teacher efficacy: A construct validation. Journal of Educational, 76, 569-582.

Gist, M. E., \& Mitchell, T. R. (1992). Self-efficacy: A theoretical-analysis of its determinants and malleability. Academy of Management Review, 17(2), 183-211.

Goddard, R. D., \& Goddard, Y. L. (2001). A multilevel analysis of the relationship between teacher and collective efficacy in urban schools. Teaching and Teacher Education, 17, 807-818.

Graham, K. J., \& Fennell, F. (2001). Principles and standards for school mathematics and teacher education: Preparing and empowering teachers. School Science and Mathematics, 101(6), 319-27.

Grissom, J. A., \& Harrington, J. R. (2010). Investing in administrator efficacy: An examination of professional development as a tool for enhancing principal effectiveness. American Journal of Education, 116(4), 583-612.

Guskey, T. R. (1981). Measurement of responsibility teachers assume for academic successes and failures in the classroom. Journal of Teacher Education, 32, 44-51.

Guskey, T. R. (2009). Closing the knowledge gap on effective professional development. Educational Horizons, 87(4), 224-233.

Guskey, T. R. (2014). Planning professional learning. Educational Leadership, 71(8), 1016.

Guskey, T. R., \& Yoon, K. S. (2009). What works in professional development. The Phi Delta Kappan, 90(7), 495-500. 
Hallinger, P. (2003). Leading educational change: Reflections on the practice of instructinoal and transformational leadership. Cambridge Journal of Education, 33(3), 329-352.

Hallinger, P., \& Heck, R. H. (1998). Exploring the principal's contribution to school effectiveness: 1980-1995. School Effectiveness and School Improvement, 9(2), $157-91$.

Hallinger, P., \& Murphy, J. (1985). Assessing the instructional management behavior of principals. The Elementary School Journal, 217-214.

Hannah, S. T., Avolio, B. J., Luthans, F., \& Harms, P. D. (2008). Leadership efficacy: Review and future directions. The Leadership Quarterly, 19(6), 669-692.

Hartnett, M. J. (1995). The relationship between principal and teacher efficacy in middle level schools in Missouri. University of Nebraska-Lincoln.

Henson, R. K. (2001). The effects of participation in teacher research on teacher efficacy. Teaching and Teacher Education, 17(7), 819-36.

Hillman, S. (1986). Measuring self-efficacy: Preliminary steps in the development of a multi-dimensional instrument. A paper presented at the annual meeting of the American Educational Research Association. San Francisco, CA.

Hirsh, S. (2006). NSDC standards provide a richer definition of professional development thandoes NCLB. Retrieved 3 2017, April, from http://www.nsdc.org/news/jsd/hirsh273.pdf

Ho, R. (2014). Handbook of univariate and multivariate data analysis with IBM SPSS (2nd ed.). Boca Raton, FL: Taylor and Francis Group. 
Houle, J. C. (2006). Professional development for urban principals in underperforming schools. Education and Urban Society, 38(2), 142-159.

Imants, J. G., \& De Bradbander, C. J. (1996). Teachers' and principals' sense of efficacy in elementary schools. Teaching and Teacher Education, 12(2), 179-195.

Jackson, D. (2000). The school improvement journey: Perspectives on leadership. School Leadership and Management, 20(1), 61-78.

Jackson, Y. (2011). The trouble with professional devlopment for teachers. The Washington Post. Retrieved November 21, 2016, from https://www.washingtonpost.com/blogs/answer-sheet/post/the-trouble-withprofessional-development-for-teachers/2011/06/30/AGRxQfrH_blog.html

Jaquith, A., Mindich, D., Wei, R. C., \& Darling-Hammond, L. (2011). Teacher professional learning in the U.S.: Case studies of state policies and strategies. Education Digest: Essential Readings Condensed for Quick Review, 77(2), 33-39. Jefferson County Public Schools. (2016). School Directory. Retrieved December 20, 2016, from jcpsky.net: https://www.jefferson.kyschools.us/sites/default/files/School\%20Directory\%20Ph one\%20List\%20Red\%20White\%20and\%20Blue.pdf

Jefferson County Public Schools. (2017). JCPS Data Books. Retrieved 12 20, 2016, from jcpsky.net: https://www.jefferson.kyschools.us/departments/data-managementresearch/data-books

Kentucky Department of Education. (2014). Technical Assistance Manual for Instructional Leaders and Training Program Providers. 
Kentucky Department of Education. (2017). Learning Environment by District. Retrieved 12 20, 2016, from Kentucky Department of Education:

https://applications.education.ky.gov/src/LearningEnvironmentByDistrict.aspx

Kentucky Department of Education. (2017). Unbridled Learning. Retrieved October 2, 2017, from education.ky.gov: http://education.ky.gov/comm/ul/Pages/default.aspx

Khourey-Bowers, C., \& Simonis, D. G. (2004). Longitudinal study of middle grades chemistry professional development: Enhancement of personal science teaching self-efficacy and outcome expectancy. Journal of Science Teacher Education, 15(3), 175-195.

Klassen, R. M., \& Chiu, M. M. (2010). Effects on teachers' self-efficacy and job satisfaction: Teacher gender, years of experience, and job stress. Journal of Educational Psychology, 102(3), 741-756.

Klassen, R. M., Usher, E. L., \& Bong, M. (2010). Teachers' collective efficacy, job satisfaction, and job stress in cross-cultural context. The Journal of Experimental Education, 78(4), 464-486.

Klein, E. J., \& Riordan, M. (2009). Putting professional development into practice: A framework for how teachers in expeditionary learning schools implement professional development. Teacher Education Quarterly, 36(4), 61-80.

Koehler, A., Feldhaus, C. R., Fernandez, E., \& Hundley, S. (2013). Alternative certification programs \& pre-service teacher preparedness. Journal of STEM Education: Innovations and Research, 14(4), 45-55. 
Kuchey, D., Morrison, J. Q., \& Greer, C. H. (2009). A professional development model for math and science educators in Catholic elementary schools: Challenges and successes. Catholic Education: A Journal of Inquiry and Practice, 12(4), 475-97.

Leithwood, K., Patten, S., \& Jantzi, D. (2010). Testing a conception of how school leadership influences student learning. Educational Administration Quarterly, 46(5), 671-706.

Levin, H. M., \& McEwan, P. J. (2001). Cost-effective analysis (2nd ed.). Thousand Oaks, CA: Sage Publications.

Leithwood, K., \& Jantzi, D. (2008). Linking leadership to student learning: The contributions of leaders efficacy. Educational Administration Quarterly, 44(4), 496-528.

Lyons, C. A., \& Murhpy, M. J. (1994). Principal self-efficacy and the use of power. A paper presented at the annual meeting of the American Educational Research Association. New Orleans, LA.

Martin, W., Strother, S., Beglau, M., Bates, L., Reitzes, T., \& Culp, K. M. (2010). Connecting instructional technology professional development to teacher and student outcomes. Journal of Research on Technology in Education, 43(1), 53-74.

Maurer, T. J. (2001). Career-relevant learning and development, worker age, and beliefs about self-efficacy for development. Journal of Management, 27(2), 123-140.

Meijer, C., \& Foster, S. (1988). The effect of teacher self-efficacy on referral chance. Journal of Special Education, 22, 375-385.

Mindich, D., \& Lieberman, A. (2012). Building a learning community: A tale of two schools. Stanford Center for Opportunity Policy in Education. 
Mizell, H. (2010). Why professional development matters. Oxford, OH: Leaning Forward.

Morris, D. B., \& Usher, E. L. (2011). Developing teaching self-efficacy in research institutions: A study of award-winning professors. Contemporary Educational Psychology, 36, 232-245.

Murphy, J., Elliott, S. N., Goldring, E., \& Porter, A. (2007). Leadership for learning: A research-based model and taxonomy of behviors. School Leadership and Management, 27(2), 179-201.

Murphy, J., Hallinger, P., \& Heck, R. H. (2013). Leading via teacher evaluation: The case of the missing clothes? Educational Researcher, 42(6), 349-354.

Nespor, J. (1987). The construction of school knowledge: A case study. The Journal of Education, 169(2), 34-54.

Noddings, N. (2012). Philosophy of Education (3rd ed.). Bouder, CO: Westview Press.

Oates, G. (2004). The color of the undergraduate experience and the black self-concept: Evidence from longitudinal data. Social Psychology Quarterly, 67(1), 16-32.

Oliver, R. (2005). Assistant principal professional growth and development: A matter that cannot be left to chance. Edcuational Leadership and Administration, 17, 89-100.

Osborne, J. W. (2016). Regression and linear modeling: Best practices in modern methods. Thousand Oaks, CA: Sage.

Osterman, K., \& Sullivan, S. (1996). New principals in an urban bureaucracy: A sense of efficacy. Journal of School Leadership, 6(6), 661-690. 
Pajares, F. (1997). Current directions in self-efficacy researh. In M. L. Maehr, \& P. R. Pintrich, Advances in motivation and achievement, Vol. 10 (pp. 1-49). Greenwich: JAI Press.

Pajares, F. (2006). Self-efficacy during childhood and adolescence: Implications for teachers and parents. In F. Pajares, \& T. Urdan, Self-efficacy Beliefs of Adolescents (pp. 117-137). Greenwich, CT: Information Age Publishing.

Parylo, O. (2012). Qualitative, quantitative, or mixed methods: An analysis of research design in articles on principal professional development (1998-2008). International Journal of Multiple Research Approaches, 6(3), 297-313.

Payne, C. M. (2008). So much reform, so little change: The persistence of failure in urban schools. Cambridge, MA: Harvard Education Press.

Pedota, P. J. (2015). How can student success support teacher self-efficacy and retention? Clearing House: A Journal of Educational Strategies, Issues and Ideas, 88(2), 5461.

Peterson, K. D. (2002). The professional development of principals: Innovations and opportunitites. Educational Administraton Quarterly, 38, 213-232.

Petrocelli, J. V. (2003). Hierarchical multiple regressino in counseling research. Measurement and Evaluation in Counseling and Development, 36(1), 9-22.

Raudenbush, S. W., Rowan, B., \& Cheong, Y. F. (1992). Contextual effects on the selfperceived efficacy of high school teachers. Sociology of Education, 65(2), 150167.

Riggs, I. M., \& Enochs, L. G. (1990). Toward the development of an elementary teacher's science teaching efficacy belief instrument. Science Education, 74(6), 625-637. 
Roberts, J. K., \& Henson, R. K. (2001). A confirmatory factor analysis of a new measure of teacher efficacy: Ohio State Teacher Efficacy Scale. A paper presented at the annual meeting of the American Educational Research Association. Seattle, WA.

Robinson, V. M., Lloyd, C., \& Rowe, K. (2008). The impact of leadership on student outcomes: An analysis of the differetial effects of leadership types. Educational Administration Quarterly, 44(5), 635-674.

Rose, J. S., \& Medway, F. J. (1981). Measurement of teachers' beliefs in their control over student outcome. Journal of Educational Research, 74, 185-190.

Rotter, J. B. (1966). Generalized expectancies for internal versus external control of reinforcement. Psychological Monographs, 80, 1-28.

Schulz, M., \& Stamov Roßnagel, C. (2010). Informal workplace learning: An exploration of age differences in learning competence. Learning \& Instruction, 20(5), 383399.

Smith, R. W., \& Guarino, A. (2005). Confirmatory factor analysis of the Principal SelfEfficacy Survey. Journal of Organizational Culture, Communications, and Conflict, 9(1), 81-86.

Smith, W., Guarino, A. J., Strom, P., Reed, C., Lamkin, M. L., \& Rushforth, K. (2003). Principal self-efficacy and effective teaching and learning environments. School Leadership \& Management, 23(4), 505-508.

Smith, W., Guarino, A., Strom, P., \& Adams, O. (2006). Effective teaching and learning environments and principal self-efficacy. Journal of Research for Educational Leaders, 3(2), 4-23. 
Stevens, J. P. (2012). Applied multivariate statistics for the social sciences (5th ed.). New York: Routledge.

Stine-Morrow, E. A., Shake, M. C., Miles, J. R., \& Noh, S. R. (2006). Adult age differences in the effects of goals on self-regulated sentence processing. Psychology and Aging, 21(4), 790-803.

Stipek, D. (2012). Context matters: Effects of student characteristics and perceived administrative and parental support on teacher self-efficacy. The Elementary School Journal, 112(4), 590-606.

Sue, V. M., \& Ritter. (2007). Conducting Online Surveys. Thousand Oaks, CA: Sage. Szymendera, M. (2013). The relationship between self-efficacy, school and personal characteristics, and principal behaviors related to affecting student achievement. Dissertation, Lehigh University.

Thibeault, J. (2016). Perspectives in AE: Supporting French teachers for a paradigm shift in grammar education: A teacher trainer's perspective. New Horizons in Adult Education \& Human Resource Development, 28(4), 49-52.

Thorpe, A., \& Bennett-Powell, G. (2014). The perceptions of secondary school middle leaders regarding their needs following a middle leadership development programme. Management in Education, 28(2), 52-57.

Touron, D. R., \& Hertzog, C. (2004). Distinguishing age differences in knowledge, strategy use, and confidence during strategic skill acquisition. Psychology and Aging, 19(3), 452-466.

Tschannen-Moran, M., \& Gareis, C. (2004). Principals' sense of efficacy: Assessing a promising construct. Journal of Educational Administration, 42(4), 573-585. 
Tschannen-Moran, M., \& Hoy, A. W. (2001). Teacher efficacy: Capturing an elusive construct. Teaching and Teacher Education, 17, 783-805.

Tschannen-Moran, M., Woolfolk Hoy, A., \& Hoy, W. K. (1998). Teacher efficacy: Its meaning and measure. Review of Educational Research, 68(2), 202-248.

Tyack, D., \& Cuban, L. (1995). Tinkering toward utopia: A century of public school reform. Cambidge: Harvard University Press.

Tyack, D., \& Tobin, W. (1994). The "grammar" of Schooling: Why has it been so hard to change? American Educational Research Journal, 31(3), 453-79.

U. S. Department of Education. (2001). Teacher preparation and professional development: 2000. National Center for Education Statistics, Washington, DC.

Usher, E. L., \& Pajares, F. (2008). Sources of self-efficacy in school: Critical review of the literature and future directions. Review of Educational Research, 78(4), 751796.

Valentine, J. W., \& Prater, M. (2011). Instructional, transformational, and managerial leadership and student achievement: High school principals make a difference. NASSP Bulletin.

Walker, J., \& Slear, S. (2011). The impact of principal leadership behaviors on teh efficacy of new and experieinced middle school teachers. NASSP Bulletin, 95(1), 46-64.

Waters, T., Marzano, R. J., \& McNulty, B. (2003). Balanced leadership: What 30 years of research tells us about the effect of leadership on student achievement, a working paper. Retrieved February 10, 2015, from http://www.mspnet.org/index.cfm/11589 
Wayne, A. J., Yoon, K. S., Zhu, P., Cronen, S., \& Garet, M. (2008). Experimenting with teacher professional development: Motives and methods. Educational Researcher, 37(8), 469-479.

Wei, R. C., Darling-Hammond, L., Andree, A., Richardson, N., \& Orphanos, S. (2009). Professional learning in the learning profession: A status report on teacher development in the United States and abroad. Dallas: National Staff Development Council. Retrieved from http://www.learningforward.org/news/NSDstudytechnicalreport2009.pdf

Weiner, B. (1979). A theory of motivation for some classroom experiences. Journal of Educational Psychology, 71, 3-25.

Woolfolk Hoy, A., \& Davis, H. A. (2006). Teacher self-efficacy and its influence on the achievement of adolescents. In F. Pajares, \& T. Urdan, Adolescence and education, Vol. 5: Self-efficacy and adolescence (pp. 117-137). Greenwich, CT: Information Age Publishing.

Yoon, K. S., Duncan, T., Lee, S. W., Scarloss, B., \& Shapley, K. L. (2007). Reviewing the evidence on how teacher professional development affects student achievement. Issues \& Answers. Regional Educational Laboratory Southwest. 
Appendix A: Permission to use instrumentation

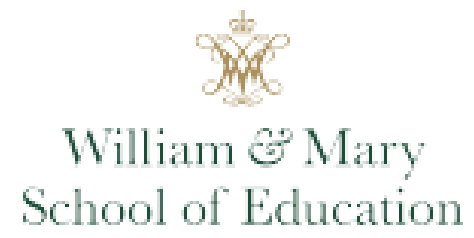

MEGAX TSCH.AKXEK-MORAK, PHD

DaOrEsSOR OR EDUCATIONaL LEADCESHIP

December 16, 2015

Brian,

You have my permission to use the Tescher Sense of Efficacy Scale (formerly called the Ohio State Teacher Sense of Efficacy Scale), which I developod with Anita Woolfolk Hoy, in your research. You can find a copy of the measure and scoring directions on my web site at http://wmpeople.wm.edu/siteipage/nttsch . Please use the following as the proper citation:

Trehannen-Moran, M \& Hoy, A. W. (2001). Teacher efficacy: Capturing an elusive construet. Teaching and Teacher Education, 17, 783-805.

You also have my pernission to use the Principals' Sense of Efficacy Scale, which I developed with Chris Gareis, in your research. The best eitation to use is:

Trehannen-Moran, M. \& Gareis, C. (2004). Principals" sense of efficacy: Assessing a promising construct. Jowrnal of Educational Administration, 42, 573-585.

I will also attach directions you can follow to access nyy password protectod web site, where you can find the supporting references for this measure as well as other articles I have written on this and relatod topies.

I would love to roceive a brief summary of your results.

All the best,

Megan Trchsmnen-Moran

The College of William and Mary

School of Education

P.O, Box 8795 - Walliamshurg, VA 23187-8795 - (757) 221-2187 - matschegwendu 
Appendix B: Principal Sense of Efficacy Scale and Scoring Guide

\begin{tabular}{|c|c|c|c|c|c|c|c|}
\hline \multicolumn{2}{|r|}{ "In your current role as principal, to what extent can you..." } & 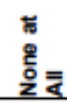 & \multicolumn{2}{|r|}{ 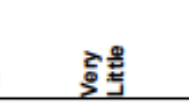 } & 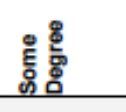 & 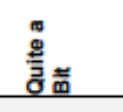 & \multirow{2}{*}{ 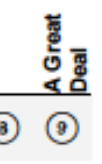 } \\
\hline 1. & facilitate student learning in your school? & (1) & (2) & (3) (4) & (5) (6) & (7) (3) & \\
\hline 2. & generate enthusiasm for a shared vision for the school? & (1) & (2) & (3) (4) & (5) () & (7) (3) & (9) \\
\hline 3. & handle the time demands of the job? & (1) & (2) & (3) (4) & (5) () & (7) (3) & ) ( \\
\hline 4. & manage change in your school? & (1) & (2) & (3) (4) & (5) () & (7) (3) & ) \\
\hline 5. & promote school spirit among a large majority of the student population? & (1) & (2) & (3) (4) & (5) () & (7) (3) & (9) \\
\hline 6. & create a positive learning environment in your school? & (1) & (2) & (3) (4) & (5) (6) & (7) (3) & 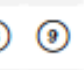 \\
\hline 7. & raise student achievement on standardized tests? & (1) & (2) & (3) (4) & (5) () & (7) (3) & ( \\
\hline 8. & promote a positive image of your school with & (1) & (2) & (3) (4) & (5) () & (7) (3) & \\
\hline 9. & motivate teachers? & (1) & (2) & (3) (4) & (5) () & (7) (3) & ) \\
\hline 10. & promote the prevailing values of the community in & (1) & (2) & (3) (4) & (5) () & (7) (3) & \\
\hline 11. & maintain control of your own daily schedule? & (1) & (2) & (3) (4) & (5) (6) & (7) (3) & \\
\hline 12. & $\begin{array}{l}\text { shape } t \\
\text { manage }\end{array}$ & (1) & (2) & (3) (4) & (5) () & (7) (3) & \\
\hline 13. & handle effectively the discipline of students in your school? & (1) & (2) & (3) (4) & (5) () & (7) () & \\
\hline 14. & promote acceptable behavior among students? & (1) & (2) & (3) (4) & (5) () & (7) (3) & \\
\hline 15. & handle the paperwork required of the job? & (1) & (2) & (3) (4) & (5) () & (7) (3) & \\
\hline 16. & promote ethical behavior among school personnel? & (1) & (2) & (3) (4) & (5) () & (7) (3) & \\
\hline 17. & cope with the stress of the job? & (1) & (2) & (3) (4) & (5) () & (7) (3) & \\
\hline 18. & prioritize among competing demands of the job? & & (2) & (3) (4) & (5) () & (7) (3) & \\
\hline
\end{tabular}




\section{Principal Self-Efficacy Scale Scoring Guide}

\section{Principal Sense of Efficacy Scale}

\section{Efficacy for Management}

Handle the time demands of the job

Handle the paperwork required of the job

Maintain control of your own daily schedule

Prioritize among competing demands of the job

Cope with the stress of the job

Shape the operational policies and procedures that are necessary to manage your school

\section{Efficacy for Instructional Leadership}

Motivate teachers

Generate enthusiasm for a shared vision for the school

Manage change in your school

Create a positive learning environment in your school

Facilitate student learning in your school

Raise student achievement on standardized tests

\section{Efficacy for Moral Leadership}

Promote acceptable behavior among students

Promote school spirit among a large majority of the student population

Handle effectively the discipline of students in your school

Promote a positive image of your school with the media Promote the prevailing values of the community in your school

Promote ethical behavior among school personnel

To score the full scale, calculate a mean of all 18 items. To calculate each of the subscales, calculate the mean of the six items listed under each heading. 


\section{Appendix C: Email Notification to Potential Participants}

Sent July 18, 2017 at 6:35 AM

Dear Principal,

I am Brian Garrett, an assistant principal in Jefferson County Public Schools. I am working toward completion of the requirements for my doctoral degree at the University of Louisville. My advisor is Dr. W. Kyle Ingle, who is designated as the principal investigator for this study.

\section{Link to principal survey}

You are invited to participate in a research study being conducted for a dissertation at the University of Louisville. The study will examine the relationship between your professional development experiences, school characteristics, and the beliefs you have about your ability to positively influence your school. All 2016-2017 school principals in Jefferson County Public Schools (JCPS) are invited to participate.

In this study you will be asked to complete an online survey which measures the level of principal selfefficacy and will take approximately 10 minutes. Additionally, each participant's 2016-2017 EILA and professional development (PD) history will be analyzed in conjunction with the survey results to measure the relationship between principal self-efficacy and PD experiences.

This study involves no known risks. While participant survey responses and PD/EILA history will be linked to the school, all collected data will be kept confidential and will only be accessed by the researcher for research purposes. Reported data will only be reported in aggregate, and no individual or identifiable data will be reported to protect participant identity.

There are no direct benefits or incentives to participating in this study. However, analysis of participant responses may lead to more relevant and effective PD opportunities for JCPS principals.

If you have questions or concerns, we would be happy to address them. Please direct your questions or comments to:

Dr. W. Kyle Ingle, Committee Chair

William.ingle@louisville.edu

Brian Garrett, Researcher

Brian.garrett@jefferson.kyschools.us

The following link will direct you to the survey. The survey will be available for responses through August 4, 2017.

\section{$\underline{\text { Link to principal survey }}$}

Thank you,

Dr. W. Kyle Ingle 


\section{Brian Garrett}

University of Louisville

College of Education and Human Development

Room 124

University of Louisville

Louisville, KY 40292 
Dear Principal,

Previously, an invitation to participate in a research study was sent to you via email. This is the final week to complete the survey for this study. This research study will assist Brian Garrett, an assistant principal in Jefferson County Public Schools in completing the requirements for a doctoral degree at the University of Louisville. The original email is below.

If you have completed the survey, thank you for your participation. You may disregard the rest of this message.

If you have not yet completed the survey, you are invited to participate. The link to survey is listed below. The survey will be open for responses through Friday August 4, 2017. Details of the study and contact information for questions or concerns are provided in the original message below.

\section{$\underline{\text { Link to principal survey }}$}

Thank you,

Dr. W. Kyle Ingle

Brian Garrett

University of Louisville

College of Education and Human Development

Room 124

University of Louisville

Louisville, KY 40292 
Dear Principal,

Previously, an invitation to participate in a research study was sent to you via email. Tomorrow, Friday August 4, 2017, is the final day to complete the survey for this study. This research study will assist Brian Garrett, an assistant principal in Jefferson County Public Schools, in completing the requirements for a doctoral degree at the University of Louisville. The original email is below.

If you have completed the survey, thank you for your participation. You may disregard the rest of this message.

If you have not yet completed the survey, you are invited to participate. The link to survey is listed below. The survey will be open for responses through Friday August 4, 2017. Details of the study and contact information for questions or concerns are provided in the original message below.

\section{Link to principal survey}

Thank you,

Dr. W. Kyle Ingle

Brian Garrett

University of Louisville

College of Education and Human Development

Room 124

University of Louisville

Louisville, KY 40292 
Dear

I am in serious need of your help. I have been working with the University of Louisville and JCPS to conduct a study on administrator professional development. My goal is to take what is learned in this research and work with JCPS to help the district provide the highest quality and most relevant professional development to principals and other school-based administrators.

As a principal during the 2016-2017 school year, you were previously invited to participate. The initial analysis of data from this study was inconclusive, due to an insufficient sample size. To increase the sample size and produce results which could potentially lead to improvements in administrator PD in JCPS, you are again invited to participate. A link to the survey is below. The survey will only take about 5 minutes to complete.

\section{Link to 2016-2017 Principal Survey}

Your participation in this study is critical to producing a usable analysis and beneficial options for JCPS to consider in administrator PD. Please consider helping by taking 5 minutes to complete the survey.

If you have any questions about this study, how the data will be analyzed, or concerns about confidentiality, please feel free to contact me.

Thank you, in advance for your participation.

Respectfully,

Brian Garrett 


\author{
C855,\&8/ $80 \mathrm{~V}, 7 \$($ \\ MBUIDTKRP DVGDUHW \\ brian.garrett@jefferson.kyschools.us
}

\title{
EDUCATION
}

Specialist in Education, Ed.S

2008-2011 University of Louisville, Louisville, KY

Master of Arts in Teaching, M.A.T.

2000-2001 Spalding University, Louisville, $K Y$

Bachelor of Science, Political Science and Business

1994-1998 Campbellsville University, Campbellsville, KY

\section{CERTIFICATIONS}

Professional Certificate for Teaching Social Studies, 8-12 2001

Professional Certificate for Teaching Business and Marketing Education, 5-12 2003

$\begin{array}{ll}\text { Rank } 1 & 2011\end{array}$

Professional Certificate for Instructional Leadership, Supervisor of Instruction 2011

Professional Certificate for Instructional Leadership, Principal, All Grades 2011

\section{EMPLOYMENT HISTORY}

Assistant Principal, Grades 6-12 2015-Current

J. Graham Brown School, Jefferson County Public Schools, Louisville, KY

Assistant Principal, Grades 9-12

2011-2015

Doss High School, Jefferson County Public Schools, Louisville, KY

Teacher, Social Studies and Business, Grades 9-12

2003-2011

Fern Creek High School, Jefferson County Public Schools, Louisville, KY 
Teacher, Social Studies and ECE-EBD

2000-2003

Bullitt Lick Middle School, Bullitt County Public Schools, Shepherdsville, KY

\section{SELECTED PROFESSIONAL EXPERIENCES}

Professional Development Committee Chair, JCPS

2016-Current

Building Assessment Coordinator, Grades 6-8, JCPS

2015-Current

PBIS Committee Chair, JCPS

2013-Current

ECE ARC Chair, JCPS

2011-2015

Instructional Technology Committee Chair, JCPS

2011-2013

Principals For Tomorrow (PFT), JCPS

2009-2010

Ninth Grade Academy, Lead Teacher, JCPS

2009-2010

Ninth Grade Academy Committee Chair, JCPS

2008-2009

Kentucky Teacher Network for Excellence in Civic Education \& Engagement, Lesson Study Pilot, University of Louisville 2009

IDEAS Principal Preparation Cohort, JCPS and University of Louisville 2008-2009

Facing History and Ourselves Summer Institute, JCPS

2008

Kentucky Teacher Network for Excellence in Civic Education \& Engagement, High

School Civics Unit Design Pilot, University of Louisville

2008

Preparing Reliable Operating Patterns for Engaged Learning (PROPEL), Pilot, JCPS

2007-2008 